\title{
Unusual Spectroscopic and Photophysical Properties of meso-tert-ButylBODIPY in Comparison to Related Alkylated BODIPY Dyes
}

Lijuan Jiao, ${ }^{*}{ }^{a}$ Changjiang Yu, ${ }^{a}$ Jun Wang, ${ }^{a}$ Edward A. Briggs,${ }^{b}$ Nicholas A. Besley, ${ }^{b}$ David Robinson, ${ }^{b}$ María J. Ruedas-Rama, ${ }^{c}$ Angel Orte, ${ }^{c}$ Luis Crovetto,${ }^{c}$ Eva M. Talavera ${ }^{c}$ Jose M. Alvarez-Pez, ${ }^{c}$ Mark Van der Auweraer, ${ }^{d}$ and Noël Boens ${ }^{d}$

${ }^{a}$ Laboratory of Functional Molecular Solids, Ministry of Education; Anhui Laboratory of MoleculeBased Materials; School of Chemistry and Materials Science, Anhui Normal University, Wuhu, Anhui, China 241000.

${ }^{b}$ School of Chemistry, University of Nottingham, University Park, Nottingham, NG7 2RD, United Kingdom.

${ }^{c}$ Department of Physical Chemistry, Faculty of Pharmacy, University of Granada, Cartuja Campus, 18701 Granada, Spain.

${ }^{d}$ Department of Chemistry, Katholieke Universiteit Leuven (KU Leuven), Celestijnenlaan 200f, 3001 Leuven, Belgium.

*Corresponding author: E-mail: jiao421@mail.ahnu.edu.cn; Fax: +86 553-388-3517 
ABSTRACT: Five alkyl-substituted difluoroboron dipyrrin (BODIPY) dyes have been synthesized: three with a methyl, isopropyl or tert-butyl group at the meso-position of the BODIPY core and two substituted with one or two tert-butyl functions at the 3/5-positions. X-Ray structural analysis, UV-vis absorption spectroscopy and fluorescence (steady-state and time-resolved) techniques have been used to study the structures and the spectroscopic/photophysical properties of these dyes. All but one of these BODIPYs are highly fluorescent in all the solvents tested, the exception being meso-tert-butylBODIPY (2). Derivative 2 differs from the other alkylated boron dipyrrins as it exhibits a broad and red-shifted fluorescence band with a large Stokes shift. In addition, very low fluorescence quantum yields and short fluorescence lifetimes characterize 2. Quantum chemical calculations indicate that $\mathbf{2}$ has a distorted, nonplanar geometry in the $S_{1}$ excited state due to the rotation of 8-tert-butyl group. Our results lead us to the conclusion that the torsional rotation about the bond connecting the meso- $\mathrm{C}$ and the quarternary $\mathrm{C}$ of the tert-butyl group of $\mathbf{2}$ plays a crucial role in the fast radiationless deactivation of this isomer.

\section{INTRODUCTION}

Dyes derived from 4,4-difluoro-4-bora-3a,4a-diaza-s-indacene (well known as BODIPY, ${ }^{1}$ acronym for

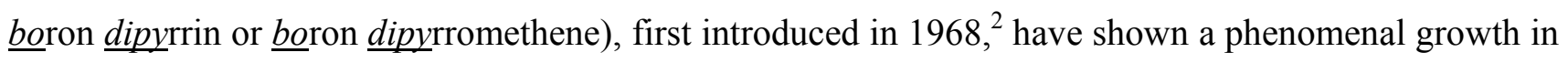
popularity since the beginning of this millennium. ${ }^{3,4}$ Currently, BODIPY derivatives have found wide applications in diverse fields, as labeling reagents, ${ }^{5,6,7,8,9,10}$ chemosensors, ${ }^{11,12,13}$ energy transfer cassettes, ${ }^{14,15}$ potential photodynamic therapy agents, ${ }^{16,17}$ and tunable laser dyes. ${ }^{18,19}$ This success can be attributed to their outstanding properties, including large molar absorption coefficients, high fluorescence quantum yields $\Phi$, absorption and fluorescence spectra with very narrow bandwidths in the visible spectral range and high (photo)stability. The other major reason for the attractiveness of boron dipyrrin derivatives is their vast scope of functionalization. ${ }^{20,21,22,23,24,25,26,27,28,29}$ 


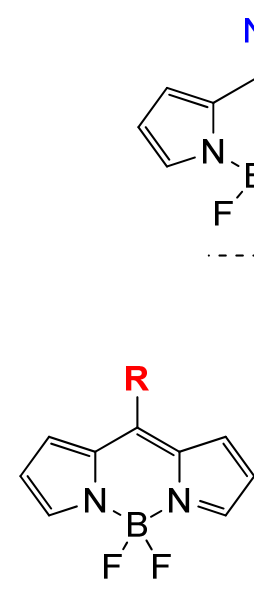

A

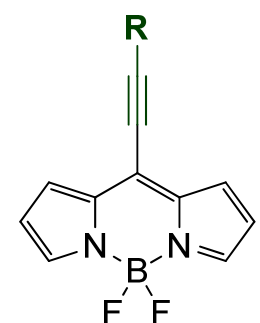

B<smiles></smiles>

$\mathrm{X}=\mathrm{Cl}, \mathrm{Br}, \mathbf{I}$

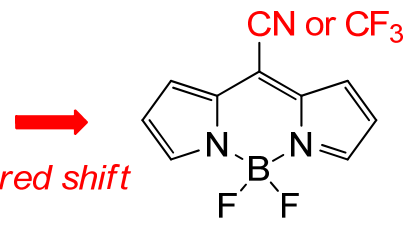

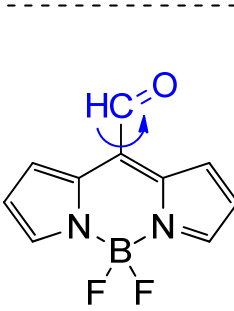

D

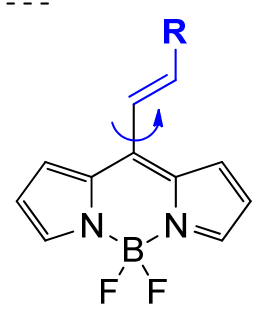

E

$\Phi>0.9$ $\Phi=0.6-0.7$ $\Phi=0.1-0.7 \quad \Phi$ (undetectable) $\Phi \leq 0.01$
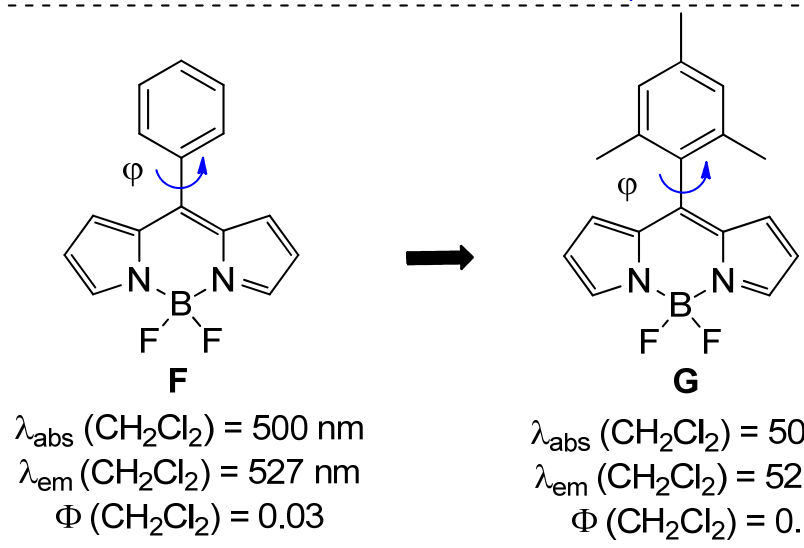

$\lambda_{\text {abs }}\left(\mathrm{CH}_{2} \mathrm{Cl}_{2}\right)=501 \mathrm{~nm}$

$\lambda_{\text {em }}\left(\mathrm{CH}_{2} \mathrm{Cl}_{2}\right)=521 \mathrm{~nm}$ $\Phi\left(\mathrm{CH}_{2} \mathrm{Cl}_{2}\right)=0.84$

Chart 1. Reported meso-substituted BODIPYs A-G with structure-controlled spectroscopic and photophysical properties. Structure A stands for 8-alkylBODIPYs such as 1, 2, 5 and $\mathbf{H}-\mathbf{L}$ (Chart 2). Data for $\mathbf{F}$ and $\mathbf{G}$ taken from ref 22.

Attachment of appropriate substituents to the BODIPY framework (at the pyrrole carbons, the central 8- or meso-position and the boron atom) can modify the photophysical (e.g., fluorescence quantum yield $\Phi$, fluorescence lifetime $\tau$ ) and spectroscopic [e.g., spectral shifts of the absorption and emission maxima $\lambda_{\text {abs }}(\max )$ and $\left.\lambda_{\mathrm{em}}(\max )\right]$ characteristics of the dye. Introducing suitable groups at the right positions of the BODIPY core is essential for fine-tuning the spectroscopic and photophysical properties of the resultant chromophore/fluorophore. The meso- or 8-position of the BODIPY framework is particularly sensitive to the substituent effect because quantum chemical calculations indicate that the electron density localized at this central position, characterized by a node in the HOMO, increases significantly upon excitation. ${ }^{30}$ Many interesting results have been found by varying the substituents at 
the meso-position (Chart 1). ${ }^{3,4}$ Electron-withdrawing groups, such as $\mathrm{CF}_{3},{ }^{31,32,33}$ result in significantly red-shifted absorption/emission spectra compared to those of classic BODIPY dyes ${ }^{3,4}$ and unsubstituted BODIPY.${ }^{34}$ Likewise, BODIPY systems with a meso-CN substituent absorb and fluoresce at ca. $60 \mathrm{~nm}$ longer wavelengths than simple alkyl-substituted BODIPYs. ${ }^{35}$ This large bathochromic shift can be attributed to a net stabilization of the LUMO level by the cyano group, whereas the HOMO level remains unperturbed (there is a node at the meso-position). Hence, this leads to a decrease of the energy gap. ${ }^{3}$ The red shifts observed when a $\mathrm{CN}$-group is added to the meso-position are particular to that site. Conversely, difluoroboron dipyrrins with electron-donating heteroatoms as in $\mathrm{NR}^{1} \mathrm{R}^{219,36,37,38,39,40}$ and OR $^{39,40,41,42}$ show blue-shifted absorption/emission spectra with high fluorescence quantum yields $\Phi$ and long fluorescence lifetimes $\tau$. Alkylation at the 8-position of the BODIPY core $\left(\mathbf{A},{ }^{43,44}\right.$ Chart 1 ; H-L, ${ }^{30,43,48}$ Chart 2, Table 3) does not spoil its excellent fluorescence properties (high $\Phi$ and long $\tau$ values). 8-Halogenated ( $\mathrm{Cl}, \mathrm{Br}, \mathrm{I})$ BODIPYs $\mathbf{C}$ have spectra that are marginally shifted in relation to common BODIPYs. The fluorescence quantum yields of 8-haloBODIPYs decrease predictably in the series $8-\mathrm{Cl}(\Phi \sim 0.7), 8-\mathrm{Br}(\Phi \sim 0.5)$ and $8-\mathrm{I}(\Phi \sim 0.1)$ due to the increasing heavy atom effect, which facilitates intersystem crossing. ${ }^{40}$ 4,4-Difluoro-8-phenylethynyl-4-bora-3a,4a-diaza-s-indacene $\mathbf{B}^{39}$ is moderately fluorescent $(\Phi \sim 0.6-0.7)$ and displays red-shifted absorption/emission spectra in comparison to classic BODIPY dyes. Interestingly, recent studies by Misra et al. ${ }^{45}$ indicated that the electron-withdrawing group at the meso-position of arylethynyl BODIPYs shifts the absorption/emission bathochromically with enhanced quantum yields, whereas the electron-donating group at the meso-position blue shifts the absorption/emission with decreased fluorescence quantum yields. Meso-enyne substituted BODIPYs show blue shifted absorption and red shifted emission with large Stokes shifts compared to meso-alkynylated BODIPYs. ${ }^{46}$ Meso-formyl substituted BODIPYs $\mathbf{D}^{26}$ 
are nonemissive compared to their meso-hydroxymethyl and meso-acetoxymethyl counterparts (which have $\Phi$ in the range of $0.7-1.0)$. Similarly, meso-alkenyl substituted derivatives $\mathbf{E}^{47,48,49}$ are virtually nonfluorescent $(\Phi \leq 0.01)$. Meso-phenyl BODIPY F has a very low fluorescence quantum yield $(\Phi \sim$ 0.05), whereas BODIPY $\mathbf{G}$ is highly fluorescent $(\Phi=0.93) .{ }^{50}$ Lindsey, Holten et al. ${ }^{50}$ have shown that the $S_{1}$ excited-state surface of $\mathbf{F}$ provides nearly no barrier to rotation of the phenyl group toward planarity. As the phenyl ring rotates into the mean plane of the difluoroboron dipyrrin (dihedral angle $\varphi$ $=0^{\circ}$, Chart 1), repulsions between the hydrogen atoms on both moieties lead to a delocalized puckered conformation. Since in this case the electronic wavefunction can be expected to be dependent on the dihedral angle between the phenyl and the BODIPY plane moieties, the derivative of the electronic wavefunction with respect to the nuclear coordinates will be significant. This induces a breakdown of the Born-Oppenheimer approximation and leads to an efficient coupling between the relaxed, distorted $S_{1}$ excited-state conformation and the ground state $S_{0}{ }^{51}$ Hence, one can expect a large matrix element for internal conversion and fast internal conversion which will lead to a negligible $\Phi$. There is no $a$ priori reason to assume a small oscillator strength because the sum of all Franck-Condon factors remains 1, whatever the shift of the minima of the potential energy surfaces. On the other hand, the two ortho-methyl groups of the meso-substituent in $\mathbf{G}$ lead to increased repulsion between the mesityl group and the BODIPY framework so that the lowest energy ground-state conformation is the one in which the aryl ring lies essentially orthogonal $\left(\varphi=90^{\circ}\right)$ to the BODIPY framework. Excitation into the $S_{1}$ excited state of $\mathbf{G}$ generates only a modest change in the mesityl group orientation. Hence, in the accessible range of dihedral angles, the electronic wavefunction in $S_{1}$ will depend only to a small degree on the nuclear coordinates, leading to a small matrix element for internal conversion between $S_{1}$ and $S_{0}$. Due to the slow internal conversion, fluorescence from the relaxed $S_{1}$ state is efficient (high $\Phi$ ). 
In this work, five alkylated BODIPY dyes have been synthesized (Scheme 1): three with a methyl, isopropyl or tert-butyl $(t$-Bu) group at the meso-position of the BODIPY scaffold and two substituted with one or two $t$-Bu groups at the 3-position or 3,5-positions. These compounds have been characterized structurally, spectroscopically and photophysically. All but one of these BODIPYs are highly fluorescent, the exception being meso-t-Bu-BODIPY 2. Bulky groups on the BODIPY core normally prevent aggregation and enhance the fluorescence. ${ }^{52,53}$ However, here we found that the substituent and its position are critical to obtaining highly fluorescent BODIPY dyes. BODIPY 2 with a meso-t-Bu group differs from the other alkylated difluoroboron diazaindacenes since it exhibits a broad and red-shifted fluorescence band with a large Stokes shift. Moreover, very low fluorescence quantum yields and short fluorescence lifetimes characterize derivative $\mathbf{2}$ in all the solvents tested. Quantum chemical calculations have been used to uncover the reasons for the exceptional spectroscopic and photophysical characteristics of BODIPY 2. These calculations indicate that BODIPY 2 has a distorted, nonplanar geometry in the $S_{1}$ excited state due to the rotation of the meso-t-Bu group.

\section{RESULTS AND DISCUSSION}

\section{Synthesis}

BODIPYs 1-5 were prepared via three different methods as shown in Scheme 1. The meso-substituted BODIPYs 1, 2 and 5 were synthesized by condensation of pyrrole with the corresponding acyl chloride and subsequent complexation with $\mathrm{BF}_{3} \cdot \mathrm{OEt}_{2}$ using our previously reported method. ${ }^{43}$ BODIPYs 3 and 4 were prepared by $\mathrm{POCl}_{3}$-catalyzed condensation of pyrrole with 5-tert-butyl-pyrrole-2-carbaldehyde or self-condensation of 5-tert-butyl-pyrrole-2-carbaldehyde and subsequent complexation with $\mathrm{BF}_{3} \cdot \mathrm{OEt}_{2}$ as described in the literature. ${ }^{54,55}$ BODIPYs $\mathbf{1}-\mathbf{5}$ have been characterized by NMR, HRMS and X-ray 
analysis (except for BODIPY 3). The synthesis of another meso-tert-butylBODIPY derivative (6) was attempted, but failed; product 7 was formed instead (Scheme S1, Supporting Information).

(a)

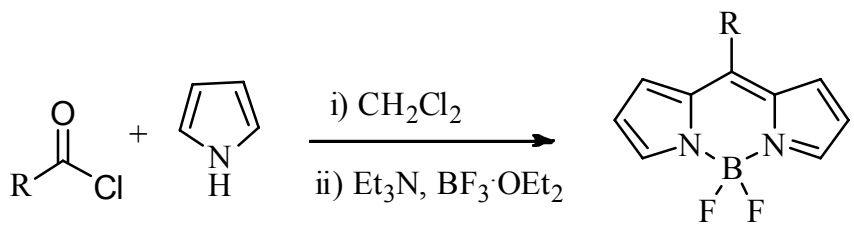

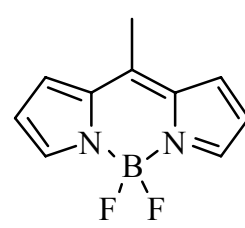

1 $33 \%$

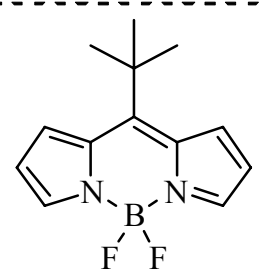

2

$12 \%$

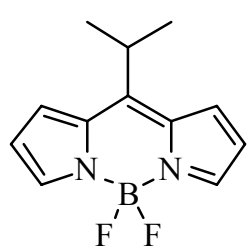

5 $18 \%$

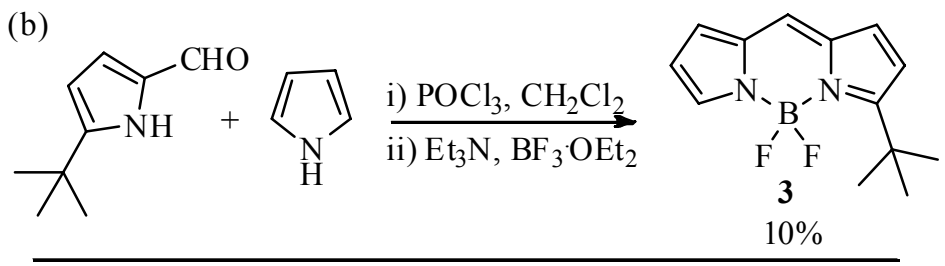

(c)

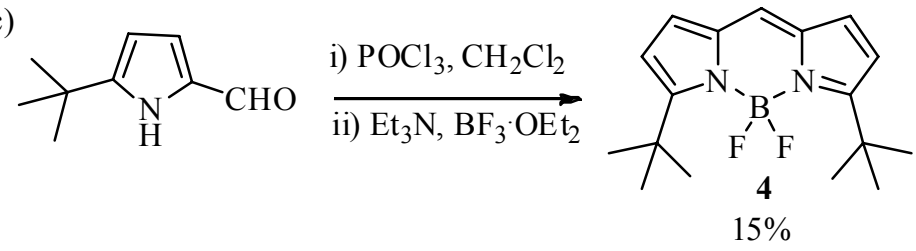

Scheme 1. Synthesis of BODIPYs 1-5.

\section{Structural Analysis}

Single crystals of BODIPYs 1, 2, 4 and 5 suitable for X-ray analysis were obtained by slow evaporation of their dichloromethane solutions. Figure 1 shows that the plane defined by $\mathrm{F}-\mathrm{B}-\mathrm{F}$ atoms for these BODIPY molecules is perpendicular to that of BODIPY ring, as is usually observed. ${ }^{23}$ As demonstrated in Table 1, the bond lengths and angles within the BODIPY cores exhibit the same geometric parameters as those reported in the literature. ${ }^{56,57,23}$ For example, the $\mathrm{B}-\mathrm{N}$ bond distances are in the range of 1.51-1.57 $\AA$, indicating the usual delocalization of the positive charge. Two independent types of crystals (4a and $\mathbf{4 b}$ in Table 1) were observed within the same unit cell for BODIPY $\mathbf{4}$. The C8-C9 
bond distances (ca. 1.54 $\AA$ ) of BODIPYs $\mathbf{2}$ and $\mathbf{5}$ are slightly longer in comparison to that of BODIPY $\mathbf{1}$ (1.49 $\AA$ ). The pyrrole-pyrrole dihedral angle is a key parameter closely associated with the planarity of the BODIPY core and the extension of the $\pi$-system, which is predominantly responsible for the observed optical properties. All four BODIPY derivatives investigated by X-ray analysis have very small pyrrole-pyrrole dihedral angles $\left(<8^{\circ}\right)$. The plane defined by the three methyl carbons attached to the quaternary carbon of the $t$-Bu group in $\mathbf{2}$ is perpendicular to the BODIPY plane. This indicates that $t$-Bu substituents cause little structural disruption of the planarity of the BODIPY core. Furthermore, the dihedral angles defined by the N-B-N plane and the pyrrole rings for these BODIPYs are all less than $18^{\circ}$, which may be attributed to the extended packing forces and structural motifs that exist in the solid state. Our result is in contrast with that previously reported for meso-diethylaminoBODIPY, ${ }^{37}$ in which the meso-diethylamino group caused a significant distortion of the planarity of the BODIPY core (the pyrrole-pyrrole dihedral angle is $34^{\circ}$ ) and with that of 9-tert-butylanthracene, ${ }^{58}$ in which the presence of the bulky $t$-Bu moiety led to an obvious deviation of planarity of the anthracene ring. In both cases, the extended $\pi$-conjugation of the chromophore was ruptured. Table S1 (Supporting Information) lists additional crystallographic data.

Multiple intramolecular and intermolecular $\mathrm{C}-\mathrm{H} \cdots \mathrm{F}$ hydrogen bonds between $\mathrm{F}$ atoms and various hydrogen atoms are formed due to the strong electronegativity of the $\mathrm{F}$ atom. These strong intermolecular hydrogen bonds also help the establishment of the crystal packing structure and make these BODIPYs nearly parallel to each other in a head-to-tail orientation. 
(a)

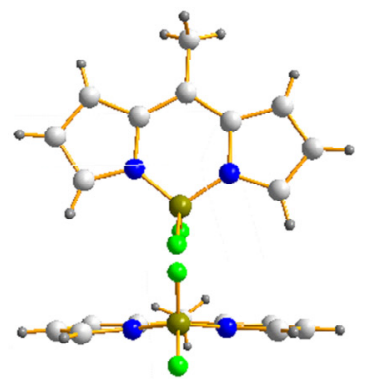

(b)

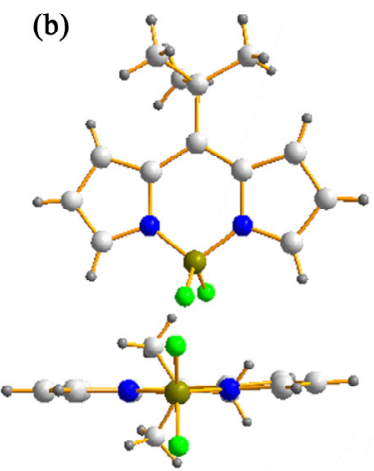

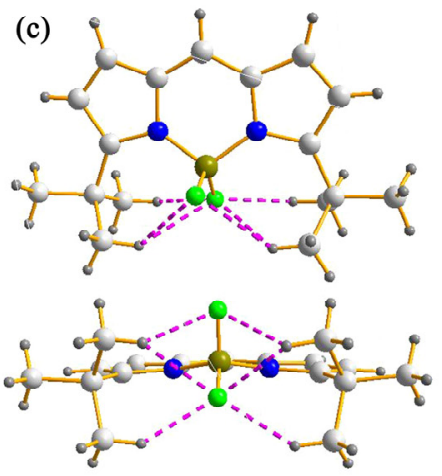

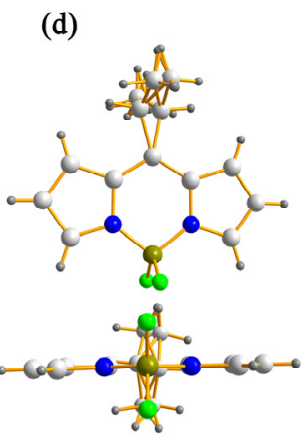

Figure 1. X-Ray structures of BODIPYs 1 (a), 2 (b), 4 (c, there are two isomers of BODIPY 4 in the unit cell: $\mathbf{4 a}$ and $\mathbf{4 b}$ ) and $\mathbf{5}$ (d, the meso-isopropyl group is disordered.). C, light gray; H, gray; N, blue; B, dark yellow; F, light green.

Table 1. Selected geometrical parameters of BODIPYs 1, 2, 4 and 5 obtained from crystallography.

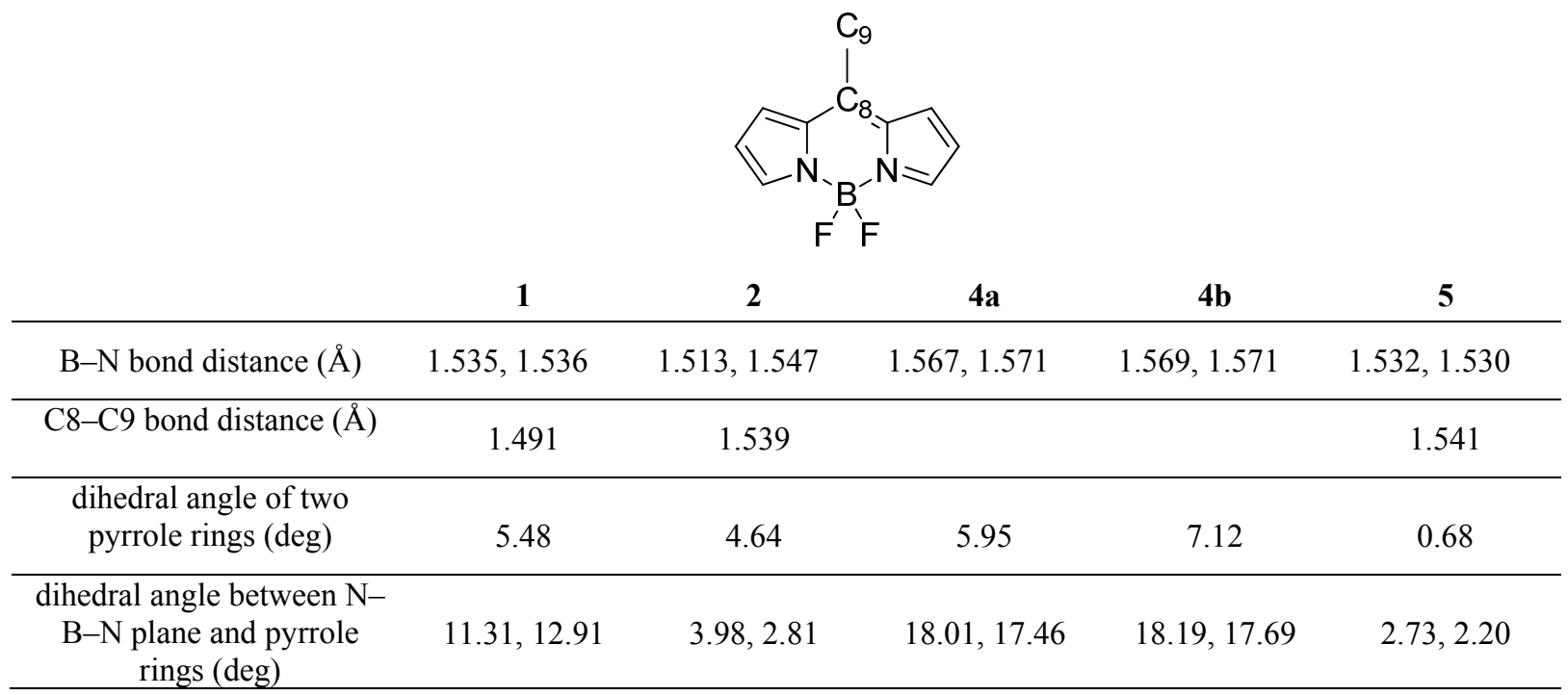

\section{UV-vis Spectroscopic and Photophysical Properties}

Except for BODIPY 2, derivatives 1-5 form intensely colored solutions and display bright fluorescence upon irradiation. A spectroscopic and photophysical characterization of dyes 1-5 as a function of the alkyl substituent(s) in 13 different solvents has been carried out. Tables 2 and S2-S5 (Supporting Information) compile the spectroscopic and photophysical data of all the dyes investigated as a function of solvent. Regarding their spectroscopic and photophysical properties, derivatives $\mathbf{1}-\mathbf{5}$ can be subdivided into two subsets: one comprising $\mathbf{1}$ and $\mathbf{3 - 5}$, the other consisting of compound $\mathbf{2}$. The 
difference between $\mathbf{2}$ and the other analogues is clearly visible, even to the naked eye. This is illustrated in Chart S1 (Supporting Information) where photographs of cuvettes containing $\mathbf{1}$ and $\mathbf{2}$ in chloroform and acetone under ambient light and UV irradiation are displayed. All BODIPY analogues tested (1-5) display the typical absorption features of classic BODIPY dyes in all solvents studied: that is, the main, narrow absorption band, assigned to the $S_{1} \leftarrow S_{0}$ transition, and a considerably weaker, broad absorption band (at shorter wavelengths) attributed to the $S_{2} \leftarrow S_{0}$ transition. The maximum of the main absorption band, $\lambda_{\text {abs }}(\max )$, is positioned within a very narrow wavelength range $(8 \mathrm{~nm})$ and is bathochromically shifted with increasing solvent polarizability (from acetonitrile to chlorobenzene). Derivatives $\mathbf{1}$ and $\mathbf{5}$ with the less bulky substituents (methyl and isopropyl, respectively) show absorption maxima at the shortest wavelengths (489-499 $\mathrm{nm}$ and $492-500 \mathrm{~nm}$ for $\mathbf{1}$ and $\mathbf{5}$, respectively), whereas increasing the size of the substituent to tert-butyl (2-4) gives rise to a red shift of $\lambda_{\text {abs }}(\max )(502-510 \mathrm{~nm}, 500-508 \mathrm{~nm}$ and 504-512 nm for 2, 3 and 4, respectively). The $\lambda_{\text {abs }}(\max )$ values of the meso-substituted dyes $\mathbf{1}, \mathbf{2}$ and $\mathbf{5}$ are comparable to those reported for meso-alkyl substituted BODIPY derivatives, such as $\mathbf{H}$ (4,4difluoro-8-propyl-4-bora-3a,4a-diaza- $s$-indacene),$^{30} \quad$ I $\quad$ (4,4-difluoro-8-pentyl-4-bora-3a,4a-diaza- $s$ indacene), ${ }^{30} \mathbf{J}$ (2-ethyl-4,4-difluoro-1,3,8-trimethyl-4-bora-3a,4a-diaza-s-indacene) ${ }^{45} \mathbf{K}$ (4,4-difluoro3,5,8-trimethyl-4-bora-3a,4a-diaza-s-indacene), ${ }^{43}$ and $\mathbf{L}$ (4,4-difluoro-1,3,5,8-tetramethyl-4-bora-3a,4adiaza-s-indacene $)^{43}$ (Chart 2, Table 3), but are at somewhat lower wavelength (i.e., at slightly higher energies) than those of unsubstituted BODIPY (503, 497, 498 and $504 \mathrm{~nm}$ in dichloromethane, methanol, ethyl acetate and cyclohexane, respectively). ${ }^{30,34}$ The small blue shifts of $\lambda_{\text {abs }}(\max )$ of 8 alkylBODIPYs with respect to unsubstituted BODIPY can be related to the inductive effect + I of the meso-alkyl groups. Quantum chemical calculations indicate that the electron density at the 8-postion increases upon excitation. ${ }^{30}$ Hence, the inductive effect $+\mathrm{I}$ of the alkyl group will raise the LUMO vis-à- 
vis the HOMO, thus increasing slightly the energy gap between both states. A similar argument can be used for compounds 3 and 4 because the 3- and 5-positions have a larger coefficient in the LUMO than in the HOMO. Hence the destabilization of the LUMO by the $+\mathrm{I}$ effect of the $t$-Bu moiety will be larger for the LUMO than for the HOMO, yielding a blue shift. The main absorption band is always very narrow: the full width at half of its maximum, fwhm ${ }_{a b s}$, averaged over all the solvents, equals $900 \pm 100$ $\mathrm{cm}^{-1}$ for $\mathbf{1},(9.7 \pm 0.8) \times 10^{2} \mathrm{~cm}^{-1}$ for $2,900 \pm 100 \mathrm{~cm}^{-1}$ for $\mathbf{3},(6.0 \pm 0.6) \times 10^{2} \mathrm{~cm}^{-1}$ for 4 and $(8.6 \pm$ $0.6) \times 10^{2} \mathrm{~cm}^{-1}$ for 5 .
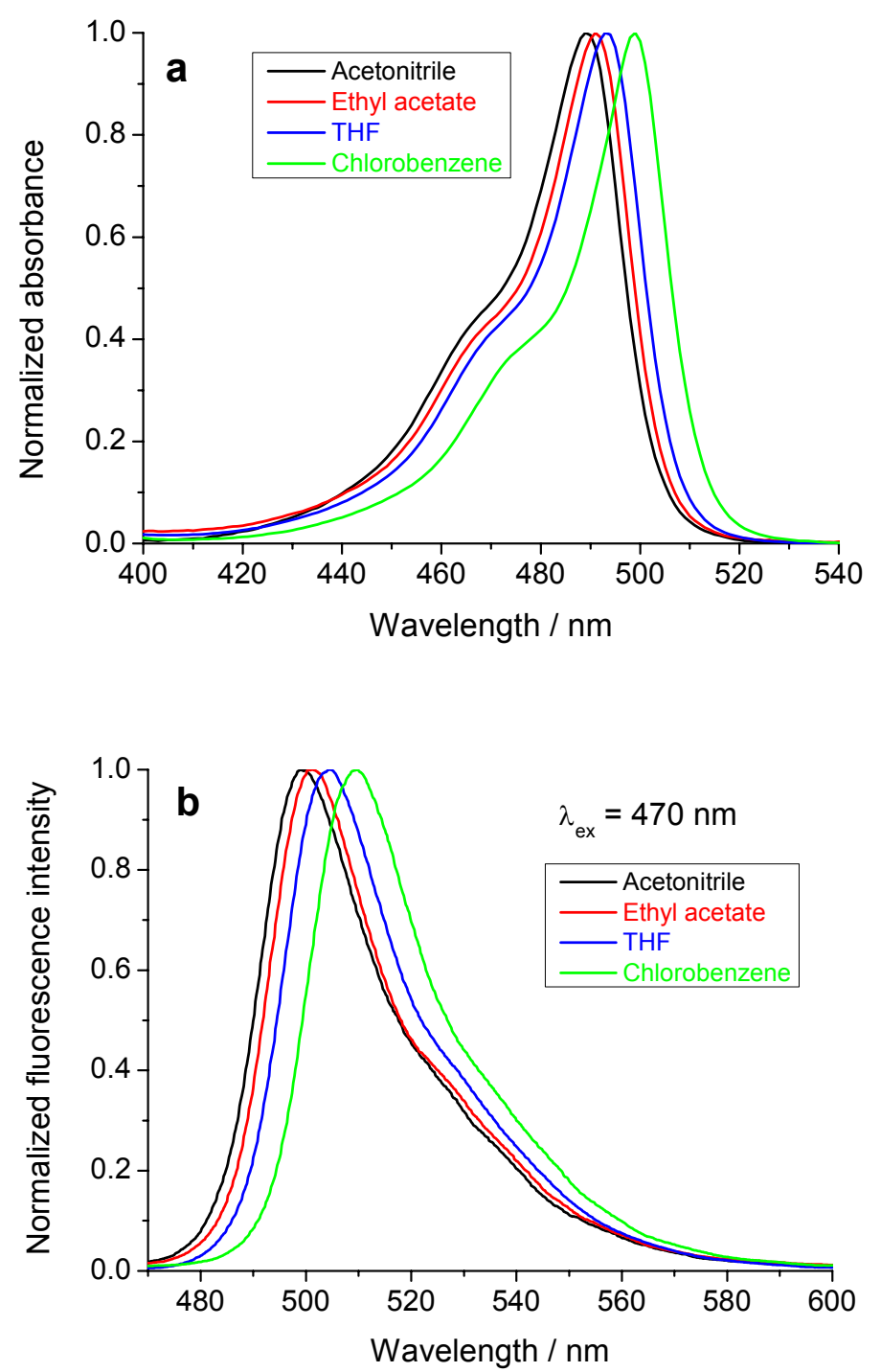

Figure 2. (a) Normalized, main $S_{1} \leftarrow S_{0}$ visible absorption bands of 1 in the solvents indicated. (b) Corresponding normalized fluorescence emission spectra upon excitation at $470 \mathrm{~nm}$. 
Derivatives $\mathbf{1}$ and 3-5 also show the characteristic emission features of BODIPY dyes: i.e., a narrow band of mirror image shape with a small Stokes shift. The maximum of the fluorescence emission band, $\lambda_{\text {em }}(\max )$, is also located within a very narrow wavelength range $(8-9 \mathrm{~nm})$ and is bathochromically shifted with increasing solvent polarizability (from methanol/acetonitrile to toluene/chlorobenzene). In accordance to what was found for absorption, dyes $\mathbf{1}$ and $\mathbf{5}$ with the most compact substituents show the shortest $\lambda_{\text {em }}(\max )(499-507 \mathrm{~nm}$ and 504-513 nm for $\mathbf{1}$ and 5, respectively), whereas compounds $\mathbf{3}$ and 4 with one and two bulky $t$-Bu group(s) produce a red shift of $\lambda_{\text {em }}(\max )(510-518 \mathrm{~nm}$ and 513-521 nm for 3 and 4, respectively) in relation to $\mathbf{1}$ and $\mathbf{5}$. The emission maxima of the meso-substituted derivatives $\mathbf{1}$ and $\mathbf{5}$ are similar to those of reported 8-alkyl substituted BODIPYs $\mathbf{H}-\mathbf{L}$ (Chart 2, Table $3),{ }^{30,43,45}$ but are, in parallel to the absorption spectra, at slightly higher energy than those of unsubstituted BODIPY $(512,507,508$ and $511 \mathrm{~nm}$ in dichloromethane, methanol, ethyl acetate and cyclohexane, respectively). ${ }^{30,34}$ The Stokes shifts, $\Delta \bar{v}$, are very small, in accordance with what is found for classic BODIPY derivatives ${ }^{3,4}$ and unsubstituted BODIPY $\left(349,395,370\right.$ and $265 \mathrm{~cm}^{-1}$ in dichloromethane, methanol and ethyl acetate, respectively). ${ }^{30,34} \Delta \bar{v}$, averaged over all the solvents, is $(3.3 \pm 0.6) \times 10^{2} \mathrm{~cm}^{-1}$ for $\mathbf{1},(3.6 \pm 0.4) \times 10^{2} \mathrm{~cm}^{-1}$ for $3,(3.5 \pm 0.4) \times 10^{2} \mathrm{~cm}^{-1}$ for 4 and $(4.6 \pm 0.5) \times$ $10^{2} \mathrm{~cm}^{-1}$ for 5 . The fluorescence band is always very narrow: the full width at half of its maximum, fwhm $_{\mathrm{em}}$, averaged over all the solvents, equals $(9.9 \pm 0.5) \times 10^{2} \mathrm{~cm}^{-1}$ for $\mathbf{1},(10.1 \pm 0.5) \times 10^{2} \mathrm{~cm}^{-1}$ for 3, $(9.2 \pm 0.4) \times 10^{2} \mathrm{~cm}^{-1}$ for 4 and $(11.8 \pm 0.4) \times 10^{2} \mathrm{~cm}^{-1}$ for $\mathbf{5}$. It should be noted that the values of $\mathrm{fwhm}_{\mathrm{em}}$ are consistently larger than the corresponding $\mathrm{fwhm}_{\mathrm{abs}}$ values. Such a difference between $\mathrm{fwhm}_{\mathrm{abs}}$ and $\mathrm{fwhm}_{\mathrm{em}}$ could suggest a decreased rigidity in the excited state $S_{1}$, leading to a steeper potential energy curve along the relevant low frequency coordinate in $S_{0}$ compared to $S_{1}$. This is not unusual because upon excitation an electron is promoted to a $\pi$-orbital with more nodes and hence less 
bonding character, making the molecule less rigid. The fluorescence quantum yields $\Phi$ of $\mathbf{1}$ and $\mathbf{3}-\mathbf{5}$ in all solvents tested are always extremely high, often reaching 1.00 . The $\Phi$ values $(0.99-1.00)$ of the meso-alkylBODIPYs $\mathbf{1}$ and $\mathbf{5}$ are similar to those of other 8-alkyl substituted analogues $\mathbf{H}-\mathbf{L}$ (Chart 2, Table 3$),{ }^{30,43,45}$ and unsubstituted BODIPY $(0.900 .87,0.93$ and 096 in acetonitrile, methanol, ethyl acetate and cyclohexane, respectively ${ }^{30,34}$ ). As a representative example of the alkylated BODIPYs $\mathbf{1}$ and 3-5, the UV-vis absorption and fluorescence emission spectra of $\mathbf{1}$ dissolved in a selection of solvents are shown in Figure 2. The analogous spectra of 3-5 are shown in Figures S1-S3 (Supporting Information) and are of similar shape as those of $\mathbf{1 .}$

The most interesting feature is that the $8-t-\mathrm{Bu}$ substituted compound $\mathbf{2}$ exhibits strikingly uncommon fluorescence characteristics among the compounds studied. In contrast to the other alkyl-substituted BODIPYs, which are highly fluorescent $(\Phi \sim 1.0)$, derivative 2 has low quantum yields $\Phi$ in all solvents used (Table 2), This effect is remarkable, as the replacement of the sec-hydrogen in the isopropyl group of $\mathbf{5}$ by a methyl group in $\mathbf{2}$ causes such a large decrease in the fluorescence emission efficiency of $\mathbf{2}$, when compared to $\mathbf{5}$. At first sight, it seems equally astonishing that moving the $t$-Bu substituent from the 3-position (in 3) to the 8-position (in 2) yields such a large drop in $\Phi$. The $\Phi$-values of 2 are dependent on the solvent and improve with increasing solvent polarizability, from 0.031 in diethyl ether to 0.108 in chlorobenzene. Furthermore, in contrast to $\mathbf{1}$ and $\mathbf{3}-\mathbf{5}$, the emission spectra of compound $\mathbf{2}$ are more red-shifted and broader, and the emission bands are not distinct mirror images of the $S_{1} \leftarrow S_{0}$ absorption band (Figure 3). Although the width of the absorption band (expressed as fwhm $\mathrm{abs}_{\text {) }}$ of 2 is comparable to that of $\mathbf{1}$ and $\mathbf{3}-\mathbf{5}$, this is not the case anymore for the width of the emission band. Indeed, fwhm $\mathrm{em}_{\text {of }} \mathbf{2}$, averaged over all the solvents, is $(20.8 \pm 0.6) \times 10^{2} \mathrm{~cm}^{-1}$, nearly double of that found for $\mathbf{1}$ and 3-5. The emission maxima $\lambda_{\mathrm{em}}(\max )$ of $\mathbf{2}$ are located at lower energy with respect to $\mathbf{1}$ and $\mathbf{5}$ and 
other reported meso-alkylBODIPYs, such as $\mathbf{H}-\mathbf{L}$ (Chart 2, Table 3). ${ }^{30,43,45}$ Consequently, the Stokes shifts $\Delta \bar{v}$ of $2\left[(15.6 \pm 0.8) \times 10^{2} \mathrm{~cm}^{-1}\right]$ are much larger than those of other 8-alkyl substituted BODIPY analogues. This reflects a much larger shift of the equilibrium position along a low frequency coordinate, as e.g. twisting of the BODIPY core upon excitation in $\mathbf{2}$ compared to the other derivatives. The strong increase of the fwhm of the emission spectra compared to the excitation spectra is opposite to what has been found for some conjugated oligomers, ${ }^{59}$ where planarization occurs upon excitation. This would suggest that the relaxed $S_{1}$ state of 2 is significantly less planar than its $S_{0}$ state.
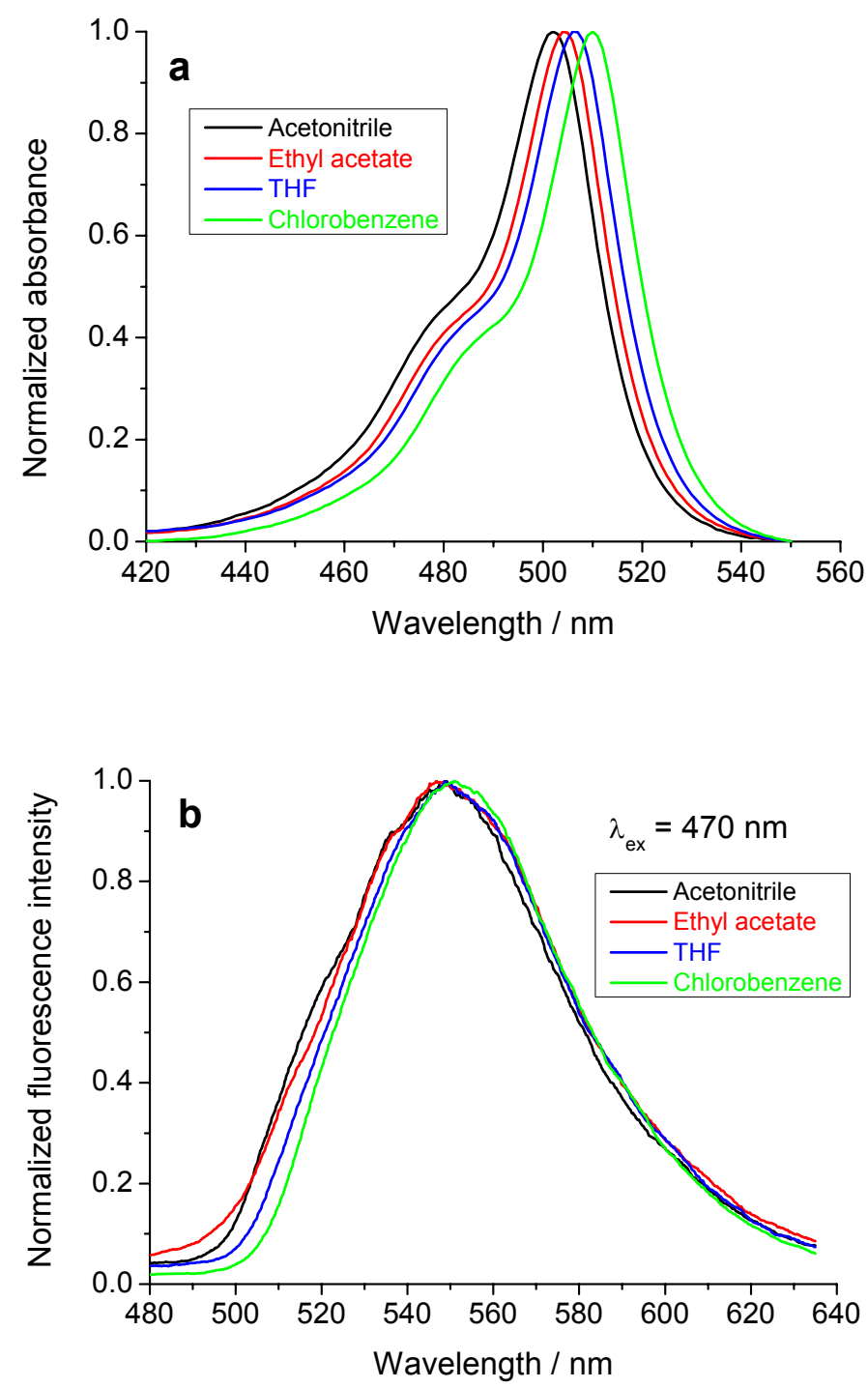

Figure 3. (a) Normalized, main $S_{1} \leftarrow S_{0}$ visible absorption bands of 2 in the solvents indicated. (b) Corresponding normalized fluorescence emission spectra upon excitation at $470 \mathrm{~nm}$. 
Table 2. Spectroscopic and photophysical data of $\mathbf{2}$ as a function of solvent. ${ }^{a}$

\begin{tabular}{|c|c|c|c|c|c|c|c|c|c|c|}
\hline & Solvent & $\begin{array}{c}\lambda_{\mathrm{abs}}(\max ) \\
/ \mathrm{nm}\end{array}$ & $\lambda_{\mathrm{em}}(\max )$ & $\begin{array}{l}\Delta \bar{v} \\
/ \mathrm{cm}^{-1}\end{array}$ & $\begin{array}{l}\text { fwhm } \\
/ \mathrm{cm}^{-1}\end{array}$ & $\begin{array}{l}\text { fwhm }_{\mathrm{em}} \\
/ \mathrm{cm}^{-1}\end{array}$ & $\Phi^{b}$ & $\begin{array}{l}\tau^{c} \\
/ \mathrm{ns}\end{array}$ & $\begin{array}{c}k_{\mathrm{f}}^{d} \\
/ 10^{8} \mathrm{~s}^{-1}\end{array}$ & $\begin{array}{c}k_{\mathrm{nr}}{ }^{d} \\
/ 10^{8} \mathrm{~s}^{-1}\end{array}$ \\
\hline 1 & $\mathrm{CH}_{3} \mathrm{OH}$ & 504 & 547 & 1560 & 1079 & 2127 & $0.040 \pm 0.002$ & 1.00 & $0.40 \pm 0.02$ & $9.60 \pm 0.04$ \\
\hline 2 & $\mathrm{CH}_{3} \mathrm{CN}$ & 502 & 549 & 1705 & 1130 & 2195 & $0.039 \pm 0.002$ & 1.16 & $0.34 \pm 0.02$ & $8.28 \pm 0.03$ \\
\hline 3 & $\left(\mathrm{C}_{2} \mathrm{H}_{5}\right)_{2} \mathrm{O}$ & 506 & 551 & 1614 & 964 & 2086 & $0.031 \pm 0.002$ & 0.99 & $0.31 \pm 0.02$ & $9.79 \pm 0.04$ \\
\hline 4 & $\left(\mathrm{CH}_{3}\right)_{2} \mathrm{CO}$ & 504 & 547 & 1560 & 897 & 2043 & $0.040 \pm 0.002$ & 1.16 & $0.34 \pm 0.02$ & $8.28 \pm 0.03$ \\
\hline 5 & $t-\mathrm{BuOMe}^{e}$ & 506 & 551 & 1614 & 931 & 1988 & $0.035 \pm 0.001$ & 1.10 & $0.32 \pm 0.01$ & $8.77 \pm 0.03$ \\
\hline 6 & $\mathrm{EtOAc}^{e}$ & 504 & 547 & 1560 & 901 & 2113 & $0.039 \pm 0.002$ & 1.06 & $0.37 \pm 0.02$ & $9.07 \pm 0.03$ \\
\hline 7 & Hexane & 508 & 555 & 1667 & 908 & 2097 & $0.036 \pm 0.002$ & 1.10 & $0.33 \pm 0.02$ & $8.76 \pm 0.03$ \\
\hline 8 & $\mathrm{Bu}_{2} \mathrm{O}^{e}$ & 508 & 551 & 1536 & 995 & 2120 & $0.042 \pm 0.003$ & 1.16 & $0.36 \pm 0.02$ & $8.26 \pm 0.03$ \\
\hline 9 & $\mathrm{THF}^{e}$ & 506 & 549 & 1548 & 1037 & 2078 & $0.045 \pm 0.001$ & 1.27 & $0.35 \pm 0.01$ & $7.52 \pm 0.03$ \\
\hline 10 & $\mathrm{CH}_{2} \mathrm{Cl}_{2}$ & 507 & 550 & 1542 & 822 & 2061 & $0.069 \pm 0.002$ & 1.75 & $0.39 \pm 0.01$ & $5.32 \pm 0.02$ \\
\hline 11 & $\mathrm{CHCl}_{3}$ & 509 & 549 & 1431 & 968 & 2016 & $0.083 \pm 0.002$ & 2.12 & $0.39 \pm 0.01$ & $4.33 \pm 0.02$ \\
\hline 12 & Toluene & 510 & 551 & 1459 & 1006 & 2037 & $0.081 \pm 0.005$ & 1.81 & $0.45 \pm 0.03$ & $5.08 \pm 0.03$ \\
\hline 13 & $\mathrm{PhCl}^{e}$ & 510 & 551 & 1459 & 931 & 2037 & $0.108 \pm 0.005$ & 2.33 & $0.46 \pm 0.02$ & $3.83 \pm 0.02$ \\
\hline
\end{tabular}

${ }^{a}$ The solvents are numbered according to increasing refractive index $n .{ }^{b}$ Fluorescence quantum yield \pm one standard uncertainty. $\Phi$ determined vs. fluorescein in $0.1 \mathrm{~N} \mathrm{NaOH}\left(\Phi_{\mathrm{r}}=0.90\right)$ as reference. ${ }^{c}$ Globally determined fluorescence lifetime. The standard errors on $\tau$, obtained from the diagonal elements of the covariance matrix available from the global analysis fit of decay traces recorded at three different emission wavelengths $\left(\lambda_{\mathrm{em}}=565,570\right.$ and $575 \mathrm{~nm}$. $\left.\lambda_{\mathrm{ex}}=485 \mathrm{~nm}\right)$, are between 3 and 6 ps. ${ }^{d}$ Fluorescence rate constant $\left(k_{\mathrm{f}}\right)$ or rate constant for nonradiative decay $\left(k_{\mathrm{nr}}\right) \pm$ propagated error. The propagated errors are calculated using the standard uncertainties on $\Phi$ and the standard errors on $\tau$. ${ }^{e} t$-BuOMe $=t e r t$-butyl methyl ether $(\mathrm{MTBE}), \mathrm{EtOAc}=$ ethyl acetate, $\mathrm{Bu}_{2} \mathrm{O}=$ dibutyl ether, $\mathrm{THF}=$ tetrahydrofuran, $\mathrm{PhCl}=$ chlorobenzene.

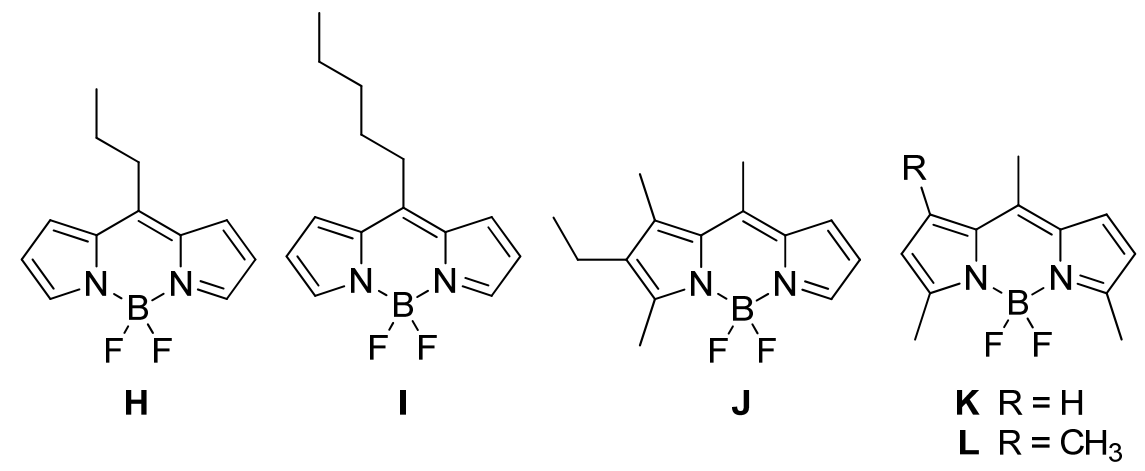

Chart 2. Molecular structure of meso-alkylated BODIPY derivatives $\mathbf{H}-\mathbf{L}$ in the literature. ${ }^{30,48}$ 
Table 3. Selected spectroscopic and photophysical data of meso-alkylated BODIPY dyes reported in the literature.

\begin{tabular}{|c|c|c|c|c|c|c|c|c|}
\hline & Solvent & $\begin{array}{c}\lambda_{\mathrm{abs}}(\max ) \\
/ \mathrm{nm}\end{array}$ & $\lambda_{\mathrm{em}}(\max )$ & $\begin{array}{l}\Delta \bar{v} \\
/ \mathrm{cm}^{-1}\end{array}$ & $\Phi$ & $\begin{array}{l}\tau^{e} \\
/ \mathrm{ns}\end{array}$ & $\begin{array}{c}k_{\mathrm{f}}^{e} \\
/ 10^{8} \mathrm{~s}^{-1}\end{array}$ & $\begin{array}{c}k_{\mathrm{nr}}{ }^{e} \\
/ 10^{8} \mathrm{~s}^{-1}\end{array}$ \\
\hline \multirow{3}{*}{$\mathbf{H}^{a}$} & $\mathrm{CH}_{3} \mathrm{OH}$ & 491 & 502 & 430 & 0.88 & 7.15 & 1.23 & 0.16 \\
\hline & $\mathrm{EtOAc}^{d}$ & 492 & 502 & 415 & 0.90 & 6.62 & 1.35 & 0.15 \\
\hline & Cyclohexane & 497 & 505 & 315 & 0.95 & 6.23 & 1.52 & 0.08 \\
\hline \multirow[t]{3}{*}{$\mathbf{I}^{a}$} & $\mathrm{CH}_{3} \mathrm{OH}$ & 491 & 503 & 475 & 0.89 & 7.42 & 1.20 & 0.15 \\
\hline & $\mathrm{EtOAc}^{d}$ & 492 & 503 & 465 & 0.94 & 6.83 & 1.37 & 0.08 \\
\hline & Cyclohexane & 497 & 507 & 385 & 0.97 & 6.50 & 1.49 & 0.04 \\
\hline \multirow[t]{3}{*}{$\mathbf{J}^{b}$} & $\mathrm{CH}_{3} \mathrm{OH}$ & 496 & 513 & 668 & 0.76 & 5.78 & 1.31 & 0.41 \\
\hline & $\mathrm{EtOAc}^{d}$ & 496 & 513 & 668 & 0.84 & 5.57 & 1.50 & 0.28 \\
\hline & Cyclohexane & 504 & 515 & 735 & 0.96 & 5.46 & 1.75 & 0.07 \\
\hline $\mathbf{K}^{c}$ & $\mathrm{CH}_{3} \mathrm{CN}$ & 501 & 510 & 352 & 1.0 & 6.20 & 1.61 & 0.00 \\
\hline $\mathbf{L}^{c}$ & $\mathrm{CH}_{3} \mathrm{CN}$ & 494 & 504 & 402 & 1.0 & 5.84 & 1.71 & 0.00 \\
\hline
\end{tabular}

${ }^{a}$ Data taken from ref $30 .{ }^{b}$ Data taken from ref $48 \mathrm{~b} .{ }^{c}$ Data taken from ref $43 \mathrm{a} .{ }^{d}$ EtOAc $=$ ethyl acetate. ${ }^{e}$ Fluorescence lifetime $(\tau)$, fluorescence rate constant $\left(k_{\mathrm{f}}\right)$, rate constant for nonradiative decay $\left(k_{\mathrm{nr}}\right)$.

As described above (see also Tables 2 and S2-S5, Supporting Information), for each compound studied, the solvatochromic effect on $\lambda_{\text {abs }}(\max )$ and $\lambda_{\text {em }}(\max )$ is small. Indeed, the maxima of the main absorption band and of the fluorescence emission band of each dye are located within a very narrow wavelength range $(8-9 \mathrm{~nm})$. It is interesting to investigate which solvent property/properties is/are responsible for these small observed solvatochromic shifts of $\lambda_{\text {abs }}(\max )$ and $\lambda_{\text {em }}(\max )$. The most recent and comprehensive treatment of the influence of the solvent is based on a set of four empirical, complementary, mutually independent solvent scales, as proposed by Catalán. ${ }^{60}$ In this method, the polarizability and dipolarity of a particular solvent are characterized by the parameters SP and SdP, respectively, whereas solvent acidity and basicity are described by the scales SA and SB, respectively (eq 1). The $\{\mathrm{SA}, \mathrm{SB}, \mathrm{SP}, \mathrm{SdP}\}$ parameters for a large number of solvents are given in ref 60 . Mathematically, the solvent effect on the physicochemical observable $y$ can be expressed by the 
multilinear eq $1:^{60,61}$

$$
y=y_{0}+a_{\mathrm{SA}} \mathrm{SA}+b_{\mathrm{SB}} \mathrm{SB}+c_{\mathrm{SP}} \mathrm{SP}+d_{\mathrm{SdP}} \mathrm{SdP}
$$

where $y_{0}$ represents the physicochemical property of interest in the gas phase; $a_{\mathrm{SA}}, b_{\mathrm{SB}}, c_{\mathrm{SP}}$ and $d_{\mathrm{SdP}}$ are regression coefficients that describe the sensitivity of the property $y$ to the various solvent-solute interaction mechanisms, and $\{\mathrm{SA}, \mathrm{SB}, \mathrm{SP}, \mathrm{SdP}\}$ are independent solvent parameters (indices) accounting for various types of solvent-solute interactions.

The spectroscopic observables $y$ analyzed in this paper are the absorption maxima $\bar{v}_{\text {abs }}=1 / \lambda_{\text {abs }}(\max )$ and the emission maxima $\bar{v}_{\mathrm{em}}=1 / \lambda_{\mathrm{em}}(\max )$ of $\mathbf{1}-\mathbf{5}$, expressed in $\mathrm{cm}^{-1}$. Use of the Catalán solvent parameter set $\{\mathrm{SA}, \mathrm{SB}, \mathrm{SP}, \mathrm{SdP}\}$ (eq 1) gives excellent fits to $y=\overline{\mathrm{v}}_{\text {abs }}$ of $\mathbf{1}-\mathbf{5}$ using the correlation coefficient $r$ as goodness-of-fit criterion $(r=0.984,0.975,0.989,0.987$ and 0.985 for $\mathbf{1}-\mathbf{5}$, respectively; Tables S6-S7, Supporting Information). Similarly, good-quality fits are also found for the multilinear analysis of $y=\bar{v}_{\mathrm{em}}$ of $\mathbf{1}-\mathbf{5}$ according to eq $1(r=0.972,0.899,0.987,0.963$ and 0.920 for $\mathbf{1}-\mathbf{5}$, respectively; Tables S6-S7, Supporting Information). The extra benefit of the generalized (Catalán) treatment of the solvent effect is that it allows one to separate the relative contributions of dipolarity, polarizability, acidity and basicity of the medium. Hence, we used the new methodology to unravel which solvent property/properties is/are primarily accountable for the measured shifts of $\bar{v}_{\text {abs }}$ and $\bar{v}_{\text {em }}$. For that reason, analyses of $\bar{v}_{\text {abs }}$ and $\bar{v}_{\text {em }}$ according to eq 1 were performed first with $\{\mathrm{SA}, \mathrm{SB}, \mathrm{SP}$, $\mathrm{SdP}\}$ as independent variables and then with progressively less $(3,2,1)$ independent variables. Here, we shall describe the analyses of $\bar{v}_{\text {abs }}$ and $\bar{v}_{\text {em }}$ of $\mathbf{1}$ and $\mathbf{2}$ only. The corresponding analyses of 3-5 can be found in the Supporting Information. All the analyses of $\bar{v}_{\text {abs }}$ and $\bar{v}_{\text {em }}$ demonstrate that specific interactions (parameterized by $\{\mathrm{SA}, \mathrm{SB}\}$ ) have practically no influence on the position of these spectral maxima. 
The fit of $y=\bar{v}_{\text {abs }}$ of 1 according to eq 1 with $\{\mathrm{SA}, \mathrm{SB}, \mathrm{SP}, \mathrm{SdP}\}$ as independent variables yields relatively large estimates of $c_{\mathrm{SP}}$ and $d_{\mathrm{SdP}}$ with high precision (i.e., comparatively small standard errors) in comparison to $\left\{a_{\mathrm{SA}}, b_{\mathrm{SB}}\right\}$ (Table $\mathrm{S} 6$, Supporting Information). This points to solvent polarizability and dipolarity as major parameters influencing the position of $\bar{v}_{\text {abs }}$ of $\mathbf{1}$. If either SP or SdP was left out as independent variable in the analyses of $\bar{v}_{\text {abs }}$ of $\mathbf{1}$ according to eq 1 (that is, with $\{\mathrm{SA}, \mathrm{SB}, \mathrm{SdP}\}$ and $\{\mathrm{SA}, \mathrm{SB}, \mathrm{SP}\}$, respectively), low $r$-values $(0.791$ and 0.744 , respectively) were found, implying the importance of these solvent parameters. Conversely, omitting either SA or SB from the analysis (that is, with $\{\mathrm{SB}, \mathrm{SP}, \mathrm{SdP}\}$ and $\{\mathrm{SA}, \mathrm{SP}, \mathrm{SdP}\}$ as independent variables, respectively) gives excellent fits $(r=$ 0.962 and 0.982 , respectively), confirming the insignificance of these solvent parameters. Further corroboration for SP and SdP as major factors comes from the six analyses with two solvent scales as independent variables: the analysis with $\{\mathrm{SP}, \mathrm{SdP}\}$ yields the best fit with $r=0.959$, which is only fractionally lower than that for the full analysis according to eq $1(r=0.984)$. That specific interactions (parameterized by $\{\mathrm{SA}, \mathrm{SB}\}$ ) have practically no influence on the position of $\overline{\mathrm{v}}_{\text {abs }}$ of $\mathbf{1}$ is further corroborated by the unacceptable multilinear fit of $\bar{v}_{\text {abs }}$ according to eq 1 with $\{\mathrm{SA}, \mathrm{SB}\}$ as independent variables $(r=0.588)$.

Analogous analyses of $\bar{v}_{\text {em }}$ of $\mathbf{1}$ indicate that solvent polarizability and dipolarity are the main factors determining the position of $\bar{v}_{\mathrm{em}}$, but polarizability has a larger influence. Indeed, the analysis of $y=\bar{v}_{\mathrm{em}}$ of 1 according to eq 1 with $\{\mathrm{SA}, \mathrm{SB}, \mathrm{SP}, \mathrm{SdP}\}$ also yields relatively large estimates of $c_{\mathrm{SP}}$ and $d_{\mathrm{SdP}}$ with comparatively small standard errors in relation to $\left\{a_{\mathrm{SA}}, b_{\mathrm{SB}}\right\}$, emphasizing the importance of solvent polarizability and dipolarity (Table S6, Supporting Information). Note that the large $c_{\mathrm{SP}}$-coefficients are negative in the analyses of $\bar{v}_{\text {abs }}$ and $\bar{v}_{\text {em }}$, in agreement with the observation that more polarizable solvents (increasing SP) cause a red shift of $\lambda_{\text {abs }}(\max )$ and $\lambda_{\text {em }}(\max )$ (i.e., smaller $\bar{v}_{\text {abs }}$ and $\bar{v}_{\text {em }}$ ). As 
observed for the absorption maxima, $c_{\mathrm{SP}}$ and $d_{\mathrm{SdP}}$ estimated in the analyses of $\bar{v}_{\mathrm{em}}$ have opposite signs. However, whereas the values of $c_{\mathrm{SP}}$ from $\bar{v}_{\text {abs }}$ and $\bar{v}_{\mathrm{em}}$ are similar, the $d_{\mathrm{SdP}}$ value from emission data is ca. one half of that from absorption data, signifying the dimished influence of (di)polarity on the shifts of $\bar{v}_{\text {em. }}$. This is confirmed by the following extra analyses. Of the four analyses of $\bar{v}_{\text {em }}$ of $\mathbf{1}$ according to eq 1 with three independent variables, the analysis with $\{\mathrm{SA}, \mathrm{SB}, \mathrm{SdP}\}$ produces by far the lowest $r$ value (0.583), implying the major importance of polarizability (Table S6, Supporting Information). Exclusion of SA or SB or SdP from the analysis gives good-to-excellent fits (with $r=0.956,0.969$ and 0.877, respectively). Extra proof for SP (and to a lesser degree SdP) as key solvent scale(s) determining $\bar{v}_{\mathrm{em}}$ is derived from the six analyses according to eq 1 with two solvent scales as independent variables: the three analyses involving SP (that is, with $\{\mathrm{SA}, \mathrm{SP}\},\{\mathrm{SB}, \mathrm{SP}\}$ and $\{\mathrm{SdP}, \mathrm{SP}\}$ ) give superior fits with the analysis with $\{\mathrm{SdP}, \mathrm{SP}\}$ yielding the best fit $(r=0.954)$. Extra evidence that solvent polarizability is the major cause for the solvent dependence of $\bar{v}_{\mathrm{em}}$ of $\mathbf{1}$ derives from the excellent fit of $\bar{v}_{\mathrm{em}} \mathrm{vs}$. the Bayliss function $^{62} f(n)=\left(n^{2}-1\right) /\left(2 n^{2}+1\right)$, with $r=0.966$.

Also for 2, analyses according to eq 1 were carried out in which systematically one, two and three solvent scales were omitted in order to determine which solvent properties predominantly account for the shifts of $\bar{v}_{\text {abs }}$ and $\bar{v}_{\text {em. }}$. The fit of $y=\bar{v}_{\text {abs }}$ of 2 according to eq 1 with $\{\mathrm{SA}, \mathrm{SB}, \mathrm{SP}, \mathrm{SdP}\}$ as independent variables yields relatively large estimates of $c_{\mathrm{SP}}$ and $d_{\mathrm{SdP}}$ with associated comparatively small standard errors in relation to $\left\{a_{\mathrm{SA}}, b_{\mathrm{SB}}\right\}$ (Table S6, Supporting Information). As observed for 1 (and 3-5, Supporting Information), this identifies solvent polarizability and dipolarity as the more important parameters determining the position of $\bar{v}_{\text {abs }}$ of $\mathbf{2}$. As found for $\mathbf{1}$ (and 3-5, Supporting Information), $c_{\mathrm{SP}}$ and $d_{\mathrm{SdP}}$ have opposite signs. The values of $c_{\mathrm{SP}}$ estimated from absorption data are similar for $\mathbf{1}-\mathbf{5}\left[(-1.1 \pm 0.1) \times 10^{3}\right]$. Also the values of $d_{\mathrm{SdP}}$ estimated from $\overline{\mathrm{v}}_{\text {abs }}$ for $\mathbf{1}-\mathbf{5}$ are alike $[(2.3 \pm$ 
$\left.0.6) \times 10^{2}\right]$. Further proof for the influence of SP and SdP comes from the analyses according to eq 1 in which one solvent scale is omitted. The analyses of $\bar{v}_{\text {abs }}$ with $\{\mathrm{SA}, \mathrm{SB}, \mathrm{SdP}\}$ and $\{\mathrm{SA}, \mathrm{SB}, \mathrm{SP}\}$ as independent variables have the lowest $r$-values ( 0.782 and 0.720 , respectively), whereas the analyses with $\{\mathrm{SB}, \mathrm{SP}, \mathrm{SdP}\}$ and $\{\mathrm{SA}, \mathrm{SP}, \mathrm{SdP}\}$ yield superior fits $(r=0.957$ and 0.974 , respectively). From the six analyses according to eq 1 with only two solvent scales as independent variables, the analysis with $\{\mathrm{SP}, \mathrm{SdP}\}$ yields by far the best fit $(r=0.956)$. This provides further evidence for SP and SdP as key solvent scales.

The fit of $y=\bar{v}_{\mathrm{em}}$ of $\mathbf{2}$ according to eq 1 with $\{\mathrm{SA}, \mathrm{SB}, \mathrm{SP}, \mathrm{SdP}\}$ yields a positive $c_{\mathrm{SP}}$-coefficient, in contrast to the negative $c_{\mathrm{SP}}$-value estimated in the analysis of $\bar{v}_{\text {abs }}$ of 2 (Table S6, Supporting Information). Negative $c_{\mathrm{SP}}$-coefficients were also recovered in all the analyses of $\bar{v}_{\text {abs }}$ and $\bar{v}_{\mathrm{em}}$ of $\mathbf{1}$ and 3-5 (Tables S6-S7, Supporting Information). The $c_{\mathrm{SP}}$-coefficients for 1 and 3-5 estimated from $\bar{v}_{\mathrm{em}}$ analyses are comparable in size $\left[(-1.3 \pm 0.1) \times 10^{3}\right]$. However, the value of $c_{\mathrm{SP}}$ recovered for 2 from emission data (i.e., 200) is ca. six times smaller. The values of $d_{\text {SdP }}$ estimated from $\bar{v}_{\text {em }}$ for $\mathbf{1}-\mathbf{5}$ are of similar magnitude $\left[(1.5 \pm 0.3) \times 10^{2}\right]$. Although the values of $c_{\mathrm{SP}}$ and $d_{\mathrm{SdP}}$ estimated in the fit of $\bar{v}_{\text {em }}$ of 2 according to eq 1 with $\{\mathrm{SA}, \mathrm{SB}, \mathrm{SP}, \mathrm{SdP}\}$ are still the largest, they are comparable to that of $b_{\mathrm{SB}}$. This result shows once more that the spectroscopic properties of $\mathbf{2}$ are different from the other alkylated BODIPY dyes studied $(\mathbf{1}, \mathbf{3}-\mathbf{5})$. Exclusion of SdP from the analysis (that is, with $\{\mathrm{SA}, \mathrm{SB}, \mathrm{SP}\}$ as independent variables in eq 1) yields a fit with the lowest $r$-value (0.625), emphasizing the importance of solvent dipolarity. As long as $\mathrm{SdP}$ is present in eq 1, the analyses (i.e., with $\{\mathrm{SA}, \mathrm{SB}, \mathrm{SdP}\},\{\mathrm{SB}, \mathrm{SP}$, $\mathrm{SdP}\}$ and $\{\mathrm{SA}, \mathrm{SP}, \mathrm{SdP}\})$ give high $r$-values $(0.884,0.895$ and 0.831 , respectively. The same holds for the analyses according to eq 1 with two independent variables: if SdP is present as independent variable, good fits are obtained. This is found for the three analyses with $\{\mathrm{SA}, \mathrm{SdP}\},\{\mathrm{SB}, \mathrm{SdP}\}$ and $\{\mathrm{SP}, \mathrm{SdP}\}$ 
yielding $r$-values of $0.830,0.883$ and 0.828 , respectively. Even the linear fit of $y=\bar{v}_{\text {em }}$ vs. SdP still has a reasonable correlation ( $r=0.827$ ), demonstrating that solvent dipolarity $(\mathrm{SdP})$ is the decisive factor for the spectroscopic shifts of $\bar{v}_{\text {em }}$. The predominant contribution of SdP to the solvent dependence of $\bar{v}_{\mathrm{em}}$ suggests a change in dipole moment upon excitation or $\mathbf{2}$. That solvent polarizability is a minor factor affecting the position of $\bar{v}_{\mathrm{em}}$ is further confirmed by the unacceptable fit of $\bar{v}_{\mathrm{em}}$ vs. the Bayliss function $^{62} f(n)(r=0.288)$. This differs from all the other analyses in which solvent polarizability (SP) and to a lesser gradation solvent dipolarity (SdP) - was found to be influencing the location of $\bar{v}_{\mathrm{em}}$.

Because of the large negative $c_{\mathrm{SP}}$ values of 1-5 in solvents (Tables S6-S7, Supporting Information), the solution $\bar{v}_{\text {abs }}$ values are always smaller than $y_{0}$, the corresponding value in the gas phase. This means that $\lambda_{\text {abs }}(\max )$ in solution is red shifted in relation to the gas phase absorption wavelength. $\lambda_{\text {em }}(\max )$ in solution for $\mathbf{1}$ and $\mathbf{3}-\mathbf{5}$ is also red shifted compared to the gas phase emission wavelength. However, due to the positive $c_{\mathrm{SP}}$ and $d_{\mathrm{SdP}}$ values for $\bar{v}_{\mathrm{em}}$ of $\mathbf{2}, \lambda_{\mathrm{em}}(\max )$ in solution for $\mathbf{2}$ is blue shifted in relation to the gas phase emission wavelength.

In order to study the temporal behavior of the fluorescence of $\mathbf{1 - 5}$, fluorescence decay measurements were performed using the single-photon timing technique with global analysis (Tables 2 and S2-S5, Supporting Information) ${ }^{63,64,65,66}$ These measurements allowed the determination of the fluorescence lifetimes $(\tau)$ and, additionally, the calculation of the rate constants for radiative $\left(k_{\mathrm{f}}=\Phi / \tau\right)$ and radiationless $\left[k_{\mathrm{nr}}=(1-\Phi) / \tau\right]$ deactivation of $S_{1}$. In all cases, the fluorescence decay histograms collected at three different emission wavelengths could be fitted globally with a single exponential function $[f(t)=\alpha \exp (-t / \tau)]$. Illustrative examples of fluorescence decay curves of $\mathbf{2}, \mathbf{4}$ and $\mathbf{5}$ and their weighted residuals in different solvents are shown in Figures S4-S6 (Supporting Information). For derivatives $\mathbf{1}$ and $\mathbf{3}-\mathbf{5}$, the fluorescence lifetimes are similar and fairly long: $\tau$, averaged over all the 
solvents, equals $6.4 \pm 0.4 \mathrm{~ns}$ for $\mathbf{1}, 6.1 \pm 0.4 \mathrm{~ns}$ for ns for $\mathbf{3}, 5.9 \pm 0.6 \mathrm{~ns}$ for $\mathbf{4}$ and $6.8 \pm 0.5 \mathrm{~ns}$ for $\mathbf{5}$ Such long fluorescence lifetimes ( $\tau \geq 6 \mathrm{~ns}$ ) were also found for unsubstituted BODIPY (7.2, 7.3, 6.9 and 6.5 ns in dichloromethane, methanol, ethyl acetate and cyclohexane, respectively), ${ }^{30,34} 8$ propylBODIPY J, 8-pentylBODIPY I and the 8-methylBODIPY analogues J, K and $\mathbf{L}$ (Chart 2, Table 3). ${ }^{30,43,45}$ In addition, compounds $\mathbf{1}$ and 3-5 showed a slight effect of the solvent polarity/polarizability on their $\tau$-values. In all cases, the longer lifetimes $\tau$ were found in less polarizable (and more polar) solvents, whereas the shorter $\tau$-values were detected in more polarizable solvents (Tables 2 and S2-S4, Supporting Information). Specifically, the shortest $\tau$-values of $\mathbf{1}(5.63 \mathrm{~ns})$ and $\mathbf{5}$ (5.89 ns) were observed in toluene; for 3 (5.33 ns) and 4 (4.88 ns), the shortest $\tau$-values were measured in chlorobenzene. Conversely, the longest $\tau$-values for $\mathbf{1}(6.91 \mathrm{~ns}), \mathbf{3}(6.65 \mathrm{~ns}), \mathbf{4}(6.89 \mathrm{~ns})$ and $\mathbf{5}$ (7.44 ns) were detected in the more polar (and less polarizable) solvents methanol, acetonitrile, acetone and methanol, respectively. Due to high $\Phi$-values $(\sim 1.0)$ of $\mathbf{1}-\mathbf{3}$ and $\mathbf{5}$, their fluorescent lifetimes $\tau$ will be determined by the inverse of $k_{\text {f }}$, which is proportional to $n^{2}$. In contrast, the $\tau$-values of $\mathbf{2}$ are rather low $(1.4 \pm 0.5$ ns), but interestingly, the effect of the solvent polarity/polarizability was the opposite of $\mathbf{1}$ and 3-5. Indeed, the shortest $\tau$-value $(0.99 \mathrm{~ns})$ of 2 was found in diethyl ether and the longest (2.33 ns) in chlorobenzene (Table 2). Contrary to $\mathbf{1}-\mathbf{3}$ and $\mathbf{5}$, the fluorescence lifetime $\tau$ of $\mathbf{2}$ is determined by the inverse of $k_{\mathrm{nr}}$ and not by $k_{\mathrm{f}}^{-1}$. Consequently, the solvent dependence of $\tau$ of 2 reflects that of $k_{\mathrm{nr}}$.

For dyes $\mathbf{1}$ and 3-5, the fluorescence deactivation processes are nearly solvent independent and highly effective. The radiative deactivation rate constant $k_{\mathrm{f}}$, averaged over all the solvents, equals $(1.6 \pm$ $0.1) \times 10^{8} \mathrm{~s}^{-1}$ for $\mathbf{1},(1.6 \pm 0.1) \times 10^{8} \mathrm{~s}^{-1}$ for $\mathbf{3},(1.7 \pm 0.2) \times 10^{8} \mathrm{~s}^{-1}$ for $\mathbf{4}$ and $(1.5 \pm 0.1) \times 10^{8} \mathrm{~s}^{-1}$ for $\mathbf{5}$. These values are very similar to those reported for unsubstituted BODIPY $\left(k_{\mathrm{f}}=1.2 \times 10^{8} \mathrm{~s}^{-1}, 1.3 \times 10^{8}\right.$ $\mathrm{s}^{-1}$ and $1.5 \times 10^{8} \mathrm{~s}^{-1}$ in methanol, ethyl acetate and cyclohexane), ${ }^{30} 8$-propylBODIPY $\mathbf{H},{ }^{30} 8$ - 
pentylBODIPY $\mathbf{I},{ }^{30}$ and the 8-methyl substituted derivatives $\mathbf{J}, \mathbf{K}$ and $\mathbf{L}^{43,45}$ (Chart 2, Table 3). Because $\Phi$ is (nearly) 1.00 for these alkyl-substituted BODIPYs, their associated nonradiative rate constants $k_{\mathrm{nr}}$ are negligible. In contrast, deactivation of $S_{1}$ of $\mathbf{2}$ via fluorescence is less operative: $k_{\mathrm{f}}$ equals only (3.7 \pm $0.5) \times 10^{7} \mathrm{~s}^{-1}$, averaged over all the solvents tested. This value is approximately one quarter of the $k_{\mathrm{f}}$ values measured for $\mathbf{1}$ and 3-5. The nonradiative deactivation processes of $S_{1}$ are favored for $\mathbf{2}$; the values of $k_{\mathrm{nr}}$ for 2 range from $(3.83 \pm 0.02) \times 10^{8} \mathrm{~s}^{-1}$ in chlorobenzene to $(9.79 \pm 0.04) \times 10^{8} \mathrm{~s}^{-1}$ in diethyl ether.

\section{Quantum Chemical Calculations}

Quantum chemical calculations have proven useful in determining spectroscopic properties of BODIPY-derived compounds. Lindsey, Holten and coworkers ${ }^{50}$ investigated the effect of phenyl substituents located at the 8-position of the BODIPY ring using the SAC-CI method to probe the electronically excited states. It was discovered that in the $S_{1}$ state, there was no barrier to rotation of the phenyl group (with respect to the plane of the BODIPY core) which allowed an efficient coupling to a nonradiative deexcitation mechanism, hence the low fluorescence quantum yields observed experimentally. In a recent paper, ${ }^{67}$ Mukherjee and Thilagar investigated the effect of alkyl-group substitutions at different sites around the BODIPY core upon the relative stability between the different isomeric structures in their electronic ground state. They found that alkyl substituents at 3/5-positions (on the pyrrole rings) contributed to stabilization of the ground state energy, while the BODIPY derivatives became more planar.

In this work, the structures and emission energies of 1-3 were calculated (at $0 \mathrm{~K}$ ) both in the gas phase and solvated in dichloromethane using Density Functional Theory (DFT) with a polarizable continuum dielectric medium representing the solvent. For compounds 1, $\mathbf{2}$ and $\mathbf{3}$, the calculated 
$\lambda_{\text {em }}(\max )$ were $532 \mathrm{~nm}, 620 \mathrm{~nm}$ and $539 \mathrm{~nm}$, respectively, from the $S_{0}$ and $S_{1}$ minimum energy geometries (no thermal broadening). These values are red shifted with respect to the experimental ones by over ca. $1000 \mathrm{~cm}^{-1}$ for $\mathbf{1}$ and $\mathbf{3}$ and ca. $2000 \mathrm{~cm}^{-1}$ for $\mathbf{2}$. Given in Table 4 are some of the computed geometrical parameters for both the $S_{0}$ and $S_{1}$ states. In the $S_{0}$ state, all three BODIPY derivatives show a very small dihedral angle between the two pyrrole rings, with $\mathbf{3}$ displaying a very planar conformation of the BODIPY core. These data are in excellent agreement with the X-ray crystal data given in Table 1. Compound 2 shows a distorted, nonplanar geometry in the $S_{1}$ state, characterized by a very large dihedral angle between the pyrrole rings of $27^{\circ}$ in the gas phase and $25^{\circ}$ in dichloromethane, compared to much smaller angles for $\mathbf{1}$ and $\mathbf{3}$ ( $4^{\circ}$ and $0^{\circ}$, respectively). This gives rise to a destabilized groundstate electronic structure of 2 at the $S_{1}$ geometry $(0.20 \mathrm{eV}$ relative to the ground state minimum), whereas $\mathbf{1}$ and $\mathbf{3}$ show much smaller destabilization of the ground-state electronic structure at their respective $S_{1}$ geometries ( $0.05 \mathrm{eV}$ and $0.03 \mathrm{eV}$ for compounds $\mathbf{1}$ and $\mathbf{3}$, respectively), leading to the red shifted emsission maximum of $\mathbf{2}$ relative to $\mathbf{1}$ and $\mathbf{3}$. This can account for the large Stokes shift and broad emission band of $\mathbf{2}{ }^{68}$ This is illustrated schematically in Figure 4. For $\mathbf{1}$ and $\mathbf{2}$, the alkyl substituent (at position 8), is in an eclipsed conformation (relative to the BODIPY core) in the $S_{0}$ state and this rotates to a staggered conformation upon excitation to the $S_{1}$ state. Compound $\mathbf{3}$, with the alkyl substituent at position 3 (on the pyrrole ring), displays a different behavior, with the alkyl group staying in an eclipsed conformation in both the $S_{0}$ and $S_{1}$ states. ChelpG atomic charges were calculated for the $S_{0}$ and $S_{1}$ states for each of the BODIPY derivatives in order to understand changes in the electron density upon excitation. For $\mathbf{1}$ and $\mathbf{3}$, a modest increase in negative charge is found at the 8-position (from +0.126 e to -0.099 e for $\mathbf{1}$; from -0.330 e to -0.575 e for 3 ). BODIPY 2 displays quite different behavior: upon initial excitation, the partial charge goes from -0.484 e to -0.738 e. However, upon 
geometrical relaxation, the partial charge reduces to -0.374 e. This is reflected in the calculated dipole moments of 2, with the ground-state and Franck-Condon excited-state dipole moments of 5.1 D and 4.1 $\mathrm{D}$, respectively. This clarifies the influence of the solvent dipolarity on the absorption spectra, suggesting a modest decrease of the dipole moment upon excitation. Upon relaxation of the excitedstate geometry, the $S_{1}$ dipole moment increases to $5.1 \mathrm{D}$ (identical to the $S_{0}$ dipole moment), clearly indicating that polar solvents will drive this geometry reorganization. At the CASPT2 level, which gives a more balanced treatment of the two electronic states considered here than DFT, the calculated relaxed $S_{1}$ dipole moment is ca. $0.4 \mathrm{D}$ higher than the $S_{0}$ dipole moment at the relaxed $S_{0}$ geometry (i.e., groundstate equilibrium geometry), in line with the earlier conclusion that solvent dipolarity (parameterized by $\mathrm{SdP}$ ) has a major contribution to the solvent dependence of the emission maxima $\bar{v}_{\mathrm{em}}$ of $\mathbf{2}$. For $\mathbf{1}$ and $\mathbf{3}$, the geometrical relaxation causes a much smaller increase in the excited-state dipole moments of $0.1 \mathrm{D}$ and $0.3 \mathrm{D}$, respectively.

DFT provides a good balance between computational efficiency and accuracy, but for the calculation of conical intersections, one must use a method that can deal with near-degeneracies in the wavefunction (and also be able to calculate nonadiabatic coupling terms). For these calculations, we use the CASSCF method with CASPT2 corrected energies. The geometry for each state calculated with CASSCF shows good agreement with the DFT results, with a significant distortion from planarity in the $S_{1}$ state of 2. Figure 5 shows the visual representations of the $S_{0}$ and $S_{1}$ geometries of 2 calculated with CASSCF, along with the $\mathrm{S}_{1} / \mathrm{S}_{0}$ conical intersection. (The conical intersection was only calculated between the two states mentioned - the calculations are computationally very costly and only available for coupling between two states). The deviation from planarity in the $S_{1}$ state is clear to see, as is the relationship between the $S_{1}$ geometry and the conical intersection. Upon excitation, the relaxation of the 
geometry causes a large deviation from planarity. The barrier from the $S_{1}$ state to the conical intersection is very low, at $0.1 \mathrm{eV}$ (at the CASPT2 level). The rotation of the $t$-Bu group is therefore critical to the radiationless deexcitation pathway resulting in the low fluorescence quantum yields observed experimentally.

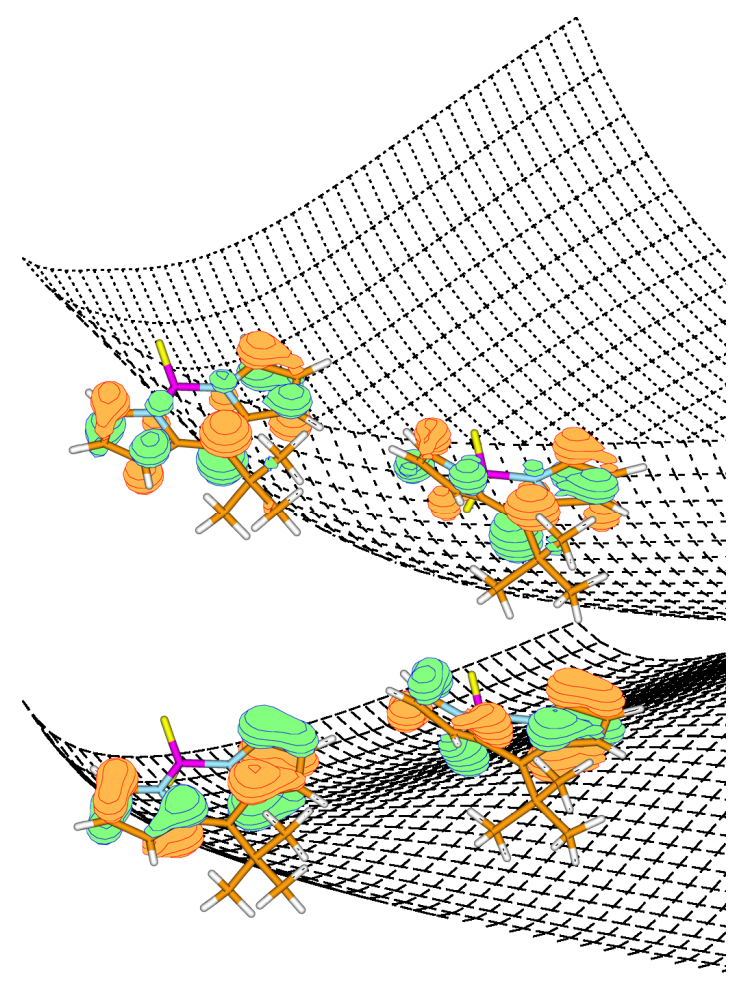

Figure 4. Illustrative representation of the destabilization of the ground state of 2 at the $S_{1}$ geometry; (left) the HOMOLUMO pair at the $S_{0}$ geometry; (right) the HOMO-LUMO pair at the $S_{1}$ geometry. The HOMO is depicted in the lower picture (lower energy) and the LUMO in the upper picture (higher energy). The figure is an illustration to make clear the destabilisation of the HOMO - it is not the actual energy surface.

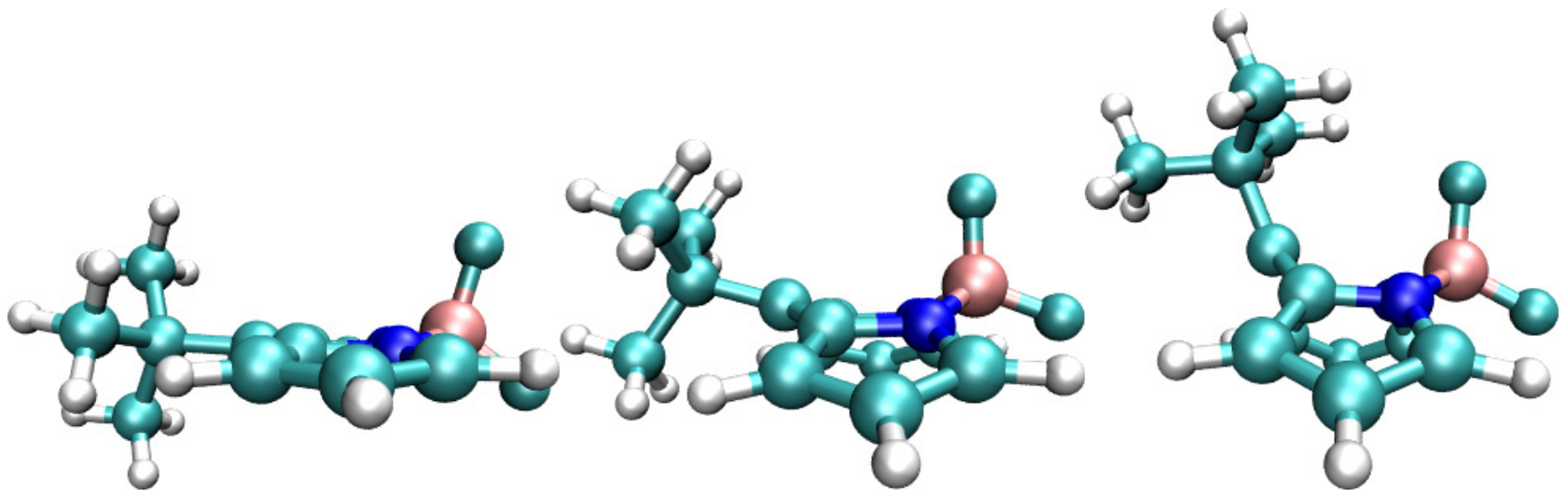

Figure 5. Calculated CASSCF/6-31G* geometries for 2 viewed from the end of one of the pyrrole rings; $S_{0}$ (left); $S_{1}$ (center); $S_{1} / S_{0}$ conical intersection (right). 
Table 4. Selected relaxed geometrical parameters of BODIPYs 1, 2 and 3 obtained from B3LYP / 6-311G(d) DFT calculations. Bond distances in Ångstrom $(\AA)$, dihedral angles between pyrrole rings in degrees $\left(^{\circ}\right)$.

1

$S_{0}$

\begin{tabular}{|c|c|c|c|c|c|c|}
\hline & $S_{0}$ & $S_{1}$ & $S_{0}$ & $S_{1}$ & $S_{0}$ & $S_{1}$ \\
\hline & \multicolumn{6}{|c|}{ Gas phase } \\
\hline B-N $(\AA)$ & 1.561 & 1.558 & 1.549 & 1.556 & $1.577,1.561$ & $1.559,1.577$ \\
\hline C8-C9 (Å) & 1.505 & 1.500 & 1.551 & 1.534 & - & - \\
\hline \multirow[t]{2}{*}{ Dihedral angle $\left({ }^{\circ}\right)$} & 4 & 4 & 4 & 27 & 0 & 0 \\
\hline & \multicolumn{6}{|c|}{ Solvated (Dichloromethane) } \\
\hline $\mathrm{B}-\mathrm{N}(\AA)$ & 1.551 & 1.545 & 1.537 & 1.543 & $1.567,1.590$ & $1.559,1.577$ \\
\hline C8-C9 $(\AA)$ & 1.502 & 1.500 & 1.550 & 1.535 & - & - \\
\hline Dihedral angle $\left(^{\circ}\right)$ & 4 & 4 & 4 & 25 & 0 & 0 \\
\hline
\end{tabular}

2 3

The calculated emission spectra taken from the ab initio molecular dynamics (AIMD) simulations are given in Figures S7-S8 (Supporting Information). The calculated spectra are built by considering emission energies at each geometry in the AIMD trajectory, adding a small Gaussian distribution and adding to the overall spectrum; they display the characteristic mirror image profile in comparison to the experimentally observed spectra. The solvated spectra show a larger broadening than for the gas phase; 3 in particular displays a large degree of broadening. It is worth noting that the calculated emission profiles (and therefore the broadening) are based on the assumption of a normalized emission intensity (i.e., we assume a fluorescence quantum yield of 1 for each given geometry). Given the nonradiative relaxation mechanism noted for $\mathbf{2}$, we would expect the calculated profile to be slightly different to that given in Figure S8 and possibly more like the experimentally observed spectrum [Figure 3(b)], although we cannot calculate the fluorescence quantum yield directly. 


\section{Conclusions}

In summary, alkyl-substituted difluoroboron diazaindacenes generally have spectroscopic and photophysical properties that are common to classic BODIPYs, i.e., (i) absorption and fluorescence spectra with narrow bandwidths that are slightly blue-shifted in relation to unsubstituted BODIPY, (ii) small Stokes shifts, (iii) high quantum yields $\Phi$, and (iv) relatively long fluorescence lifetimes ( $\tau>5 \mathrm{~ns}$ ). The meso-alkylated derivatives $\mathbf{1}$ and $\mathbf{5}$, and the $t$-Bu substituted analogues $\mathbf{3}$ and $\mathbf{4}$ display these features. However, dye 2 with a $t$-Bu substituent at the 8-position is a remarkable exception. Indeed, compared to its $3-t$-Bu substituted isomer $\mathbf{3}$, the fluorescence emission of $\mathbf{2}$ is bathochromically shifted by over $30 \mathrm{~nm}$, the emission bandwidth of 2 is more than twice as large and its Stokes shift is approximately four times larger. Moreover, isomer 2 is virtually nonfluorescent with fluorescence lifetimes in the range of 1-2 ns. These strikingly aberrant characteristics are only observed when the $t$ $\mathrm{Bu}$ group is attached to the BODIPY framework at the 8-position: other alkyl groups at the 8-position (e.g., methyl in $\mathbf{1}$ and isopropyl in 5) or tert-butyl groups at other positions (e.g., 3-position in $\mathbf{3}$ and 3,5positions in 4) do not generate these peculiar features. Quantum chemical calculations have been used to comprehend these atypical spectroscopic and photophysical properties.

\section{EXPERIMENTAL SECTION}

The instrumentation used, the protocol for the relative determination of the fluorescence quantum yields $\Phi$, the collection and analysis of time-resolved fluorescence traces, the crystal structure determination with the crystallographic data for $\mathbf{1 , 2}, \mathbf{4}$ and $\mathbf{5}$, and the analysis of the solvent-dependent spectroscopic properties of 3-5 are described in the Supporting Information. 


\section{Synthesis}

\section{General Procedure for the Synthesis of BODIPYs 1, 2 and 5}

Acyl chloride $(3.5 \mathrm{mmol})$ was added dropwise to freshly distilled pyrrole $(7 \mathrm{mmol})$ in dried $\mathrm{CH}_{2} \mathrm{Cl}_{2}$ $(100 \mathrm{~mL})$. The reaction mixture was stirred at room temperature for $12 \mathrm{~h}$ under argon. Triethylamine (3 $\mathrm{mL})$ and $\mathrm{BF}_{3} \cdot \mathrm{Et}_{2} \mathrm{O}(5 \mathrm{~mL})$ were then added at ice-bath condition, and the reaction mixture was stirred at room temperature for $2 \mathrm{~h}$. The reaction mixture was subsequently washed with water, dried over anhydrous $\mathrm{Na}_{2} \mathrm{SO}_{4}$, filtered, and evaporated under vacuum. The crude product was purified by column chromatography on silica gel (petroleum ether/ethyl acetate $=10 / 1, \mathrm{v} / \mathrm{v}$ ) and the greenish-yellow band was collected to give the target BODIPYs.

BODIPY 1 [4,4-difluoro-8-methyl-4-bora-3a,4a-diaza-s-indacene]: Yield 33\% (238 mg). Mp: 154-155 ${ }^{\circ} \mathrm{C} .{ }^{1} \mathrm{H}$ NMR $\left(300 \mathrm{MHz}, \mathrm{CDCl}_{3}\right): \delta 7.83(\mathrm{~s}, 2 \mathrm{H}), 7.28(\mathrm{~s}, 2 \mathrm{H}), 6.52(\mathrm{~s}, 1 \mathrm{H}), 2.61(\mathrm{~s}, 3 \mathrm{H}) \mathrm{ppm} .{ }^{13} \mathrm{C}$ NMR (75 $\left.\mathrm{MHz}, \mathrm{CDCl}_{3}\right): \delta 146.0,134.4,135.5,128.1,118.0,16.1 \mathrm{ppm}$. HRMS (APCI): Calculated for $\mathrm{C}_{10} \mathrm{H}_{10} \mathrm{BF}_{2} \mathrm{~N}_{2}[\mathrm{M}+\mathrm{H}]^{+}:$207.0905, found 207.0916.

BODIPY 2 [8-tert-butyl-4,4-difluoro-4-bora-3a,4a-diaza-s-indacene]: Yield 12\% (108 mg). Mp: 135$136{ }^{\circ} \mathrm{C} .{ }^{1} \mathrm{H}$ NMR $\left(300 \mathrm{MHz}, \mathrm{CDCl}_{3}\right): \delta 7.83(\mathrm{~s}, 1 \mathrm{H}), 7.67(\mathrm{~s}, 1 \mathrm{H}), 6.54(\mathrm{~s}, 1 \mathrm{H}), 1.73(\mathrm{~s}, 5 \mathrm{H}) \mathrm{ppm} .{ }^{13} \mathrm{C}$ NMR (75 MHz, $\left.\mathrm{CDCl}_{3}\right): \delta 162.1,142.1,134.5,132.4,117.4,40.4,35.8$ ppm. HRMS: Calculated for $\mathrm{C}_{13} \mathrm{H}_{16} \mathrm{BF}_{2} \mathrm{~N}_{2}[\mathrm{M}+\mathrm{H}]^{+}: 249.1375$, found. 249.1375.

BODIPY 5 [4,4-difluoro-8-isopropyl-4-bora-3a,4a-diaza-s-indacene]: Yield 18\% (150 mg). Mp: 178$179{ }^{\circ} \mathrm{C} .{ }^{1} \mathrm{H}$ NMR $\left(500 \mathrm{MHz}, \mathrm{CDCl}_{3}\right): \delta 7.85(\mathrm{~s}, 2 \mathrm{H}), 7.41(\mathrm{~s}, 2 \mathrm{H}), 6.53(\mathrm{~s}, 2 \mathrm{H}), 3.56-3.47(\mathrm{~m}, 1 \mathrm{H}), 1.56$ $(\mathrm{d}, 6 \mathrm{H}, J=7.2 \mathrm{~Hz}) .{ }^{13} \mathrm{C} \mathrm{NMR}\left(75 \mathrm{MHz}, \mathrm{CDCl}_{3}\right): \delta 157.6,143.2,134.0,128.6,117.8,32.4,24.8$. HRMS: Calculated for $\mathrm{C}_{12} \mathrm{H}_{14} \mathrm{BF}_{2} \mathrm{~N}_{2}[\mathrm{M}+\mathrm{H}]^{+}:$235.1213, found. 235.1215. 
Synthesis of BODIPY 3 [3-tert-butyl-4,4-difluoro-4-bora-3a,4a-diaza-s-indacene]

At ice-cold condition under argon, to 5-tert-butyl-pyrrole-2-carbaldehyde (302 $\mathrm{mg}, 2 \mathrm{mmol})$ in $5 \mathrm{~mL}$ $\mathrm{CH}_{2} \mathrm{Cl}_{2}$ was added pyrrole $(134 \mathrm{mg}, 2 \mathrm{mmol})$ in $\mathrm{CH}_{2} \mathrm{Cl}_{2}(1 \mathrm{~mL})$ and then $\mathrm{POCl}_{3}(188 \mu \mathrm{L}, 2 \mathrm{mmol})$ in $\mathrm{CH}_{2} \mathrm{Cl}_{2}(1 \mathrm{~mL})$. The reaction mixture was stirred at this ice-cold condition for $1 \mathrm{~h}$. To the reaction mixture was added triethylamine $(2.8 \mathrm{~mL})$ and the mixture was stirred for 10 min before the subsequent addition of $\mathrm{BF}_{3} \cdot \mathrm{OEt}_{2}(3 \mathrm{~mL})$ through a syringe. The reaction mixture was left stirring for $4 \mathrm{~h}$, poured into water and extracted with $\mathrm{CH}_{2} \mathrm{Cl}_{2}$. The organic layers were combined and the solvent was removed under vacuum. The crude product was purified by chromatography (silica gel, petroleum ether $/ \mathrm{CH}_{2} \mathrm{Cl}_{2}=$ 3/1, v/v) and the desired compound was obtained in $10 \%$ yield $(50 \mathrm{mg})$. Mp: $103-104{ }^{\circ} \mathrm{C} .{ }^{1} \mathrm{H}$ NMR $(300$ $\left.\mathrm{MHz}, \mathrm{CDCl}_{3}\right): \delta 7.76(\mathrm{~s}, 1 \mathrm{H}), 7.24(\mathrm{~s}, 1 \mathrm{H}), 7.09(\mathrm{~d}, J=4.2 \mathrm{~Hz}, 1 \mathrm{H}), 7.01(\mathrm{~s}, 1 \mathrm{H}), 6.53(\mathrm{~d}, J=4.2 \mathrm{~Hz}$, $1 \mathrm{H}), 6.48(\mathrm{~s}, 1 \mathrm{H}), 1.53(\mathrm{~s}, 9 \mathrm{H}) \mathrm{ppm} .{ }^{13} \mathrm{C} \mathrm{NMR}\left(75 \mathrm{MHz}, \mathrm{CDCl}_{3}\right): \delta 174.8,141.5,138.1,133.5,133.2$, 129.6, 128.2, 119.1, 117.7, 35.2, 30.3 ppm. HRMS (APCI): Calculated for $\mathrm{C}_{13} \mathrm{H}_{15} \mathrm{BFN}_{2}[\mathrm{M}-\mathrm{F}]^{+}$: 229.13123, found 229.13017. HRMS (APCI): Calculated for $\mathrm{C}_{13} \mathrm{H}_{16} \mathrm{BF}_{2} \mathrm{~N}_{2}[\mathrm{M}+\mathrm{H}]^{+}:$249.1375, found 249.1364.

Synthesis of BODIPY 4 [3,5-bis(tert-butyl)-4,4-difluoro-4-bora-3a,4a-diaza-s-indacene]

To 5-tert-butyl-pyrrole-2-carbaldehyde (302 mg, $2 \mathrm{mmol}$ ) in $10 \mathrm{~mL}$ dry $\mathrm{CH}_{2} \mathrm{Cl}_{2}$ under argon was added $\mathrm{POCl}_{3}(0.22 \mathrm{~mL}, 2.4 \mathrm{mmol})$ in $\mathrm{CH}_{2} \mathrm{Cl}_{2}(2 \mathrm{~mL})$ in a dropwise manner over $5 \mathrm{~min}$ at $0{ }^{\circ} \mathrm{C}$. The solution was slowly warmed to room temperature and stirred for $6 \mathrm{~h}$. After cooling the reaction mixture to $0{ }^{\circ} \mathrm{C}$, triethylamine $(1.4 \mathrm{~mL}, 10 \mathrm{mmol})$ was added dropwise to this reaction mixture over $5 \mathrm{~min}$. After stirring for $15 \mathrm{~min}, \mathrm{BF}_{3} \cdot \mathrm{OEt}_{2}(2.0 \mathrm{~mL}, 16 \mathrm{mmol})$ was added dropwise to the solution over $5 \mathrm{~min}$. The reaction mixture was warmed to room temperature and stirred for $10 \mathrm{~h}$. The mixture was passed through a short pad of silica gel and eluted with $\mathrm{CH}_{2} \mathrm{Cl}_{2}$ to remove the polar impurities. Solvents were removed under 
vacuum. The residue was dissolved in $\mathrm{CH}_{2} \mathrm{Cl}_{2}$, washed with water, brine and dried over $\mathrm{Na}_{2} \mathrm{SO}_{4}$. The solvent was removed under vacuum, the crude product was purified by chromatography (silica gel, petroleum ether $/ \mathrm{CH}_{2} \mathrm{Cl}_{2}=3 / 1, \mathrm{v} / \mathrm{v}$ ), and the desired compound was obtained as a red powder in $15 \%$ yield (46 mg). Mp: $138-139{ }^{\circ} \mathrm{C} .{ }^{1} \mathrm{H}$ NMR $\left(300 \mathrm{MHz}, \mathrm{CDCl}_{3}\right): \delta 7.14(\mathrm{~s}, 1 \mathrm{H}), 6.98(\mathrm{~s}, 2 \mathrm{H}), 6.50(\mathrm{~s}, 2 \mathrm{H})$, $1.53(\mathrm{~s}, 18 \mathrm{H}) \mathrm{ppm} .{ }^{13} \mathrm{C} \mathrm{NMR}\left(75 \mathrm{MHz}, \mathrm{CDCl}_{3}\right): \delta 171.5,136.1,130.0,127.9,118.1,35.0,30.6,30.5$, 30.4 ppm. HRMS (APCI): Calculated for $\mathrm{C}_{17} \mathrm{H}_{23} \mathrm{BFN}_{2}[\mathrm{M}-\mathrm{F}]^{+}$: 285.1938, found 285.1934. HRMS (APCI): Calculated for $\mathrm{C}_{17} \mathrm{H}_{24} \mathrm{BF}_{2} \mathrm{~N}_{2}[\mathrm{M}+\mathrm{H}]^{+}:$305.2001, found 305.1994.

\section{Computational Details}

Structures of the ground $\left(S_{0}\right)$ and the first singlet excited $\left(S_{1}\right)$ state we optimized using unrestricted DFT with the B3LYP functional and the 6-311G(d) basis set. In order to study the first singlet excited within Kohn-Sham DFT, the maximum overlap method (MOM) ${ }^{69}$ was employed to converge the SCF procedure to an excited-state solution. In this procedure, an initial set of orbitals for the ground state is generated, then a $\beta$ electron is excited from the HOMO to the LUMO; the MOM procedure then prevents the variational collapse to the ground state within the subsequent SCF calculation. This approach has the advantage that the orbitals are specifically optimized for the state of interest and the transition energies can be calculated using a $\triangle \mathrm{SCF}$ approach. This approach is accurate for a large number of states; ${ }^{69,70,71,72,73}$ however, the excitation energy to valence orbitals (i.e., non-Rydberg) leading to open-shell singlet states is usually underestimated. The reason for this deficiency is associated with the use of a single determinant describing a mixed-spin state. The computed excitation energies (and thus gradients) can be improved significantly by applying the Ziegler post-SCF spinpurification correction,

$$
E=2 E_{S}-E_{T}
$$


where $E$ is the energy of the spin-purified (true) singlet state, $E_{S}$ is the energy of the spin-mixed state and $E_{T}$ is the energy of the corresponding triplet state. This approach has been successfully applied previously to the BODIPY core. ${ }^{74}$ Solvation was taken into account using the polarizable continuum model (PCM), with a dielectric constant set to 9.08 .

$\mathrm{Ab}$ initio molecular dynamics (AIMD) simulations were performed in both the gas phase and solvated phase, using the PCM. All AIMD simulations were run for a total of $10^{4}$ steps, with a time step of 10 a.u. Fock matrix extrapolation was employed, using the last 10 Fock matrices and extrapolated using a $5^{\text {th }}$ order polynomial. Ground-state and excited-state potential energy surfaces were explored using the MOM method outlined above. All DFT calculations were performed with the Q-Chem software. $^{75}$

Geometry optimizations of the $S_{0}, S_{1}$ and $S_{0} / S_{1}$ conical intersection were also calculated with the complete active space self-consistent field (CASSCF) method. For each of the BODIPY derivatives investigated, an active space of 12 electrons in 11 orbitals was employed, with state-averaging over the first two singlet states. The 6-31G(d) basis set was used. CASSCF provides an accurate zeroth-order wavefunction in which near-degeneracies are treated at the full configuration interaction (CI) level. However, for accurate relative energies, one must use a multi-reference variant of CI or perturbation theory in order to correctly describe the dynamical electron correlation. In this work, we have used the CASPT2 method of Werner and coworkers ${ }^{76,77}$ with the IPEA modified zeroth-order Hamiltonian shift suggested by Malmqvist et al. ${ }^{78}$ All CASSCF calculations were performed with Molpro. ${ }^{79,80}$

\section{Supporting Information}

Experimental section (instrumentation, relative determination of fluorescence quantum yield $\Phi$, timeresolved fluorescence, crystal structure determination), calculated frontier orbitals, absorption and 
fluorescence emission spectra of 3-5, time-resolved fluorescence traces, photographs of cuvettes containing $\mathbf{1}$ and $\mathbf{2}$ in chloroform and acetone under ambient light and UV irradiation, spectroscopic/photophysical data of BODIPYs $\mathbf{1}$ and 3-5, additional crystallographic data for 1, 2, 4 and 5, results of the analysis of the solvent-dependent spectroscopic properties according to Catalán, DFT calculated emission spectra of $\mathbf{1}-\mathbf{3}$, and copies of NMR spectra of $\mathbf{1}-\mathbf{5}$ and $\mathbf{7}$.

\section{ACKNOWLEDGMENTS}

This work is supported by the National Nature Science Foundation of China (Grants Nos. 21472002 and 21372011). DR and NAB would like to thank the University of Nottingham for provision of time on the High Performance Computing cluster. MVdA is indebted to BELSPO through IAP VII/05 and to the KU Leuven Research Fund through GOA 2011/3.

\section{REFERENCES}

(1) R. P. Haugland, The Handbook. A guide to fluorescent probes and labeling technologies, 10th ed.; Invitrogen: Eugene, OR, 2005.

(2) A. Treibs and F.-H. Kreuzer, Liebigs Ann. Chem., 1968, 718, 208-223.

(3) A. Loudet and K. Burgess, Chem. Rev., 2007, 107, 4891-4932.

(4) G. Ulrich, R. Ziessel and A. Harriman, Angew. Chem. Int. Ed., 2008, 47, 1184-1201.

(5) R. West, C. Panagabko and J. Atkinson, J. Org. Chem., 2010, 75, 2883-2892.

(6) A. B. Descalzo, H,-J. Xu, Z.-L. Xue, K. Hoffmann, Z. Shen, M. G. Weller, X.-Z. You and K. Rurack, Org. Lett., 2008, 10, 1581-1585.

(7), K. S. Krishnan, C. Bengtsson, J. A. D. Good, S. Mirkhanov, E. Chorell, L. B.-Å. Johansson and F. Almqvist, J. Org. Chem., 2013, 78, 12207-12213.

(8) K. Krumova, L. E. Greene and G. Cosa, J. Am. Chem. Soc., 2013, 135, 17135-17143.

(9) X. Zhang, Y. Xiao, J. Qi, J. Qu, B. Kim, X. Yue and K. D. Belfield, J. Org. Chem., 2013, 78, 9153-9160.

(10) L. C. D. de Rezende and F. da S. Emery, Orbital Elec. J. Chem., 2013, 5, 62-83.

(11) S. T. Manjare, J. Kim, Y. Lee and D. G. Churchill, Org. Lett., 2014, 16, 520-5223.

(12) M. Zhang, Y. Wu, S. Zhang, H. Zhu, Q. Wu, L. Jiao and E. Hao, Chem. Commun., 2012, 48, 8925-8927.

(13) N. Boens, V. Leen and W. Dehaen, Chem. Soc. Rev., 2012, 41, 1130-1172.

(14) S. Diring, F. Puntoriero, F. Nastasi, S. Campagna and R. Ziessel, J. Am. Chem. Soc., 2009, 131, 6108-6110.

(15) Y. Ueno, J. Jose, A. Loudet, C. Pérez-Bolívar, P. Anzenbacher Jr. and K. Burgess, J. Am. Chem. Soc., 2011, 133, 51-55.

(16) S. G. Awuah and Y. You, RSC Adv., 2012, 2, 11169-11183.

(17) A. Kamkaew, S. H. Lim, H. B. Lee, L. V. Kiew, L. Y. Chung and K. Burgess, Chem. Soc. Rev., 2013, 42, 77-88. 
(18) D. Zhang, V. Martín, I. García-Moreno, A. Costela, M. E. Pérez-Ojeda and Y. Xiao, Phys. Chem. Chem. Phys., 2011, 13, 13026-13033.

(19) J. Bañuelos, V. Martín, C. F. Gómez-Durán, I. J. Arroyo Córdoba, E. Peña-Cabrera, I. García-Moreno, Á. Costela, M. E. Pérez-Ojeda, T. Arbeloa and I. López Arbeloa, Chem. Eur. J., 2011, 17, 7261-7270.

(20) N. Boens, B. Verbelen and W. Dehaen, Eur. J. Org. Chem., 2015, xxx. DOI: 10.1002/ejoc.201500682.

(21) (a) L. Jiao, C. Yu, J. Li, Z. Wang, M. Wu and E. Hao, J. Org. Chem., 2009, 74, 7525-7528. (b) L. Jiao, C. Yu, M. Liu, Y. Wu, K. Cong, T. Meng, Y. Wang and E. Hao, J. Org. Chem., 2010, 75, 6035-6038.

(22) C. Yu, L. Jiao, H. Yin, J. Zhou, W. Pang, Y. Wu, Z. Wang, G. Yang and E. Hao, Eur J. Org. Chem., 2011, 5460-5468.

(23) L. Jiao, W. Pang, J. Zhou, Y. Wei, X. Mu, G. Bai and E. Hao, J. Org. Chem., 2011, 76, 9988-9996.

(24) O. Buyukcakir, O. A. Bozdemir, S. Kolemen, S. Erbas and E. U. Akkaya, Org. Lett., 2009, 11, 4644-4647.

(25) A. Haefele, C. Zedde, P. Retailleau, G. Ulrich and R. Ziessel, Org. Lett., 2010, 12, 1672-1675.

(26) K. Krumova and G. Cosa, J. Am. Chem. Soc., 2010, 132, 17560-17569.

(27) T. Bura, P. Retailleau, G. Ulrich and R. Ziessel, J. Org. Chem., 2011, 76, 1109-1117.

(28) V. Lakshmi and M. Ravikanth, J. Org. Chem., 2011, 76, 8466-8471.

(29) (a) T. Rohand, M. Baruah, W. Qin, N. Boens and W. Dehaen, Chem. Commun., 2006, 266-268. (b) T. Rohand, W. Qin, N. Boens and W. Dehaen, Eur. J. Org. Chem., 2006, 4658-4663. (c) V. Leen, V. Zaragozí Gonzalvo, W. M. De Borggraeve, N. Boens and W. Dehaen, Chem. Commun., 2010, 46, 4908-4910. (d) V. Leen, M. Van der Auweraer, N. Boens and W. Dehaen, Org. Lett., 2011, 13, 1470-1473. (e) V. Leen, D. Miscoria, S. Yin, A. Filarowski, J. M. Ngongo, M. Van der Auweraer, N. Boens and W. Dehaen, J. Org. Chem., 2011, 76, 8168-8176.

(30) J. Bañuelos, I. J. Arroyo-Córdoba, I. Valois-Escamilla, A. Alvarez-Hernández, E. Peña-Cabrera, R. Hu, B. Z. Tang, I. Esnal, V. Martínez and I. López Arbeloa, RSC Adv., 2011, 1, 677-684.

(31) L. N. Sobenina, A. M. Vasil'tsov, O. V. Petrova, K. B. Petrushenko, I. A. Ushakov, G. Clavier, R. Meallet-Renault, A. I. Mikhaleva and B. A. Trofimov, Org. Lett., 2011, 13, 2524-2527.

(32) S. G. Awuah, J. Polreis, V. Biradar and Y. You, Org. Lett., 2011, 13, 3884-3887.

(33) S. Choi, J. Bouffard and Y. Kim, Chem. Sci., 2014, 5, 751-755.

(34) A. Schmitt, B. Hinkeldey, M. Wild and G. Jung, J. Fluoresc., 2009, 19, 755-758.

(35) G. Sathyamoorthi, J. H. Boyer, T. H. Allik and S. Chandra, Heteroat. Chem., 1994, 5, 403-407.

(36) C. F. A. Gómez-Durán, I. García-Moreno, A. Costela, V. Martin, R. Sastre, J. Bañuelos, F. López Arbeloa, I. López Arbeloa and E, Peña-Cabrera, Chem. Commun., 2010, 46, 5103-5105.

(37) C. A. Osorio-Martínez, A. Urías-Benavides, C. F. A. Gómez-Durán, J. Bañuelos, I. Esnal, I. López Arbeloa and E. Peña-Cabrera, J. Org. Chem., 2012, 77, 5434-5438.

(38) R. I. Roacho, A. Metta-Magaña, M. M. Portillo, E. Peña-Cabrera and K. H. Pannell, J. Org. Chem., 2013, 78, 42454250 .

(39) (a) V. Leen, P. Yuan, L. Wang, N. Boens and W. Dehaen, Org. Lett., 2012, 14, 6150-6153. (b) N. Boens, L. Wang, V. Leen, P. Yuan, B. Verbelen, W. Dehaen, M. Van der Auweraer, W. D. De Borggraeve, L. Van Meervelt, J. Jacobs, D. Beljonne, C. Tonnelé, R. Lazzaroni, M. J. Ruedas-Rama, A. Orte, L. Crovetto, E. M. Talavera and J. M. Alvarez-Pez, J. Phys. Chem. A, 2014, 118, 1576-1594.

(40) (a) R. Misra, B. Dhokale, T. Jadhav and S. M. Mobin, New. J. Chem., 2014, 38, 3579-3585. (b) R. Misra, B. Dhokale, T. Jadhav and S. M. Mobin, Organometallics, 2014, 33, 1867-1877.

(41) L. Wang, Y. Zhang and Y. Xiao, RSC Adv., 2013, 3, 2203-2206.

(42) J. O. Flores-Rizo, I. Esnal, C. A. Osorio-Martínez, C. F. A. Gómez-Durán, J. Bañuelos, I. López Arbeloa, K. H. Pannell, A. J. Metta-Magaña and E. Peña-Cabrera, J. Org. Chem., 2013, 78, 5867-5877.

(43) M. Zhang, E. Hao, Y. Xu, S. Zhang, H. Zhu, Q. Wang, C. Yu and L. Jiao, RSC Adv., 2012, 2, 11215-11218. 
(44) (a) E. Palao, A. R. Agarrabeitia, J. Bañuelos-Prieto, T. Arbeloa López, I. López Arbeloa, D. Armesto and M. J. Ortiz, Org. Lett., 2013, 15, 4454-4457. (b) J. Bañuelos-Prieto, A. R. Agarrabeitia, I. García-Moreno, I. López-Arbeloa, A. Costela, L. Infantes, M. E. Perez-Ojeda, M. Palacios-Cuesta and M. J. Ortiz, Chem. Eur. J., 2010, 16, $14094-14105$.

(45) (a) B. Dhokale, T. Jadhav, S. M. Mobin and R. Misra, J. Org. Chem., 2015, 80, 8018-8025. (b) R. Misra, B. Dhokale, T. Jadhav and S. M. Mobin, Dalton Trans., 2014, 43, 4854-4861.

(46) B. Dhokale, T. Jadhav, S. M. Mobin and R. Misra, Dalton Trans., 2015, 44, 15803-15812.

(47) (a) C. Yu, Y. Xu, L. Jiao, J. Zhou, Z. Wang and E. Hao, Chem. Eur. J., 2012, 18, 6437-6442. (b) N. Shivran, S. Mula, T. K. Ghanty and S. Chattopadhyay, Org. Lett., 2011, 13, 5870-5873.

(48) B. Dhokale, T. Jadhav, S. M. Mobin and R. Misra, Chem. Commun., 2014, 50, 9119-9121.

(49) R. Lincoln, L. E. Greene, C. Bain, J. O. Flores-Rizo, D. S. Bohle and G. Cosa, J. Phys. Chem. B, 2015, 119 , 4758-4765.

(50) H. L. Kee, C. Kirmaier, L. Yu, P. Thamyongkit, W. J. Youngblood, M. E. Calder, L. Ramos, B. C. Noll, D. F. Bocian, W. R. Scheidt, R. R. Birge, J. S. Lindsey and D. Holten, J. Phys. Chem. B, 2005, 109, 20433-20443.

(51) B. A. Henry and W. Siebrand, in Organic Molecular Photophysics, Vol. 1, Birks, J. B., Ed. John Wiley \& Sons: London, 1973, pp 153-238.

(52) T. T. Vu, M. Dvorko, E. Y. Schmidt, J.-F. Audibert, P. Retailleau, B. A. Trofimov, R. B. Pansu, G. Clavier and R. Méallet-Renault, J. Phys. Chem. C, 2013, 117, 5373-5385.

(53) J. Bañuelos Prieto, F. López Arbeloa, V. Martínez Martínez, T. Arbeloa López and I. López Arbeloa, J. Phys. Chem. A, 2004, 108, 5503-5508.

(54) V. Leen, T. Leemans, N. Boens and W. Dehaen, Eur. J. Org. Chem., 2011, 4386-4396.

(55) L. Wu and K. Burgess, Chem. Commun., 2008, 4933-4935.

(56) J.-s. Lu, S.-B. Ko, N. R. Walters and S. Wang, Org. Lett., 2012, 14, 5660-5663.

(57) H. Lu, Q. Wang, L. Gai, Z. Li, Y. Deng, X. Xiao, G. Lai and Z. Shen, Chem. Eur. J., 2012, 18, 7852-7861.

(58) G. H. Penner, Y.-C. P. Chang, P. Nechala and R. Froese, J. Org. Chem., 1999, 64, 447-452.

(59) H. Bässler, in Electronic Materials: The Oligomer Aproach. K. Müllen and G. Wegner, Eds., Wiley VCH: Weinheim (Germany) 1998, pp. 404-447.

(60) J. Catalán, J. Phys. Chem. B, 2009, 113, 5951-5960.

(61) A. Filarowski, M. Kluba, K. Cieślik-Boczula, A. Koll, A. Kochel, L. Pandey, W. M. De Borggraeve, M. Van der Auweraer, J. Catalán and N. Boens, Photochem. Photobiol. Sci., 2010, 9, 996-1008.

(62) N. S. Bayliss, J. Chem. Phys., 1950, 18, 292-296.

(63) W. Becker, Advanced Time-correlated Single Photon Counting Techniques, Springer Series in Chemical Physics, Vol. 81, Springer: Berlin, 2005

(64) M. vandeVen, M. Ameloot, B. Valeur and N. Boens, J. Fluoresc., 2005, 15, 377-413.

(65) N. Boens, W. Qin, N. Basarić, J. Hofkens, M. Ameloot et al., Anal. Chem., 2007, 79, 2137-2149.

(66) H. Lemmetyinen, N. V. Tkachenko, B. Valeur, J.-i. Hotta, M. Ameloot, N. P. Ernsting, T. Gustavsson and N. Boens, Pure Appl. Chem., 2014, 86, 1969-1998.

(67) S, Mukherjee and P. Thilagar, RSC Adv., 2015, 5, 2706-2714.

(68) R. A. Marcus, J. Chem. Phys., 1965, 143, 1261-1274.

(69) A. T. B. Gilbert, N. A. Besley and P. M. W. Gill, J. Phys. Chem. A, 2008, 112, 13164-13171.

(70) N. A. Besley, A. T. B. Gilbert and P. M. W. Gill, J. Chem. Phys., 2009, 130, 124308 (7 pp).

(71) D. Robinson and N. A. Besley, Phys Chem. Chem. Phys., 2010, 12, 9667-9676.

(72) O. V. Ershova and N. A. Besley, Chem. Phys. Lett., 2011, 513, 179-183.

(73) T. Ziegler, A. Rauk and E. J. Baerends, Theor. Chim. Acta, 1977, 43, 261-271.

(74) E. A. Briggs, N. A. Besley and D. Robinson, J. Phys. Chem. A, 2013, 117, 2644-2650.

(75) Y. Shao, L. F. Molnar, Y. Jung, J. Kussman, C. Ochsenfeld et al., Phys. Chem. Chem. Phys., 2006, 8, $3172-3191$. 
(76) H.-J. Werner, Mol. Phys., 1996, 89, 645-661.

(77) P. Celani and H.-J.Werner, J. Chem. Phys., 2000, 112, 5546-5557.

(78) G. Ghigo, B. O. Roos and P.-Å. Malmqvist, Chem. Phys. Lett., 2004, 396, 142-149.

(79) H.-J. Werner, P. J. Knowles, G. Knizia, F. R. Manby and M. Schütz, WIREs Comput. Mol. Sci., 2012, 2, $242-253$.

(80) MOLPRO, version 2012.1, A Package of Ab Initio Programs, H.-J. Werner, P. J. Knowles, G. Knizia, F. R. Manby, M. Schütz and others, see http://www.molpro.net 
Supporting Information

\section{Unusual Spectroscopic and Photophysical Properties of meso-tert-ButylBODIPY in Comparison to Related Alkylated BODIPY Dyes}

Lijuan Jiao, ${ }^{* a}$ Changjiang Yu,${ }^{a}$ Jun Wang, ${ }^{a}$ Edward A. Briggs, ${ }^{b}$ Nicholas A.

Besley, ${ }^{b}$ David Robinson, ${ }^{b}$ María J. Ruedas-Rama, ${ }^{c}$ Angel Orte,${ }^{c}$ Luis Crovetto, ${ }^{c}$

Eva M. Talavera, ${ }^{c}$ Jose M. Alvarez-Pez, ${ }^{c}$ Mark Van der Auweraer, ${ }^{d}$ and Noël

Boens $^{d}$

${ }^{a}$ Laboratory of Functional Molecular Solids, Ministry of Education; Anhui Laboratory of Molecule-Based Materials; School of Chemistry and Materials Science, Anhui Normal University, Wuhu, Anhui, China 241000.

${ }^{b}$ School of Chemistry, University of Nottingham, University Park, Nottingham, NG7 2RD, United Kingdom.

${ }^{c}$ Department of Physical Chemistry, Faculty of Pharmacy, University of Granada, Cartuja Campus, 18701 Granada, Spain.

${ }^{d}$ Department of Chemistry, Katholieke Universiteit Leuven (KU Leuven), Celestijnenlaan 200f, 3001 Leuven, Belgium.

* Corresponding author: E-mail: jiao421@mail.ahnu.edu.cn; Fax: +86 553-388-3517 


\section{Contents}

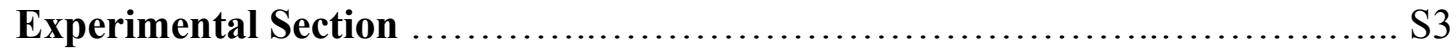

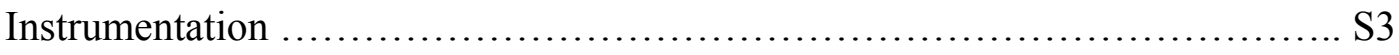

Relative Determination of Fluorescence Quantum Yield $\Phi$..................... S3

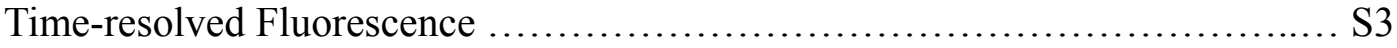

Crystal Structure Determination ...................................... S4

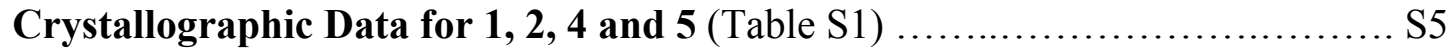

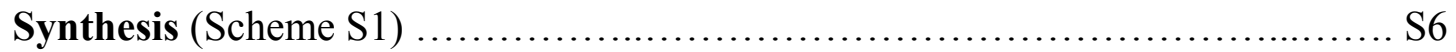

Photographs of Cuvettes with 1 and 2 in Chloroform and Acetone (Chart S1) .. S7

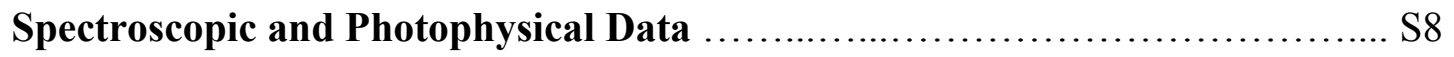

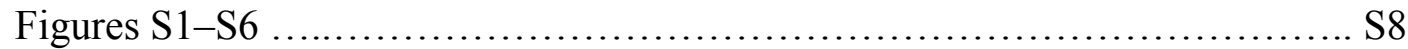

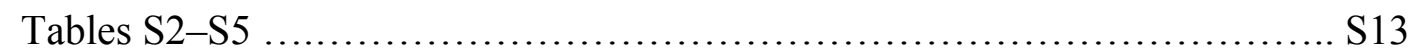

Analysis of Solvent-Dependent Spectroscopic Properties of 3-5 ............. S17

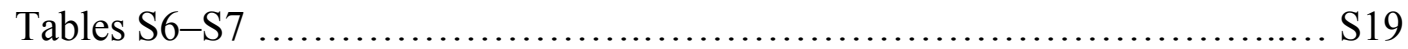

DFT Calculated Emission Spectra (from AIMD) (Figures S7-S8) ........... S21

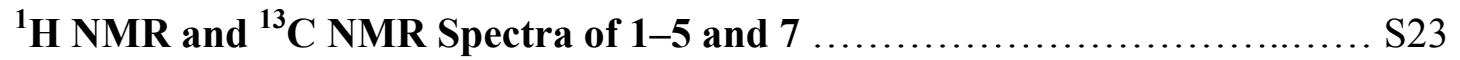

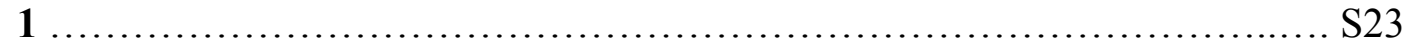

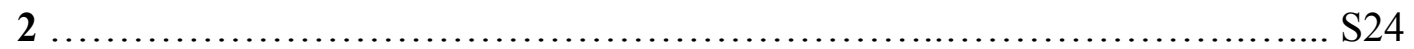

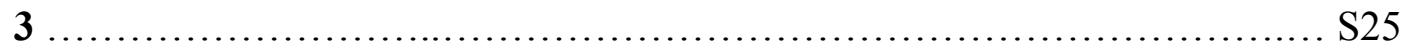

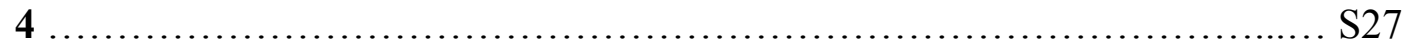

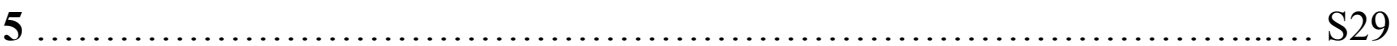

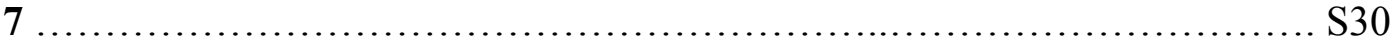

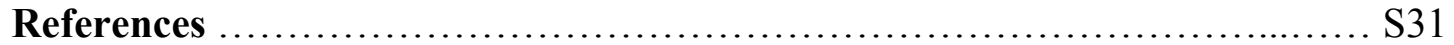




\section{Experimental Section}

\section{Instrumentation}

The NMR experiments were performed on Bruker Avance 300 (for 1-4) and Bruker Avance 500 (for 5) NMR spectrometers at room temperature. Chemical shifts $(\delta)$ are given in ppm relative to tetramethylsilane (TMS). Chemical shift multiplicities are reported as $\mathrm{s}=$ singlet and $\mathrm{d}=$ doublet. Melting points were determined with an X-4 melting-point apparatus (manufactured by Henan, Gongyi Factory, China) and are uncorrected. High-resolution mass spectra were obtained using APCI-TOF in positive mode. Absorption spectra were recorded with a Perkin-Elmer Lambda $650 \mathrm{UV} / \mathrm{V}$ is spectrophotometer with a Peltier temperature-controlled cell holder. All measurements were made at $20{ }^{\circ} \mathrm{C}$, using $5 \times 10 \mathrm{~mm}$ cuvettes. Steady-state fluorescence emission spectra were collected on a JASCO FP-6500 spectrofluorometer equipped with a 450 $\mathrm{W}$ xenon lamp for excitation, with temperature controller ETC-273T at $20{ }^{\circ} \mathrm{C}$, using $5 \times 10 \mathrm{~mm}$ cuvettes.

\section{Relative Determination of Fluorescence Quantum Yield $\Phi$}

For the relative determination of the fluorescence quantum yield $\Phi$ in a series of solvents, the following formula (eq S1) was used: ${ }^{1,2}$

$$
\Phi_{x}=\Phi_{r} \times \frac{F_{x}}{F_{r}} \times \frac{1-10^{-A_{r}\left(\lambda_{\mathrm{ex}}\right)}}{1-10^{-A_{x}\left(\lambda_{\mathrm{ex}}\right)}} \times \frac{n_{x}^{2}}{n_{r}^{2}}
$$

The subscripts $x$ and $r$ refer respectively to sample $x$ (i.e., BODIPY derivatives 1-5) and reference (standard) fluorophore $r$ with known quantum yield $\Phi_{r}$ in a specific solvent; $F$ stands for the spectrally corrected, integrated fluorescence spectra; $A\left(\lambda_{\text {ex }}\right)$ denotes the absorbance at the used excitation wavelength $\lambda_{\text {ex }} ; n$ represents the refractive index of the solvent (in principle at the average emission wavelength). To minimize inner filter effects, the absorbance at the excitation wavelength $\lambda_{\text {ex }}$ was kept under 0.1 . The measurements were performed using $5 \times 10 \mathrm{~mm}$ cuvettes, with $10 \mathrm{~mm}$ optical path length for absorption and a right-angle (L-) arrangement for fluorescence emission collection, using excitation through the long side and emission collection through the shorter side, to avoid auto-absorption inner-filter effect. Fluorescein in $0.1 \mathrm{~N} \mathrm{NaOH}$ was used as fluorescence quantum yield reference $\left(\Phi_{r}=0.90\right) .^{3}$ All measurements were done on non-degassed samples at $20{ }^{\circ} \mathrm{C}$. The averages and standard uncertainties of $\Phi$ reported in Tables 3 and S2-S5 are computed from eight independent $\Phi$ measurements, resulting from $(2$ conc. of sample $x) \times(2$ conc. of reference $r) \times(2$ excitation wavelengths $\lambda_{\mathrm{ex}}=460$ and $470 \mathrm{~nm}$ ). Note that 460 and $470 \mathrm{~nm}$ were selected as $\lambda_{\text {ex }}$ because they allow one to collect the complete emission spectrum, required for the integration of the spectral band.

\section{Time-resolved Fluorescence}

Fluorescence decay traces were recorded by the single photon timing method, ${ }^{4,5,6,7}$ 
using the FluoTime200 fluorometer (PicoQuant $\mathrm{GmbH}$ ). The excitation source consisted of a $485 \mathrm{~nm}$ pulsed diode laser (LDH series from PicoQuant $\mathrm{GmbH}$ ) with a minimum pulse width of $88 \mathrm{ps}$, and operated at a pulse repetition rate of 10 or 20 depending on the compound probed. Fluorescence decay histograms were collected at three different emission wavelengths selected by a grating monochromator, after a polarizer set at the 'magic angle' to avoid polarization artifacts. The fluorescence traces were collected over 1320 channels, with a time increment of 36 ps per channel, until they reached $2 \times 10^{4}$ counts in the peak channel. Histograms of the instrument response functions were collected using a LUDOX scatterer.

\section{Crystal Structure Determination}

Crystals of BODIPYs 1, 2, 4 and 5 suitable for X-ray structural analysis were obtained by slow diffusion of hexane into their dichloromethane solutions at room temperature over a one-week period. The vial containing this solution was loosely capped to promote the crystallization upon hexane diffusion. Data were collected using a diffractometer equipped with a graphite crystal monochromator situated in the incident beam for data collection at room temperature. Cell parameters were retrieved using $\mathrm{SMART}^{8}$ software and refined using $\mathrm{SAINT}^{9}$ on all observed reflections. The determination of unit cell parameters and data collections were performed with Mo $\mathrm{K} \alpha$ radiation $(\lambda)$ at $0.71073 \AA$. Data reduction was performed using the SAINT software, which corrects for Lp and decay. The structure was solved by the direct method using the SHELXS-97 program and refined by least squares method on $F^{2}$, SHELXL-97, ${ }^{10}$ incorporated in SHELXTL V5.10. ${ }^{11}$ The crystallographic data of 1, 2, 4 and 5 are compiled in Table S1. CCDC 995007 (1), CCDC 995010 (2), CCDC 995008 (4) and CCDC 995009 (5) contain the supplementary crystallographic data for this paper and can be obtained free of charge via www.ccdc.cam.ac.uk/conts/retrieving.html (or from the Cambridge Crystallographic Data Centre, 12, Union Road, Cambridge CB2 1EZ, UK; fax: +44-1223-336033; or deposit@ccdc.cam.ac.uk). 


\section{Crystallographic Data for 1, 2, 4 and 5}

Table S1. Crystallographic data for 1, 2, 4 and 5, measured in this work at Anhui Normal University (China).

\begin{tabular}{|c|c|c|c|c|}
\hline & 1 & 2 & 4 & 5 \\
\hline Formula & $\mathrm{C}_{10} \mathrm{H}_{9} \mathrm{BF}_{2} \mathrm{~N}_{2}$ & $\mathrm{C}_{13} \mathrm{H}_{15} \mathrm{BF}_{2} \mathrm{~N}_{2}$ & $\mathrm{C}_{17} \mathrm{H}_{23} \mathrm{BF}_{2} \mathrm{~N}_{2}$ & $\mathrm{C}_{24} \mathrm{H}_{26} \mathrm{~B}_{2} \mathrm{~F}_{4} \mathrm{~N}_{4}$ \\
\hline$M(\mathrm{~g} / \mathrm{mol})$ & 206.00 & 248.08 & 304.18 & 468.11 \\
\hline Crystal system & triclinic & orthorhombic & triclinic & monoclinic \\
\hline Space group & $\mathrm{P}-1$ & $\operatorname{Pna2(1)}$ & $\mathrm{P}-1$ & $\mathrm{C} 2 / \mathrm{c}$ \\
\hline$a(\AA)$ & $7.7265(7)$ & $14.254(2)$ & $10.9260(9)$ & $16.054(2)$ \\
\hline$b(\AA)$ & $7.7446(7)$ & $13.5629(19)$ & $12.1904(10)$ & $12.6204(19)$ \\
\hline$c(\AA)$ & $16.6941(15)$ & $6.4554(9)$ & $13.1824(11)$ & $13.685(3)$ \\
\hline$\alpha\left(^{\circ}\right)$ & $102.946(1)$ & 90.00 & $103.996(1)$ & 90.00 \\
\hline$\beta\left(^{\circ}\right)$ & $93.552(1)$ & 90.00 & $99.116(1)$ & $120.228(1)$ \\
\hline$\gamma\left({ }^{\circ}\right)$ & $92.329(1)$ & 90.00 & $90.038(1)$ & 90.00 \\
\hline$V\left(\AA^{3}\right)$ & $970.16(15)$ & $1248.0(3)$ & $1680.8(2)$ & $2395.7(8)$ \\
\hline$Z$ & 4 & 4 & 4 & 4 \\
\hline$T(\mathrm{~K})$ & 293 & 293 & 293 & 293 \\
\hline$\rho_{\text {calcd }}\left(\mathrm{g} \mathrm{cm}^{-3}\right)$ & 1.410 & 1.320 & 1.202 & 1.298 \\
\hline$\mu(\operatorname{Mo~K} \alpha)\left(\mathrm{mm}^{-1}\right)$ & 0.111 & 0.099 & 0.085 & 0.098 \\
\hline$F(000)$ & 424.0 & 520.0 & 648.0 & 976.0 \\
\hline Crystal size $\left(\mathrm{mm}^{3}\right)$ & $0.15 \times 0.13 \times 0.12$ & $0.16 \times 0.14 \times 0.12$ & $0.15 \times 0.13 \times 0.12$ & $0.13 \times 0.12 \times 0.1$ \\
\hline Reflections measured & 8480 & 10436 & 14676 & 9286 \\
\hline Unique reflections & 4380 & 2786 & 7576 & 4704 \\
\hline$R($ int $)$ & 0.0194 & 0.0509 & 0.0208 & 0.0260 \\
\hline$w R_{2}$ (all data) & 0.1379 & 0.2688 & 0.1293 & 0.0987 \\
\hline$R_{1}(>2 \operatorname{sigma}(\mathrm{I}))$ & 0.0454 & 0.0764 & 0.0462 & 0.0373 \\
\hline CCDC deposition no & 995007 & 995010 & 995008 & 995009 \\
\hline
\end{tabular}




\section{Synthesis}

The synthesis of $\mathbf{1 - 5}$, completed at Anhui Normal University (China), is described in the main paper.
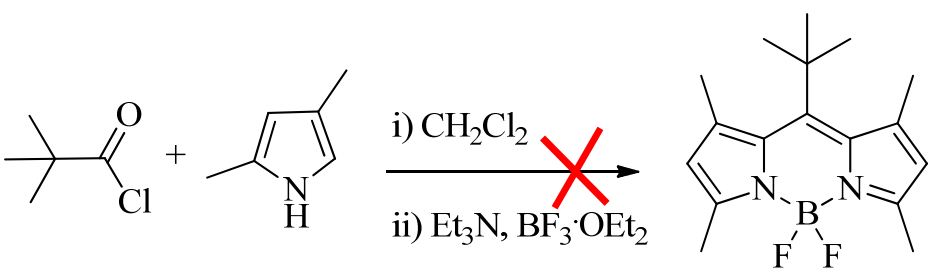

6

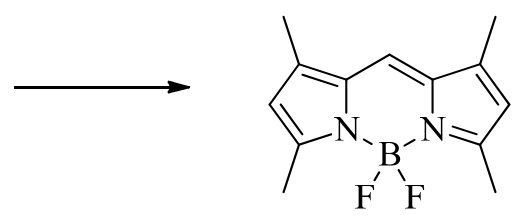

7

Scheme S1. The attempted synthesis of meso-tert-butylBODIPY 6 resulted in meso-unsubstituted BODIPY 7.

Initially, we rationalized that the unusually low $\Phi$-values for $\mathbf{2}$ may be due to the free rotation of the tert-butyl group, which promotes the nonradiative decay (internal conversion) process. Therefore, if we could restrict the free rotation of the tert-butyl group by installing methyl groups at the 1,7-positions of BODIPY (as in compound $\mathbf{6}$, 8-tert-butyl-4,4-difluoro-1,3,5,7-tetramethyl-4-bora-3a,4a-diaza-s-indacene, Scheme $\mathrm{S} 1$ ), we might be able to improve the fluorescence quantum yield. However, the condensation of pivaloyl chloride with 2,4-dimethylpyrrole in dichloromethane gave only the meso-unsubstituted compound 7 after the subsequent $\mathrm{BF}_{2}$ complexation reaction.

Synthesis of 7 [4,4-difluoro-1,3,5,7-tetramethyl-4-bora-3a,4a-diaza-s-indacene]: Pivaloyl chloride (368 $\mu \mathrm{L}, 3 \mathrm{mmol}$ ) was added dropwise to freshly distilled 2,4-dimethylpyrrole (665 mg, $7 \mathrm{mmol}$ ) in $100 \mathrm{~mL}$ dry dichloromethane. The reaction mixture was stirred at room temperature for $12 \mathrm{~h}$ under argon. Then triethylamine (3 $\mathrm{mL})$ and $\mathrm{BF}_{3} \cdot \mathrm{Et}_{2} \mathrm{O}(8 \mathrm{~mL})$ were added to the reaction mixture at ice-cold condition. The reaction mixture was stirred at room temperature for $2 \mathrm{~h}$, washed with water, dried over anhydrous $\mathrm{Na}_{2} \mathrm{SO}_{4}$, and filtered. The solvent was then evaporated under vacuum and the crude product was purified by column chromatography on silica gel (petroleum ether/ethyl acetate $=10 / 1, \mathrm{v} / \mathrm{v}$ ) to give 7 in $6 \%$ yield $(45 \mathrm{mg}) .{ }^{1} \mathrm{H}$ NMR $\left(300 \mathrm{MHz}, \mathrm{CDCl}_{3}\right): \delta 7.04(\mathrm{~s}, 1 \mathrm{H}), 6.04(\mathrm{~s}, 2 \mathrm{H}), 2.53(\mathrm{~s}, 6 \mathrm{H}), 2.25(\mathrm{~s}, 6 \mathrm{H}) .{ }^{13} \mathrm{C}$ NMR $\left(75 \mathrm{MHz}, \mathrm{CDCl}_{3}\right): \delta 156.7,141.2,133.4,120.1,119.0,14.6,11.2$. The data correspond to those of the literature. ${ }^{12}$ 


\section{Photographs of Cuvettes with 1 and 2 in Chloroform and Acetone}

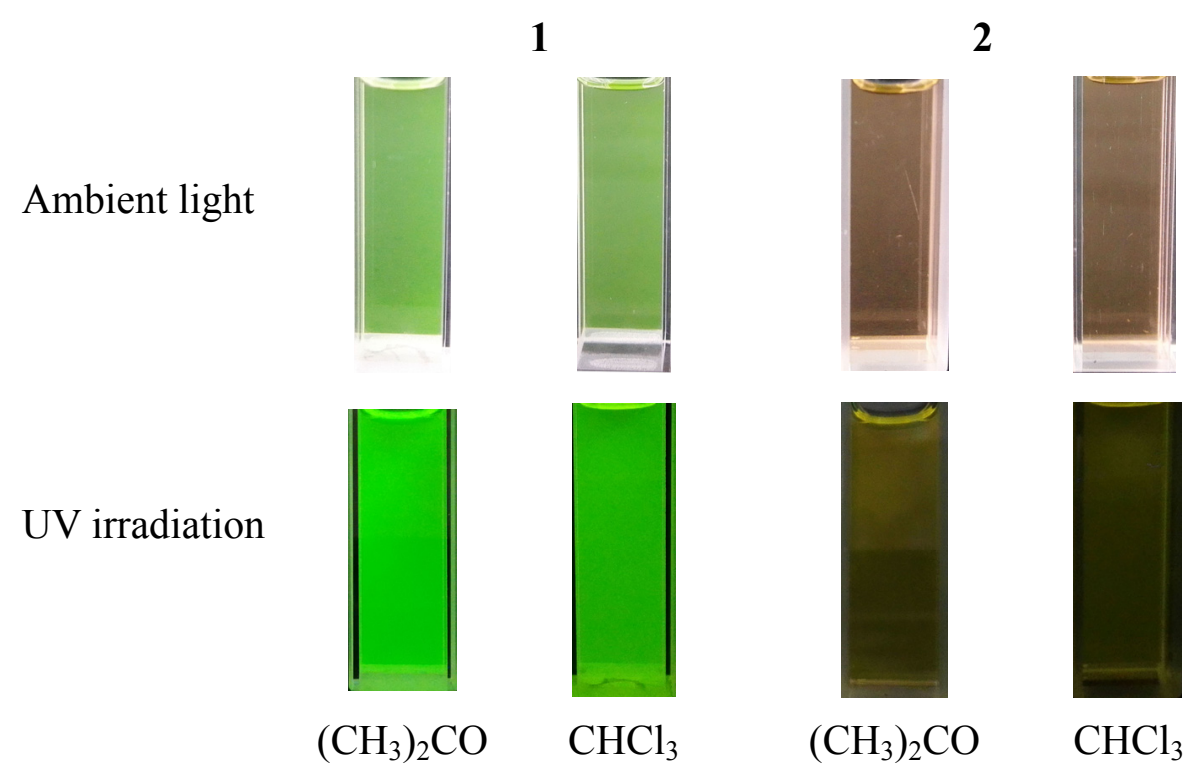

Chart S1. Photographs of cuvettes containing 1 and $\mathbf{2}$ in acetone and chloroform under ambient light (top) and $365 \mathrm{~nm}$ irradiation (bottom). 


\section{Spectroscopic and Photophysical Data}

All spectroscopic and photophysical data of 1-5 were measured at the University of Granada (Spain).
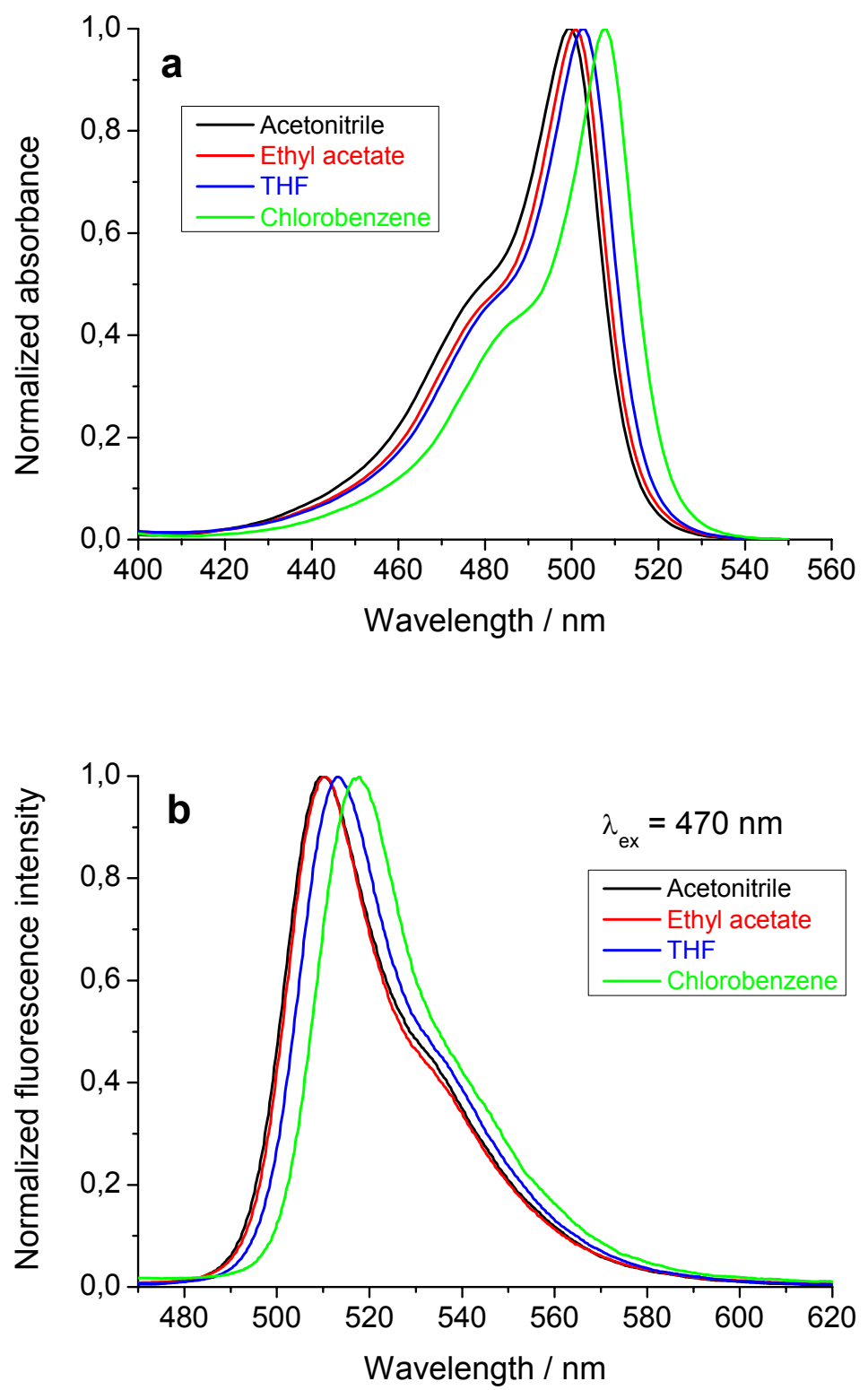

Figure S1. (a) Normalized, main $S_{1} \leftarrow S_{0}$ visible absorption bands of $\mathbf{3}$ in the solvents indicated. (b) Corresponding normalized fluorescence emission spectra upon excitation at $470 \mathrm{~nm}$. 

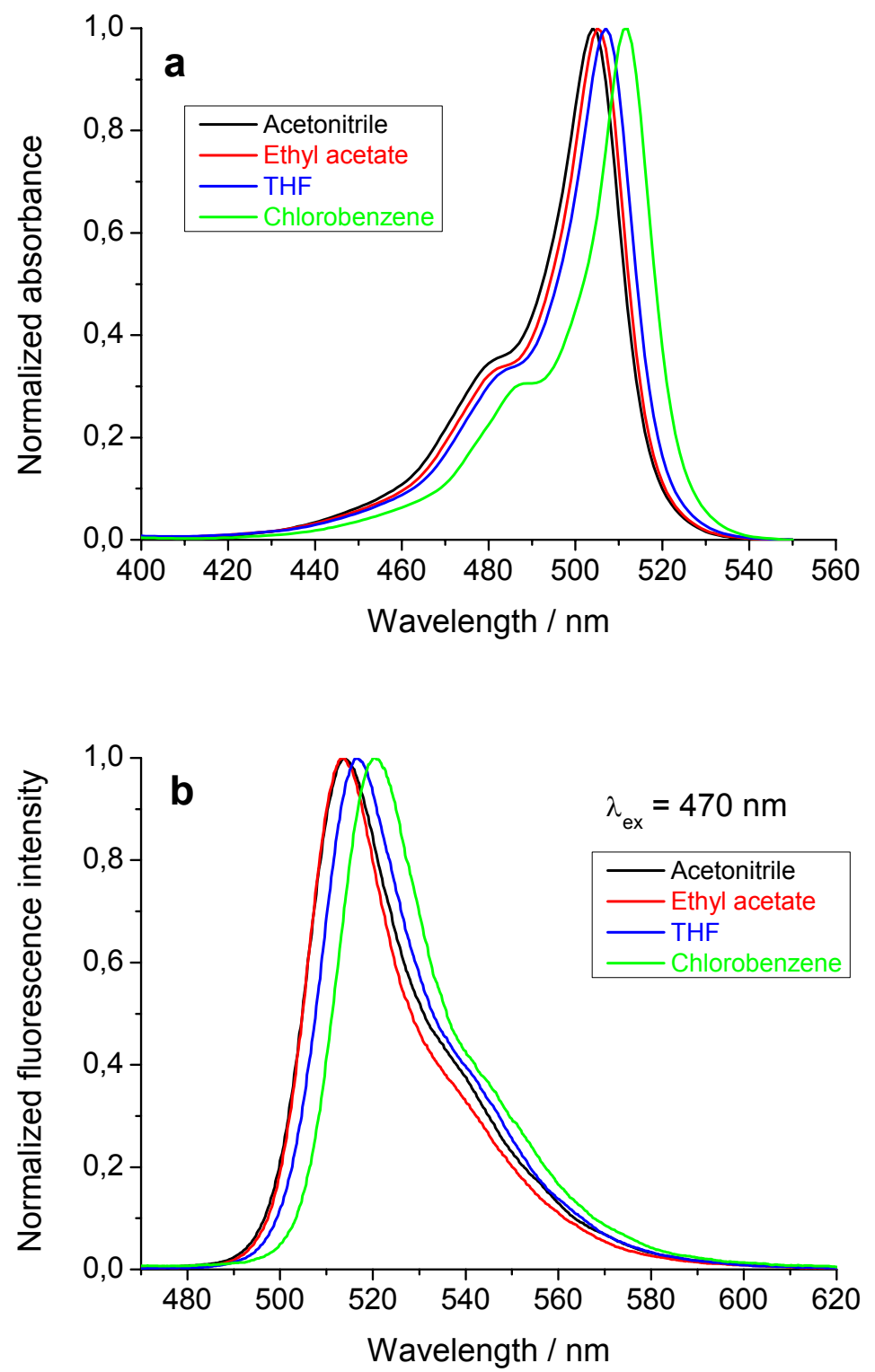

Figure S2. (a) Normalized, main $S_{1} \leftarrow S_{0}$ visible absorption bands of 4 in the solvents indicated. (b) Corresponding normalized fluorescence emission spectra upon excitation at $470 \mathrm{~nm}$. 

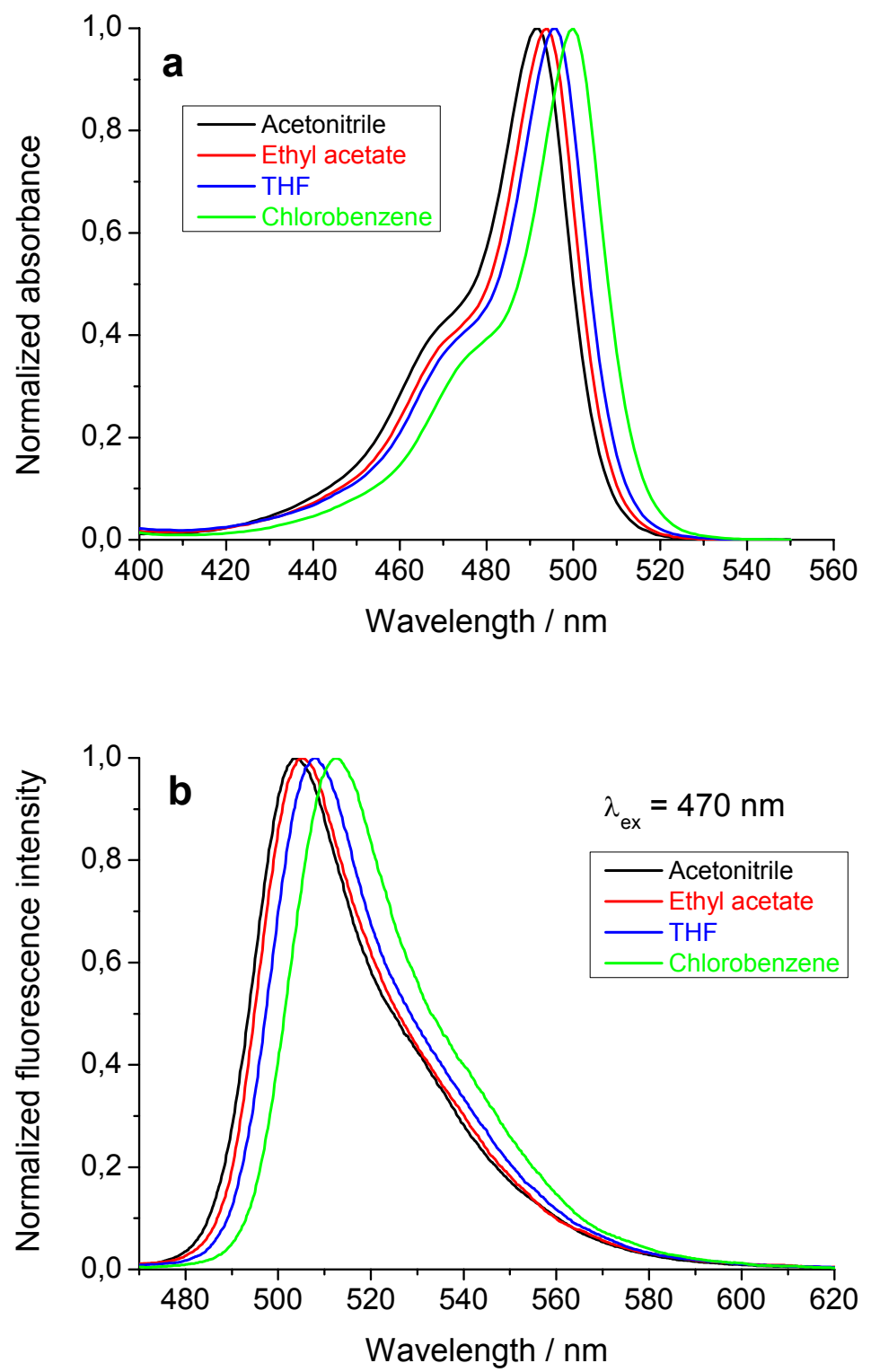

Figure S3. (a) Normalized, main $S_{1} \leftarrow S_{0}$ visible absorption bands of 5 in the solvents indicated. (b) Corresponding normalized fluorescence emission spectra upon excitation at $470 \mathrm{~nm}$. 

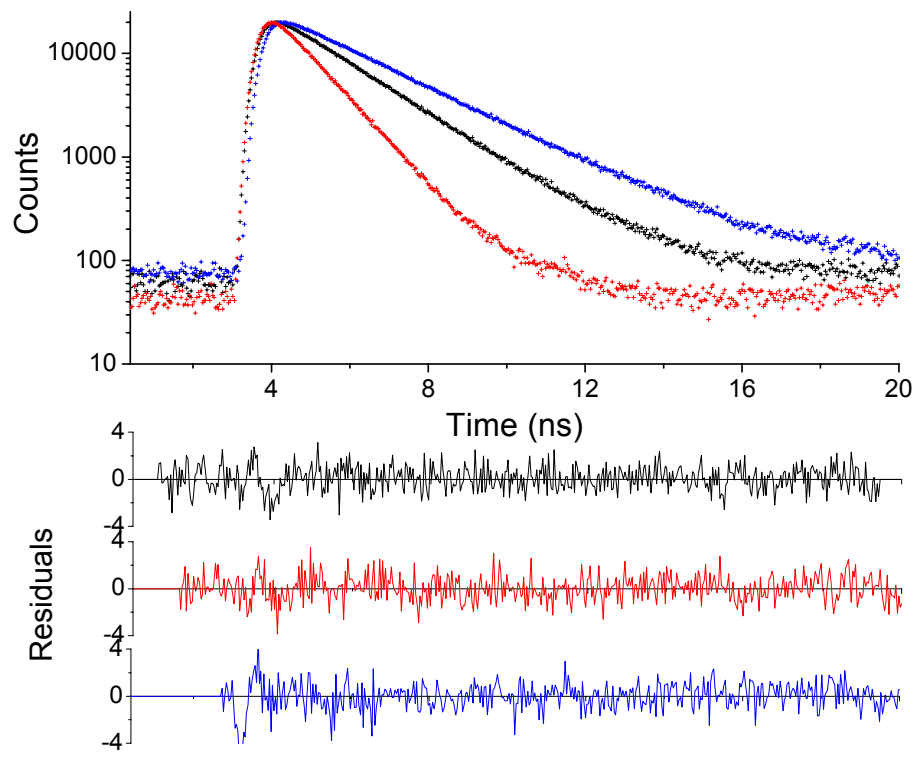

Figure S4. Fluorescence decay traces and corresponding weighted residuals from mono-exponential fits of $\mathbf{2}$ in dichloromethane (black), methanol (red) and chlorobenzene (blue). $\lambda_{\mathrm{ex}}=485 \mathrm{~nm}, \lambda_{\mathrm{em}}=565 \mathrm{~nm}$.

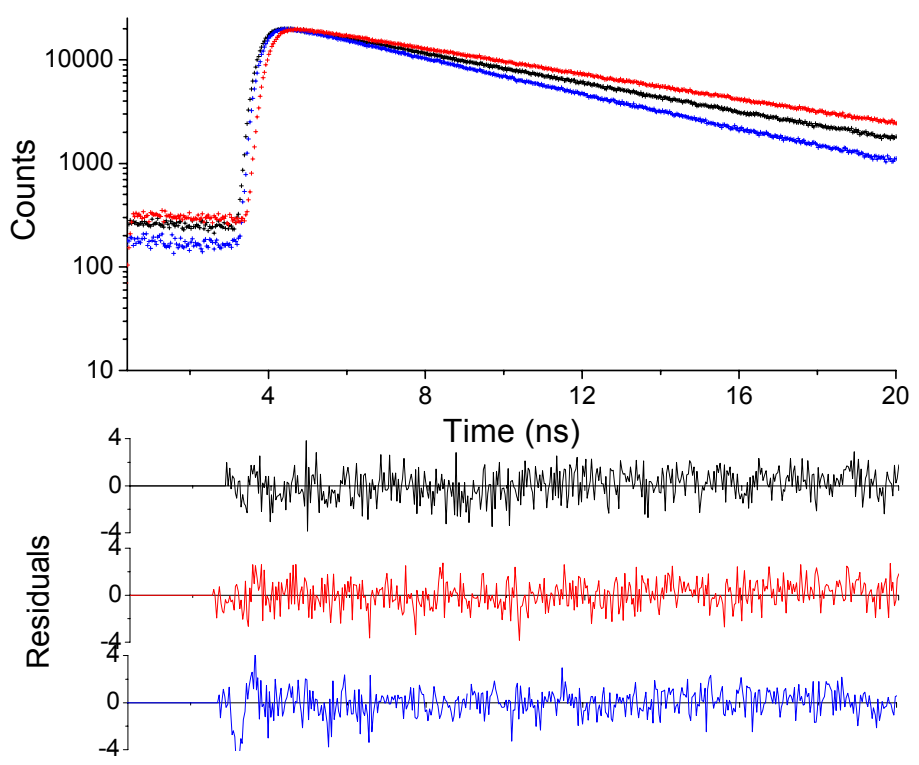

Figure S5. Fluorescence decay traces and corresponding weighted residuals from mono-exponential fits of $\mathbf{4}$ in dibutyl ether (black), methanol (red) and chlorobenzene (blue). $\lambda_{\mathrm{ex}}=485 \mathrm{~nm}, \lambda_{\mathrm{em}}=510 \mathrm{~nm}$. 


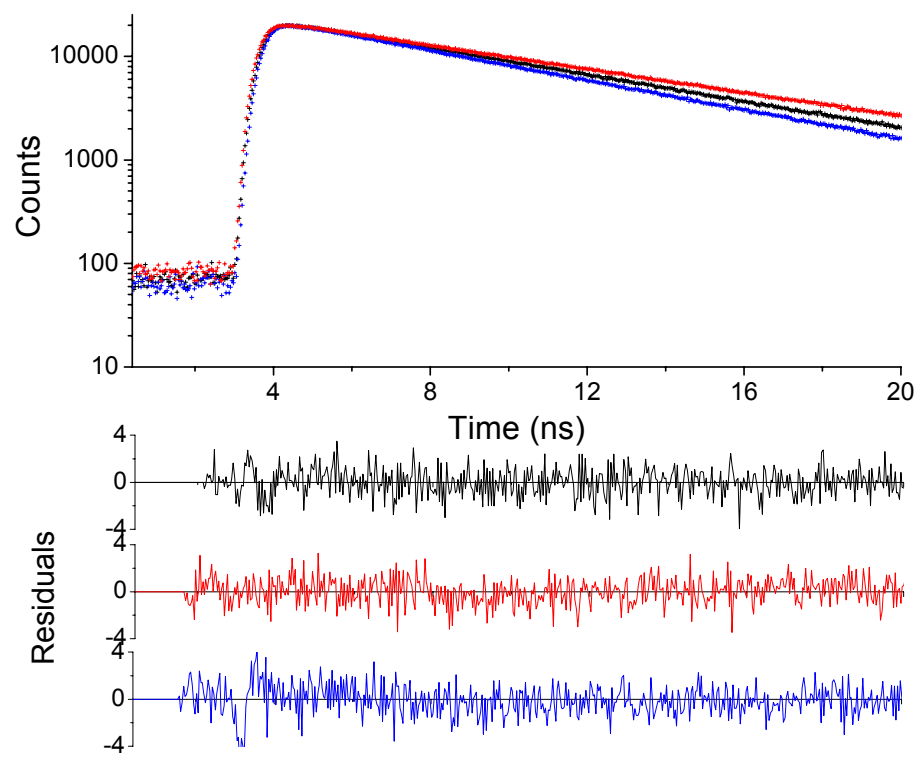

Figure S6. Fluorescence decay traces and corresponding weighted residuals from mono-exponential fits of 5 in dibutyl ether (black), methanol (red) and chlorobenzene (blue). $\lambda_{\mathrm{ex}}=485 \mathrm{~nm}, \lambda_{\mathrm{em}}=510 \mathrm{~nm}$. 
Table S2. Spectroscopic and photophysical data of $\mathbf{1}$ as a function of solvent. ${ }^{a}$

\begin{tabular}{|c|c|c|c|c|c|c|c|c|c|}
\hline & Solvent & $\begin{array}{c}\lambda_{\mathrm{abs}}(\max ) \\
/ \mathrm{nm}\end{array}$ & $\begin{array}{c}\lambda_{\mathrm{em}}(\max ) \\
/ \mathrm{nm}\end{array}$ & $\begin{array}{c}\Delta \bar{v} \\
/ \mathrm{cm}^{-1}\end{array}$ & $\begin{array}{l}\text { fwhm } \\
\mathrm{abs} \\
/ \mathrm{cm}^{-1}\end{array}$ & $\begin{array}{l}\text { fwhm }_{\mathrm{em}} \\
\quad / \mathrm{cm}^{-1}\end{array}$ & $\Phi^{b}$ & $\begin{array}{l}\tau^{c} \\
/ \mathrm{ns}\end{array}$ & $\begin{array}{c}k_{\mathrm{f}}^{d} \\
/ 10^{8} \mathrm{~s}^{-1}\end{array}$ \\
\hline 1 & $\mathrm{CH}_{3} \mathrm{OH}$ & 491 & 500 & 367 & 1037 & 1031 & $1.00 \pm 0.03$ & 6.91 & $1.45 \pm 0.05$ \\
\hline 2 & $\mathrm{CH}_{3} \mathrm{CN}$ & 489 & 499 & 410 & 1066 & 1065 & $1.00 \pm 0.06$ & 6.73 & $1.49 \pm 0.09$ \\
\hline 3 & $\left(\mathrm{C}_{2} \mathrm{H}_{5}\right)_{2} \mathrm{O}$ & 493 & 501 & 324 & 877 & 985 & $1.00 \pm 0.04$ & 6.73 & $1.49 \pm 0.05$ \\
\hline 4 & $\left(\mathrm{CH}_{3}\right)_{2} \mathrm{CO}$ & 490 & 500 & 408 & 1017 & 1059 & $1.00 \pm 0.04$ & 6.88 & $1.45 \pm 0.06$ \\
\hline 5 & $t$-BuOMe $e^{e}$ & 493 & 501 & 324 & 877 & 993 & $1.00 \pm 0.04$ & 6.65 & $1.50 \pm 0.05$ \\
\hline 6 & $\mathrm{EtOAc}^{e}$ & 491 & 500 & 367 & 1013 & 1019 & $1.00 \pm 0.03$ & 6.47 & $1.55 \pm 0.05$ \\
\hline 7 & Hexane & 496 & 501 & 201 & 676 & 899 & $1.00 \pm 0.05$ & 6.46 & $1.55 \pm 0.07$ \\
\hline 8 & $\mathrm{Bu}_{2} \mathrm{O}^{e}$ & 496 & 503 & 281 & 784 & 943 & $1.00 \pm 0.05$ & 6.21 & $1.61 \pm 0.07$ \\
\hline 9 & $\mathrm{THF}^{e}$ & 493 & 502 & 364 & 960 & 1018 & $1.00 \pm 0.03$ & 6.13 & $1.63 \pm 0.06$ \\
\hline 10 & $\mathrm{CH}_{2} \mathrm{Cl}_{2}$ & 495 & 503 & 321 & 870 & 970 & $1.00 \pm 0.04$ & 6.23 & $1.61 \pm 0.06$ \\
\hline 11 & $\mathrm{CHCl}_{3}$ & 497 & 504 & 279 & 820 & 933 & $1.00 \pm 0.02$ & 6.30 & $1.59 \pm 0.03$ \\
\hline 12 & Toluene & 498 & 507 & 356 & 856 & 1009 & $1.00 \pm 0.04$ & 5.63 & $1.78 \pm 0.08$ \\
\hline 13 & $\mathrm{PhCl}^{e}$ & 499 & 507 & 316 & 856 & 997 & $1.00 \pm 0.04$ & 5.66 & $1.77 \pm 0.07$ \\
\hline
\end{tabular}

${ }^{a}$ The solvents are numbered according to increasing refractive index $n$.

${ }^{b}$ Fluorescence quantum yield \pm one standard uncertainty. $\Phi$ determined vs. fluorescein in $0.1 \mathrm{~N} \mathrm{NaOH}$ $\left(\Phi_{\mathrm{r}}=0.90\right)$ as reference.

${ }^{c}$ Globally determined fluorescence lifetime. The standard errors on $\tau$, obtained from the diagonal elements of the covariance matrix available from the global analysis fit of decay traces recorded at three different emission wavelengths $\left(\lambda_{\mathrm{em}}=510,515\right.$ and $520 \mathrm{~nm}$. $\left.\lambda_{\mathrm{ex}}=485 \mathrm{~nm}\right)$, are between 19 and 23 ps.

${ }^{d}$ Fluorescence rate constant $\left(k_{\mathrm{f}}\right) \pm$ propagated error. Because $\Phi$ is 1.00 in all solvents studied, the rate constant for nonradiative decay $\left(k_{\mathrm{nr}}\right)$ is vanishingly small. The propagated errors are calculated using the standard uncertainties on $\Phi$ and the standard errors on $\tau$. The propagated errors on $k_{\mathrm{nr}}$ are between 3 $\times 10^{6} \mathrm{~s}^{-1}$ and $9 \times 10^{6} \mathrm{~s}^{-1}$.

${ }^{e} t$-BuOMe $=$ tert-butyl methyl ether $(\mathrm{MTBE})$, EtOAc $=$ ethyl acetate, $\mathrm{Bu}_{2} \mathrm{O}=$ dibutyl ether, $\mathrm{THF}=$ tetrahydrofuran, $\mathrm{PhCl}=$ chlorobenzene. 
Table S3. Spectroscopic and photophysical data of $\mathbf{3}$ as a function of solvent. ${ }^{a}$

\begin{tabular}{|c|c|c|c|c|c|c|c|c|c|c|}
\hline & Solvent & $\begin{array}{c}\lambda_{\mathrm{abs}}(\max ) \\
/ \mathrm{nm}\end{array}$ & $\begin{array}{c}\lambda_{\mathrm{em}}(\max ) \\
/ \mathrm{nm}\end{array}$ & $\begin{array}{c}\Delta \bar{v} \\
/ \mathrm{cm}^{-1}\end{array}$ & $\begin{array}{l}\text { fwhm }{ }_{\mathrm{abs}} \\
/ \mathrm{cm}^{-1}\end{array}$ & $\begin{array}{l}\text { fwhm }_{\mathrm{em}} \\
\qquad / \mathrm{cm}^{-1}\end{array}$ & $\Phi^{b}$ & $\begin{array}{l}\tau^{c} \\
/ \mathrm{ns}\end{array}$ & $\begin{array}{c}k_{\mathrm{f}}^{d} \\
/ 10^{8} \mathrm{~s}^{-1}\end{array}$ & $\begin{array}{c}k_{\mathrm{nr}}^{d} \\
/ 10^{8} \mathrm{~s}^{-1}\end{array}$ \\
\hline 1 & $\mathrm{CH}_{3} \mathrm{OH}$ & 500 & 510 & 392 & 1062 & 1064 & $1.00 \pm 0.04$ & 6.53 & $1.53 \pm 0.06$ & $0.00 \pm 0.06$ \\
\hline 2 & $\mathrm{CH}_{3} \mathrm{CN}$ & 500 & 510 & 392 & 1129 & 1066 & $1.00 \pm 0.05$ & 6.65 & $1.50 \pm 0.08$ & $0.00 \pm 0.08$ \\
\hline 3 & $\left(\mathrm{C}_{2} \mathrm{H}_{5}\right)_{2} \mathrm{O}$ & 502 & 510 & 312 & 911 & 956 & $1.00 \pm 0.02$ & 6.42 & $1.56 \pm 0.03$ & $0.00 \pm 0.03$ \\
\hline 4 & $\left(\mathrm{CH}_{3}\right)_{2} \mathrm{CO}$ & 500 & 510 & 392 & 862 & 985 & $1.00 \pm 0.04$ & 6.36 & $1.57 \pm 0.06$ & $0.00 \pm 0.06$ \\
\hline 5 & $t-\mathrm{BuOMe}^{e}$ & 502 & 511 & 351 & 856 & 1017 & $1.00 \pm 0.02$ & 6.29 & $1.59 \pm 0.03$ & $0.00 \pm 0.03$ \\
\hline 6 & EtOAc $^{e}$ & 501 & 510 & 352 & 797 & 976 & $1.00 \pm 0.05$ & 6.12 & $1.63 \pm 0.08$ & $0.00 \pm 0.08$ \\
\hline 7 & Hexane & 504 & 511 & 272 & 853 & 990 & $1.00 \pm 0.06$ & 6.23 & $1.61 \pm 0.10$ & $0.00 \pm 0.10$ \\
\hline 8 & $\mathrm{Bu}_{2} \mathrm{O}^{e}$ & 504 & 512 & 310 & 995 & 999 & $1.00 \pm 0.04$ & 5.92 & $1.69 \pm 0.07$ & $0.00 \pm 0.07$ \\
\hline 9 & $\mathrm{THF}^{e}$ & 503 & 513 & 388 & 1070 & 1051 & $0.98 \pm 0.03$ & 6.02 & $1.63 \pm 0.05$ & $0.03 \pm 0.05$ \\
\hline 10 & $\mathrm{CH}_{2} \mathrm{Cl}_{2}$ & 505 & 514 & 347 & 663 & 891 & $0.98 \pm 0.03$ & 6.09 & $1.61 \pm 0.05$ & $0.03 \pm 0.05$ \\
\hline 11 & $\mathrm{CHCl}_{3}$ & 507 & 516 & 344 & 895 & 962 & $0.95 \pm 0.02$ & 5.82 & $1.63 \pm 0.03$ & $0.09 \pm 0.03$ \\
\hline 12 & Toluene & 507 & 517 & 382 & 1009 & 1046 & $1.00 \pm 0.04$ & 5.38 & $1.86 \pm 0.07$ & $0.00 \pm 0.07$ \\
\hline 13 & $\mathrm{PhCl}^{e}$ & 508 & 518 & 380 & 848 & 1057 & $1.00 \pm 0.04$ & 5.33 & $1.88 \pm 0.08$ & $0.00 \pm 0.08$ \\
\hline
\end{tabular}

${ }^{a}$ The solvents are numbered according to increasing refractive index $n$.

${ }^{c}$ Globally determined fluorescence lifetime. The standard errors on $\tau$, obtained from the diagonal elements of the covariance matrix available from the global analysis fit of decay traces recorded at three different emission wavelengths $\left(\lambda_{\mathrm{em}}=510,515\right.$ and $520 \mathrm{~nm}$. $\left.\lambda_{\mathrm{ex}}=485 \mathrm{~nm}\right)$, are between 14 and 16 ps.

${ }^{d}$ Fluorescence rate constant $\left(k_{\mathrm{f}}\right)$ or rate constant for nonradiative decay $\left(k_{\mathrm{nr}}\right) \pm$ propagated error. The propagated errors are calculated using the standard uncertainties on $\Phi$ and the standard errors on $\tau$. ${ }^{b, e}$ See Table S2. 
Table S4. Spectroscopic and photophysical data of $\mathbf{4}$ as a function of solvent. ${ }^{a}$

\begin{tabular}{|c|c|c|c|c|c|c|c|c|c|c|}
\hline & Solvent & $\begin{array}{c}\lambda_{\mathrm{abs}}(\max ) \\
/ \mathrm{nm}\end{array}$ & $\begin{array}{c}\lambda_{\mathrm{em}}(\max ) \\
/ \mathrm{nm}\end{array}$ & $\begin{array}{c}\Delta \bar{v} \\
/ \mathrm{cm}^{-1}\end{array}$ & $\begin{array}{l}\text { fwhm }{ }_{\mathrm{abs}} \\
/ \mathrm{cm}^{-1}\end{array}$ & $\begin{array}{l}\text { fwhm }_{\mathrm{em}} \\
\qquad / \mathrm{cm}^{-1}\end{array}$ & $\Phi^{b}$ & $\begin{array}{l}\tau^{c} \\
/ \mathrm{ns}\end{array}$ & $\begin{array}{c}k_{\mathrm{f}}^{d} \\
/ 10^{8} \mathrm{~s}^{-1}\end{array}$ & $\begin{array}{c}k_{\mathrm{nr}}^{d} \\
/ 10^{8} \mathrm{~s}^{-1}\end{array}$ \\
\hline 1 & $\mathrm{CH}_{3} \mathrm{OH}$ & 504 & 513 & 348 & 753 & 941 & $1.00 \pm 0.03$ & 6.77 & $1.48 \pm 0.04$ & $0.00 \pm 0.04$ \\
\hline 2 & $\mathrm{CH}_{3} \mathrm{CN}$ & 504 & 514 & 386 & 754 & 977 & $0.98 \pm 0.04$ & 5.85 & $1.68 \pm 0.07$ & $0.03 \pm 0.07$ \\
\hline 3 & $\left(\mathrm{C}_{2} \mathrm{H}_{5}\right)_{2} \mathrm{O}$ & 506 & 514 & 308 & 653 & 927 & $1.00 \pm 0.01$ & 6.45 & $1.55 \pm 0.02$ & $0.00 \pm 0.02$ \\
\hline 4 & $\left(\mathrm{CH}_{3}\right)_{2} \mathrm{CO}$ & 505 & 514 & 347 & 680 & 920 & $0.99 \pm 0.03$ & 6.89 & $1.44 \pm 0.04$ & $0.01 \pm 0.04$ \\
\hline 5 & $t-\mathrm{BuOMe}^{e}$ & 506 & 516 & 383 & 634 & 898 & $1.00 \pm 0.04$ & 5.63 & $1.78 \pm 0.07$ & $0.00 \pm 0.07$ \\
\hline 6 & EtOAc $^{e}$ & 505 & 514 & 347 & 664 & 923 & $1.00 \pm 0.02$ & 5.46 & $1.83 \pm 0.04$ & $0.00 \pm 0.04$ \\
\hline 7 & Hexane & 509 & 516 & 267 & 676 & 911 & $1.00 \pm 0.04$ & 5.76 & $1.74 \pm 0.07$ & $0.00 \pm 0.07$ \\
\hline 8 & $\mathrm{Bu}_{2} \mathrm{O}^{e}$ & 508 & 518 & 380 & 731 & 885 & $0.97 \pm 0.02$ & 5.80 & $1.67 \pm 0.03$ & $0.05 \pm 0.04$ \\
\hline 9 & $\mathrm{THF}^{e}$ & 507 & 517 & 382 & 734 & 894 & $0.95 \pm 0.02$ & 5.63 & $1.69 \pm 0.04$ & $0.09 \pm 0.04$ \\
\hline 10 & $\mathrm{CH}_{2} \mathrm{Cl}_{2}$ & 509 & 518 & 341 & 560 & 847 & $0.95 \pm 0.02$ & 6.09 & $1.56 \pm 0.03$ & $0.08 \pm 0.03$ \\
\hline 11 & $\mathrm{CHCl}_{3}$ & 511 & 520 & 339 & 744 & 975 & $0.94 \pm 0.01$ & 6.10 & $1.54 \pm 0.02$ & $0.10 \pm 0.02$ \\
\hline 12 & Toluene & 511 & 521 & 376 & 706 & 939 & $0.98 \pm 0.03$ & 5.04 & $1.94 \pm 0.06$ & $0.04 \pm 0.06$ \\
\hline 13 & $\mathrm{PhCl}^{e}$ & 512 & 520 & 300 & 676 & 926 & $1.00 \pm 0.03$ & 4.88 & $2.05 \pm 0.06$ & $0.00 \pm 0.06$ \\
\hline
\end{tabular}

${ }^{a}$ The solvents are numbered according to increasing refractive index $n$.

${ }^{c}$ Globally determined fluorescence lifetime. The standard errors on $\tau$, obtained from the diagonal elements of the covariance matrix available from the global analysis fit of decay traces recorded at three different emission wavelengths $\left(\lambda_{\mathrm{em}}=510,515\right.$ and $520 \mathrm{~nm}$. $\left.\lambda_{\mathrm{ex}}=485 \mathrm{~nm}\right)$, are between 5 and 20 ps.

${ }^{d}$ Fluorescence rate constant $\left(k_{\mathrm{f}}\right)$ or rate constant for nonradiative decay $\left(k_{\mathrm{nr}}\right) \pm$ propagated error. The propagated errors are calculated using the standard uncertainties on $\Phi$ and the standard errors on $\tau$. ${ }^{b, e}$ See Table S2. 
Table S5. Spectroscopic and photophysical data of $\mathbf{5}$ as a function of solvent. ${ }^{a}$

\begin{tabular}{clcccccccc}
\hline & Solvent & $\begin{array}{c}\lambda_{\text {abs }}(\max ) \\
/ \mathrm{nm}\end{array}$ & $\begin{array}{c}\lambda_{\mathrm{em}}(\max ) \\
/ \mathrm{nm}\end{array}$ & $\begin{array}{c}\Delta \bar{\nu} \\
/ \mathrm{cm}^{-1}\end{array}$ & $\begin{array}{c}\mathrm{fwhm}_{\mathrm{abs}} \\
/ \mathrm{cm}^{-1}\end{array}$ & $\begin{array}{c}\mathrm{fwhm}_{\mathrm{em}} \\
/ \mathrm{cm}^{-1}\end{array}$ & $\Phi^{b}$ & $\begin{array}{c}\tau^{c} \\
/ \mathrm{ns}\end{array}$ & $\begin{array}{c}k_{\mathrm{f}}{ }^{d} \\
1\end{array}$ \\
\hline 1 & $\mathrm{CH}_{3} \mathrm{OH}$ & 493 & 505 & 482 & 925 & 1219 & $1.00 \pm 0.03$ & 7.44 & $1.34 \pm 0.04$ \\
2 & $\mathrm{CH}_{3} \mathrm{CN}$ & 492 & 504 & 484 & 964 & 1204 & $1.00 \pm 0.03$ & 7.32 & $1.37 \pm 0.04$ \\
3 & $\left(\mathrm{C}_{2} \mathrm{H}_{5}\right)_{2} \mathrm{O}$ & 495 & 508 & 517 & 840 & 1133 & $1.00 \pm 0.04$ & 7.39 & $1.35 \pm 0.05$ \\
4 & $\left(\mathrm{CH}_{3}\right)_{2} \mathrm{CO}$ & 493 & 505 & 482 & 821 & 1080 & $1.00 \pm 0.03$ & 7.08 & $1.41 \pm 0.04$ \\
5 & $t$ - $\mathrm{BuOMe}^{e}$ & 495 & 507 & 478 & 849 & 1182 & $1.00 \pm 0.03$ & 6.92 & $1.45 \pm 0.04$ \\
6 & $\mathrm{EtOAc}^{e}$ & 494 & 505 & 441 & 797 & 1172 & $1.00 \pm 0.04$ & 6.86 & $1.46 \pm 0.06$ \\
7 & $\mathrm{Hexane}^{2}$ & 497 & 507 & 397 & 858 & 1203 & $1.00 \pm 0.03$ & 7.21 & $1.39 \pm 0.04$ \\
8 & $\mathrm{Bu}_{2} \mathrm{O}^{e}$ & 497 & 507 & 397 & 905 & 1199 & $1.00 \pm 0.06$ & 6.58 & $1.52 \pm 0.09$ \\
9 & $\mathrm{THF}^{e}$ & 496 & 508 & 476 & 917 & 1186 & $0.99 \pm 0.03$ & 6.49 & $1.53 \pm 0.05$ \\
10 & $\mathrm{CH}_{2} \mathrm{Cl}_{2}$ & 497 & 509 & 474 & 756 & 1187 & $1.00 \pm 0.04$ & 6.59 & $1.52 \pm 0.06$ \\
11 & $\mathrm{CHCl}_{3}$ & 499 & 509 & 394 & 845 & 1234 & $1.00 \pm 0.02$ & 6.42 & $1.56 \pm 0.03$ \\
12 & $\mathrm{Toluene}_{13}$ & 499 & 513 & 547 & 884 & 1187 & $1.00 \pm 0.03$ & 5.89 & $1.70 \pm 0.05$ \\
13 & $\mathrm{PhCl}^{e}$ & 500 & 512 & 469 & 833 & 1182 & $1.00 \pm 0.04$ & 5.93 & $1.69 \pm 0.07$ \\
\hline
\end{tabular}

${ }^{a}$ The solvents are numbered according to increasing refractive index $n$.

${ }^{c}$ Globally determined fluorescence lifetime. The standard errors on $\tau$, obtained from the diagonal elements of the covariance matrix available from the global analysis fit of decay traces recorded at three different emission wavelengths $\left(\lambda_{\mathrm{em}}=510,515\right.$ and $\left.520 \mathrm{~nm} . \lambda_{\mathrm{ex}}=485 \mathrm{~nm}\right)$, are between 19 and 23 ps.

${ }^{d}$ Fluorescence rate constant $\left(k_{\mathrm{f}}\right) \pm$ propagated error. Because $\Phi$ is 1.00 in all the solvents studied, except THF, the rate constant for nonradiative decay $\left(k_{\mathrm{nr}}\right)$ is vanishingly small. The propagated errors are calculated using the standard uncertainties on $\Phi$ and the standard errors on $\tau$. The propagated errors on $k_{\mathrm{nr}}$ in all solvents, except THF, are between $3 \times 10^{6} \mathrm{~s}^{-1}$ and $9 \times 10^{6} \mathrm{~s}^{-1}$. In THF, $k_{\mathrm{nr}}=(2 \pm 5) \times 10^{6}$ $\mathrm{s}^{-1}$.

${ }^{b, e}$ See Table $\mathrm{S} 2$. 


\section{Analysis of Solvent-Dependent Spectroscopic Properties of 3-5}

The analysis of the spectral maxima $\bar{v}_{\text {abs }}\left[=1 / \lambda_{\text {abs }}(\max )\right]$ and $\bar{v}_{\mathrm{em}}\left[=1 / \lambda_{\mathrm{em}}(\max )\right]$ as a function of the solvent was done at the KU Leuven (Belgium) using the generalized treatment of the solvent effect proposed by Catalán. ${ }^{13}$

The interactions of the solvent with a solute have been empirically parameterized by a large number of solvent scales. The most frequently used (and well-known) single parameters to describe the nonspecific (also called general) contribution to the solvent effect experienced by any solute are possibly $E_{\mathrm{T}}(30),{ }^{14,15,16}$ Kamlet, Abboud and Taft's $\pi^{*}$ parameter, ${ }^{17}$ Dragos' $S^{\prime}$ scale, ${ }^{18}$ and Catalán and coworkers' SPP scale. ${ }^{19}$ Solvent-dependent spectral shifts are often analyzed in terms of such a single parameter. However, empirical single-parameter solvent scales regularly appear to be inappropriate because that specific parameter is so dependent on the particular probe used to construct the single-parameter scale concerned that it fails to predict the behavior of other solutes with considerably different properties from those of the probe. ${ }^{13}$ Multi-parameter approaches, which use multiple scales to describe specific and general solvent effects, have been applied successfully to various physicochemical properties. ${ }^{1}$ However, a solvatochromic behavior which is exclusively caused by changes in solvent polarizability cannot be accurately described by e.g. the Kamlet, Abboud and Taft's $\pi^{*}$ parameter because this parameter reflects the combined effect of solvent dipolarity and polarizability. To solve this problem, it is necessary to split the two contributions of the general solvent effect, namely solvent dipolarity and polarizability and, hence, to establish two corresponding, independent solvent scales for nonspecific solvent-solute interactions. This was done by Catalán, who proposed the generalized treatment of the solvent effect based on a set of four empirical, complementary, mutually independent solvent scales [for solvent polarizability (SP), dipolarity (SdP), acidity (SA) and basicity (SB), ${ }^{13}$ with corresponding weights $c_{\mathrm{SP}}, d_{\mathrm{SdP}}, a_{\mathrm{SA}}$ and $b_{\mathrm{SB}}$ (see eq 1 )].

The detailed analyses of the spectroscopic maxima $\bar{v}_{\text {abs }}$ and $\bar{v}_{\mathrm{em}}$ of BODIPYs 3-5 are given next. The results of the analyses are compiled in Table S7. From these analyses according to eq 1 with $\{\mathrm{SA}, \mathrm{SB}, \mathrm{SP}, \mathrm{SdP}\}$, three important conclusions can be drawn: (i) Solvent acidity (parameterized by SA) and basicity (parameterized by SB) have a negligible influence on the solvatochromic shifts of $\bar{v}_{\text {abs }}$ and $\bar{v}_{\text {em. }}$. (ii) For each dye, the values estimated for $c_{\mathrm{SP}}$ from the multilinear regression analyses of $\bar{v}_{\text {abs }}$ and $\bar{v}_{\text {em }}$ are always negative and have a comparable magnitude, but with a larger negative value from the $\bar{v}_{\text {em }}$ analyses. (iii) For each dye, the values estimated for $d_{\text {SdP }}$ from the multilinear regression analyses of $\bar{v}_{\text {abs }}$ and $\bar{v}_{\text {em }}$ are always positive with a larger value from the $\bar{v}_{\text {abs }}$ analyses.

\section{BODIPY 3}

The relatively large estimates of $\left\{c_{\mathrm{SP}}, d_{\mathrm{SdP}}\right\}$ with concomitant comparatively small standard errors in relation to $\left\{a_{\mathrm{SA}}, b_{\mathrm{SB}}\right\}$ identify solvent polarizability and dipolarity as the more important parameters influencing the position of $\bar{v}_{\text {abs }}$ of $\mathbf{3}$. That solvent polarizability is more essential is derived from the four analyses of $\overline{\mathrm{V}}_{\text {abs }}$ according to eq 1 , in which either SA, SB, SP, or SdP is left out as independent variable. Indeed, 
the analysis with $\{\mathrm{SA}, \mathrm{SB}, \mathrm{SdP}\}$ as independent variables has the lowest $r$-value (0.753) vs. $r=0.983,0.982$ and 0.885 for the analyses with $\{\mathrm{SB}, \mathrm{SP}, \mathrm{SdP}\},\{\mathrm{SA}, \mathrm{SP}$, $\mathrm{SdP}\}$ and $\{\mathrm{SA}, \mathrm{SB}, \mathrm{SP}\}$, respectively. Provided that SP is present as independent variable in the analyses according to eq 1 with two independent variables, excellent fits are obtained. This is found for the three analyses with $\{\mathrm{SA}, \mathrm{SP}\},\{\mathrm{SB}, \mathrm{SP}\}$ and $\{\mathrm{SdP}, \mathrm{SP}\}$ yielding $r$-values of $0.862,0.880$ and 0.976 , respectively. That the analysis with $\{\mathrm{SP}, \mathrm{SdP}\}$ yields the best fit is further evidence for SP and to a lesser degree SdP as key solvent scales. Extra evidence that solvent polarizability is a key parameter for the solvent dependence of $\bar{v}_{\text {abs }}$ is derived from the excellent fit of $\bar{v}_{\text {abs }}$ vs. the Bayliss function $^{20} f(n)=\left(n^{2}-1\right) /\left(2 n^{2}+1\right)$, with $r=0.935$.

Analogous analyses of $\bar{v}_{\text {em }}$ according to eq 1 also point to solvent polarizability and to a lesser degree dipolarity as crucial factors determining the position of emission spectra. Exclusion of SP from the analysis (that is, with $\{\mathrm{SA}, \mathrm{SB}, \mathrm{SdP}\}$ as independent variables) yields a fit with the lowest $r$-value (0.624) vs. $r=0.978,0.986$ and 0.960 for the analyses with $\{\mathrm{SB}, \mathrm{SP}, \mathrm{SdP}\},\{\mathrm{SA}, \mathrm{SP}, \mathrm{SdP}\}$ and $\{\mathrm{SA}, \mathrm{SB}, \mathrm{SP}\}$ respectively. As long as SP is present as independent variable in the analyses according to eq 1 with two independent variables, excellent fits are obtained. This is found for the three analyses with $\{\mathrm{SA}, \mathrm{SP}\},\{\mathrm{SB}, \mathrm{SP}\}$ and $\{\mathrm{SdP}, \mathrm{SP}\}$ yielding $r$-values of $0.956,0.959$ and 0.976 , respectively. Even the linear fit of $\bar{v}_{\text {em }}$ Vs. SP has an excellent correlation $(r=0.955)$, demonstrating that solvent polarizability determines mainly the spectroscopic shifts of $\bar{v}_{\text {em }}$. The excellent fit of $\bar{v}_{\text {em }}$ vs. the Bayliss function $(r=0.975)$ confirms this.

\section{BODIPY 4}

In order to find out which solvent properties principally account for the shifts of $\bar{v}_{\text {abs }}$ and $\bar{v}_{\mathrm{em}}$ of 4 , Catalán analyses according to eq 1 were carried out in which systematically one, two and three solvent scales were omitted. The results of the analyses of $\bar{v}_{\text {abs }}$ and $\bar{v}_{\text {em }}$ of $\mathbf{4}$ are very similar to those obtained for $\mathbf{3}$. From this multitude of analyses, it is evident that solvent polarizability (and to a lesser degree solvent dipolarity) are primarily responsible for the observed shifts of $\bar{v}_{\text {abs }}$ and $\bar{v}_{\text {em. }}$.

\section{BODIPY 5}

Also for this dye, Catalán analyses according to eq 1 were carried out in which systematically one, two and three solvent scales were omitted in order to determine which solvent properties predominantly account for the shifts of $\bar{v}_{\text {abs }}$ and $\bar{v}_{\text {em. The }}$ results of the analyses of $\bar{v}_{\text {abs }}$ and $\bar{v}_{\text {em }}$ of $\mathbf{5}$ are very similar to those obtained for $\mathbf{3}$ and 4. From this collection of analyses, it is concluded that solvent polarizability (SP) and to a lesser extent solvent dipolarity (SdP) are principally accountable for the measured shifts of $\bar{v}_{\text {abs }}$ and $\bar{v}_{\mathrm{em}}$. 
Table S6. Estimated coefficients $\left(y_{0}, a_{\mathrm{SA}}, b_{\mathrm{SB}}, c_{\mathrm{SP}}, d_{\mathrm{SdP}}\right.$; in $\left.\mathrm{cm}^{-1}\right)$ and correlation coefficient $(r)$ for the (multiple) linear regression analyses according to eq 1 of the absorption $\left(\bar{v}_{\text {abs }}\right)$ and fluorescence emission maxima $\left(\bar{v}_{\mathrm{em}}\right)$ of $\mathbf{1}$ and $\mathbf{2}$ as a function of the Catalán solvent scales $\{\mathrm{SA}, \mathrm{SB}, \mathrm{SP}, \mathrm{SdP}\}$ for the solvents listed in Tables 3 and S2. To highlight the differences of the $c_{\mathrm{SP}}$ and $d_{\mathrm{SdP}}$ estimates from the $\bar{v}_{\text {abs }}$ and $\bar{v}_{\mathrm{em}}$ fitting according to eq 1 , these values are displayed in red.

\begin{tabular}{|c|c|c|c|c|c|c|c|}
\hline & & $y_{0}$ & $a_{\mathrm{SA}}$ & $b_{\mathrm{SB}}$ & $c_{\mathrm{SP}}$ & $d_{\mathrm{SdP}}$ & $r$ \\
\hline \multirow[t]{15}{*}{1} & $\overline{\mathrm{V}}_{\mathrm{abs}}$ & $20936 \pm 102$ & $-189 \pm 57$ & $46 \pm 45$ & $-1266 \pm 135$ & $319 \pm 31$ & 0.984 \\
\hline & $\overline{\mathrm{V}}_{\mathrm{abs}}$ & $20855 \pm 144$ & & $55 \pm 65$ & $-1133 \pm 188$ & $274 \pm 41$ & 0.962 \\
\hline & $\overline{\mathrm{v}}_{\mathrm{abs}}$ & $21004 \pm 78$ & $-193 \pm 57$ & & $-1344 \pm 112$ & $325 \pm 30$ & 0.982 \\
\hline & $\overline{\mathrm{V}}_{\mathrm{abs}}$ & $20002 \pm 70$ & $-32 \pm 177$ & $282 \pm 122$ & & $256 \pm 98$ & 0.791 \\
\hline & $\overline{\mathrm{V}}_{\mathrm{abs}}$ & $20858 \pm 362$ & $64 \pm 182$ & $132 \pm 158$ & $-962 \pm 470$ & & 0.744 \\
\hline & $\overline{\mathrm{V}}_{\mathrm{abs}}$ & $20934 \pm 108$ & & & $-1223 \pm 152$ & $280 \pm 39$ & 0.959 \\
\hline & $\overline{\mathrm{V}}_{\mathrm{abs}}$ & $20125 \pm 64$ & $149 \pm 204$ & $306 \pm 152$ & & & 0.588 \\
\hline & $\bar{v}_{\mathrm{em}}$ & $20755 \pm 105$ & $-125 \pm 59$ & $-43 \pm 46$ & $-1316 \pm 140$ & $163 \pm 32$ & 0.972 \\
\hline & $\bar{v}_{\mathrm{em}}$ & $20701 \pm 121$ & & $-37 \pm 55$ & $-1228 \pm 157$ & $134 \pm 34$ & 0.956 \\
\hline & $\bar{v}_{\mathrm{em}}$ & $20692 \pm 80$ & $-122 \pm 58$ & & $-1245 \pm 115$ & $158 \pm 31$ & 0.969 \\
\hline & $\bar{v}_{\mathrm{em}}$ & $19783 \pm 72$ & $38 \pm 184$ & $203 \pm 126$ & & $97 \pm 102$ & 0.583 \\
\hline & $\bar{v}_{\mathrm{em}}$ & $20714 \pm 204$ & $4 \pm 103$ & $1 \pm 89$ & $-1161 \pm 265$ & & 0.877 \\
\hline & $\bar{v}_{\mathrm{em}}$ & $20716 \pm 148$ & $4 \pm 98$ & & $-1162 \pm 211$ & & 0.877 \\
\hline & $\bar{v}_{\mathrm{em}}$ & $20716 \pm 189$ & & $1 \pm 84$ & $-1163 \pm 245$ & & 0.877 \\
\hline & $\bar{v}_{\mathrm{em}}$ & $20648 \pm 89$ & & & $-1168 \pm 126$ & $130 \pm 33$ & 0.954 \\
\hline \multirow[t]{12}{*}{2} & $\overline{\mathrm{V}}_{\mathrm{abs}}$ & $20261 \pm 97$ & $-125 \pm 54$ & $15 \pm 43$ & $-943 \pm 129$ & $244 \pm 29$ & 0.975 \\
\hline & $\overline{\mathrm{V}}_{\mathrm{abs}}$ & $20208 \pm 115$ & & $21 \pm 52$ & $-856 \pm 150$ & $215 \pm 32$ & 0.957 \\
\hline & $\overline{\mathrm{V}}_{\mathrm{abs}}$ & $20284 \pm 70$ & $-126 \pm 51$ & & $-969 \pm 101$ & $246 \pm 28$ & 0.974 \\
\hline & $\overline{\mathrm{V}}_{\mathrm{abs}}$ & $19566 \pm 53$ & $-8 \pm 135$ & $191 \pm 93$ & & $197 \pm 75$ & 0.782 \\
\hline & $\overline{\mathrm{V}}_{\mathrm{abs}}$ & $20201 \pm 283$ & $69 \pm 142$ & $81 \pm 123$ & $-711 \pm 367$ & & 0.720 \\
\hline & $\overline{\mathrm{V}}_{\mathrm{abs}}$ & $20239 \pm 83$ & & & $-890 \pm 118$ & $217 \pm 30$ & 0.956 \\
\hline & $\bar{v}_{\mathrm{em}}$ & $17894 \pm 143$ & $41 \pm 80$ & $140 \pm 63$ & $201 \pm 190$ & $181 \pm 43$ & 0.899 \\
\hline & $\bar{v}_{\mathrm{em}}$ & $17911 \pm 133$ & & $138 \pm 60$ & $173 \pm 173$ & $190 \pm 37$ & 0.895 \\
\hline & $\bar{v}_{\mathrm{em}}$ & $18099 \pm 131$ & $30 \pm 95$ & & $-34 \pm 188$ & $199 \pm 51$ & 0.831 \\
\hline & $\bar{v}_{\mathrm{em}}$ & $18042 \pm 30$ & $16 \pm 77$ & $103 \pm 53$ & & $191 \pm 43$ & 0.884 \\
\hline & $\bar{v}_{\mathrm{em}}$ & $17849 \pm 239$ & $184 \pm 121$ & $189 \pm 104$ & $374 \pm 311$ & & 0.625 \\
\hline & $\bar{v}_{\mathrm{em}}$ & $18073 \pm 26$ & & & & $206 \pm 42$ & 0.827 \\
\hline
\end{tabular}


Table S7. Estimated coefficients $\left(y_{0}, a_{\mathrm{SA}}, b_{\mathrm{SB}}, c_{\mathrm{SP}}, d_{\mathrm{SdP}}\right.$; in $\left.\mathrm{cm}^{-1}\right)$ and correlation coefficient $(r)$ for the (multiple) linear regression analyses according to eq 1 of the absorption $\left(\bar{v}_{\text {abs }}\right)$ and fluorescence emission maxima $\left(\bar{v}_{\text {em }}\right)$ of $\mathbf{3}, \mathbf{4}$ and $\mathbf{5}$ as a function of the Catalán solvent scales $\{\mathrm{SA}, \mathrm{SB}, \mathrm{SP}, \mathrm{SdP}\}$ for the solvents listed in Tables S3-S5. To highlight the differences of the $c_{\text {SP }}$ and $d_{\text {SdP }}$ estimates from the $\bar{v}_{\text {abs }}$ and $\bar{v}_{\text {em }}$ fitting according to eq 1 , these values are displayed in red.

\begin{tabular}{|c|c|c|c|c|c|c|c|}
\hline & & $y_{0}$ & $a_{\mathrm{SA}}$ & $b_{\mathrm{SB}}$ & $c_{\mathrm{SP}}$ & $d_{\mathrm{SdP}}$ & $r$ \\
\hline \multirow[t]{13}{*}{3} & $\overline{\mathbf{v}}_{\mathrm{abs}}$ & $20558 \pm 73$ & $-81 \pm 41$ & $69 \pm 32$ & $-1180 \pm 97$ & $186 \pm 22$ & 0.989 \\
\hline & $\overline{\mathbf{V}}_{\mathrm{abs}}$ & $20524 \pm 82$ & & $73 \pm 37$ & $-1123 \pm 107$ & $167 \pm 23$ & 0.983 \\
\hline & $\overline{\mathrm{V}}_{\mathrm{abs}}$ & $20660 \pm 66$ & $-86 \pm 48$ & & $-1297 \pm 95$ & $195 \pm 26$ & 0.982 \\
\hline & $\overline{\mathrm{V}}_{\mathrm{abs}}$ & $19688 \pm 64$ & $66 \pm 162$ & $290 \pm 111$ & & $127 \pm 90$ & 0.753 \\
\hline & $\overline{\mathbf{V}}_{\mathrm{abs}}$ & $20512 \pm 215$ & $66 \pm 108$ & $119 \pm 94$ & $-1003 \pm 279$ & & 0.885 \\
\hline & $\overline{\mathbf{V}}_{\mathrm{abs}}$ & $20629 \pm 70$ & & & $-1243 \pm 100$ & $175 \pm 26$ & 0.976 \\
\hline & $\bar{v}_{\mathrm{em}}$ & $20422 \pm 78$ & $-105 \pm 44$ & $26 \pm 35$ & $-1399 \pm 104$ & $97 \pm 24$ & 0.987 \\
\hline & $\overline{\mathbf{v}}_{\mathrm{em}}$ & $20377 \pm 94$ & & $30 \pm 43$ & $-1326 \pm 123$ & $72 \pm 27$ & 0.978 \\
\hline & $\overline{\mathrm{V}}_{\mathrm{em}}$ & $20459 \pm 58$ & $-107 \pm 42$ & & $-1442 \pm 84$ & $100 \pm 23$ & 0.986 \\
\hline & $\bar{v}_{\mathrm{em}}$ & $19389 \pm 75$ & $69 \pm 191$ & $286 \pm 132$ & & $27 \pm 106$ & 0.624 \\
\hline & $\overline{\mathrm{v}}_{\mathrm{em}}$ & $20398 \pm 129$ & $-28 \pm 65$ & $51 \pm 56$ & $-1307 \pm 167$ & & 0.960 \\
\hline & $\bar{v}_{\mathrm{em}}$ & $20420 \pm 70$ & & & $-1375 \pm 98$ & $75 \pm 24$ & 0.976 \\
\hline & $\bar{v}_{\mathrm{em}}$ & $20461 \pm 89$ & & & $-1374 \pm 129$ & & 0.955 \\
\hline \multirow[t]{4}{*}{4} & $\overline{\mathbf{V}}_{\mathrm{abs}}$ & $20276 \pm 77$ & $-55 \pm 43$ & $106 \pm 34$ & $-1023 \pm 102$ & $181 \pm 23$ & 0.987 \\
\hline & $\overline{\mathrm{V}}_{\mathrm{abs}}$ & $20408 \pm 80$ & & & $-1162 \pm 113$ & $179 \pm 29$ & 0.967 \\
\hline & $\overline{\mathrm{V}}_{\mathrm{em}}$ & $20075 \pm 120$ & $-29 \pm 67$ & $11 \pm 53$ & $-1156 \pm 159$ & $142 \pm 37$ & 0.963 \\
\hline & $\bar{v}_{\mathrm{em}}$ & $20080 \pm 80$ & & & $-1155 \pm 114$ & $137 \pm 29$ & 0.962 \\
\hline \multirow[t]{4}{*}{5} & $\overline{\mathbf{V}}_{\mathrm{abs}}$ & $20798 \pm 79$ & $-91 \pm 44$ & $23 \pm 35$ & $-1096 \pm 105$ & $214 \pm 24$ & 0.985 \\
\hline & $\overline{\mathbf{v}}_{\mathrm{abs}}$ & $20798 \pm 66$ & & & $-1075 \pm 94$ & $196 \pm 24$ & 0.976 \\
\hline & $\bar{v}_{\mathrm{em}}$ & $20427 \pm 181$ & $-88 \pm 101$ & $-13 \pm 80$ & $-1177 \pm 240$ & $172 \pm 55$ & 0.920 \\
\hline & $\overline{\mathbf{v}}_{\mathrm{em}}$ & $20376 \pm 125$ & & & $-1101 \pm 177$ & $150 \pm 46$ & 0.912 \\
\hline
\end{tabular}




\section{Density Functional Theory (DFT) Calculated Emission Spectra (from}

\section{Ab Initio Molecular Dynamics)}

All DFT calculations were performed at the University of Nottingham (United Kingdom).

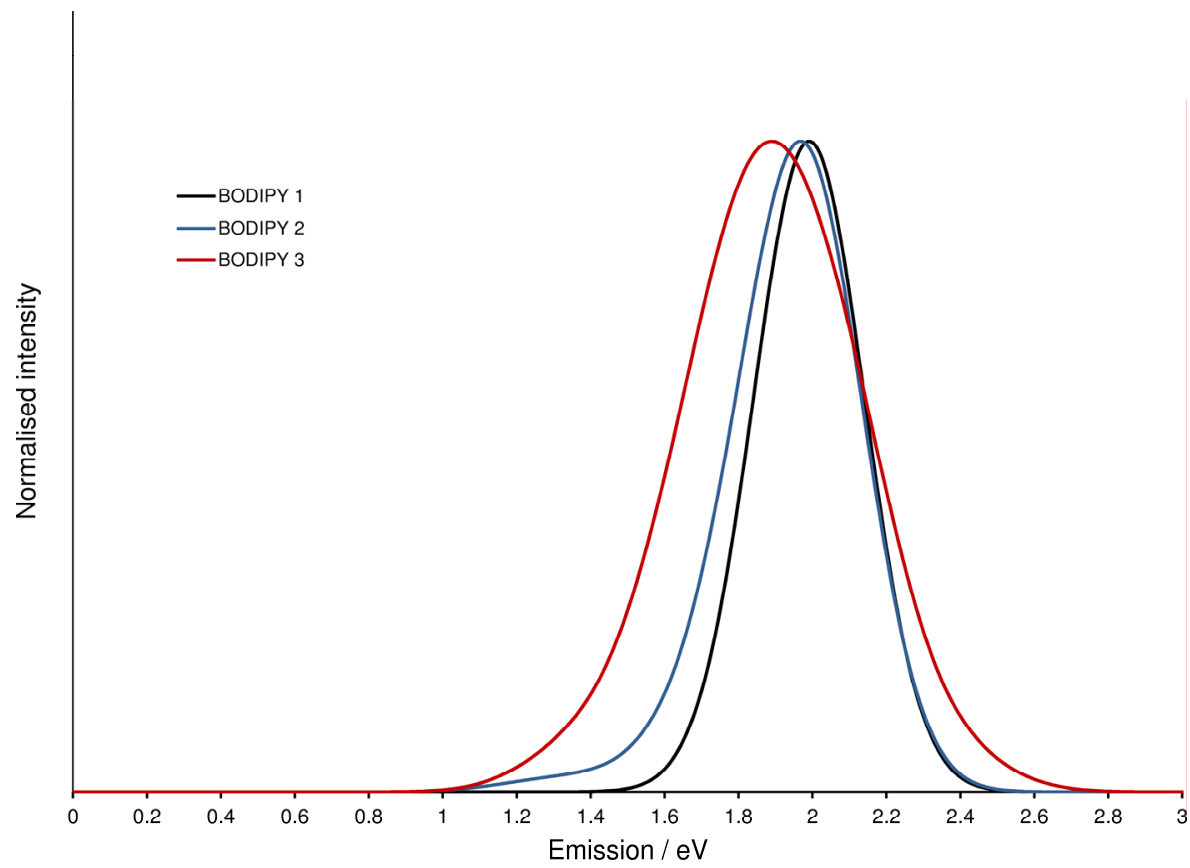

Figure S7-a. Calculated gas-phase emission spectra (in $\mathrm{eV}$ ) of 1, 2 and 3, using DFT (B3LYP/6-311G*).

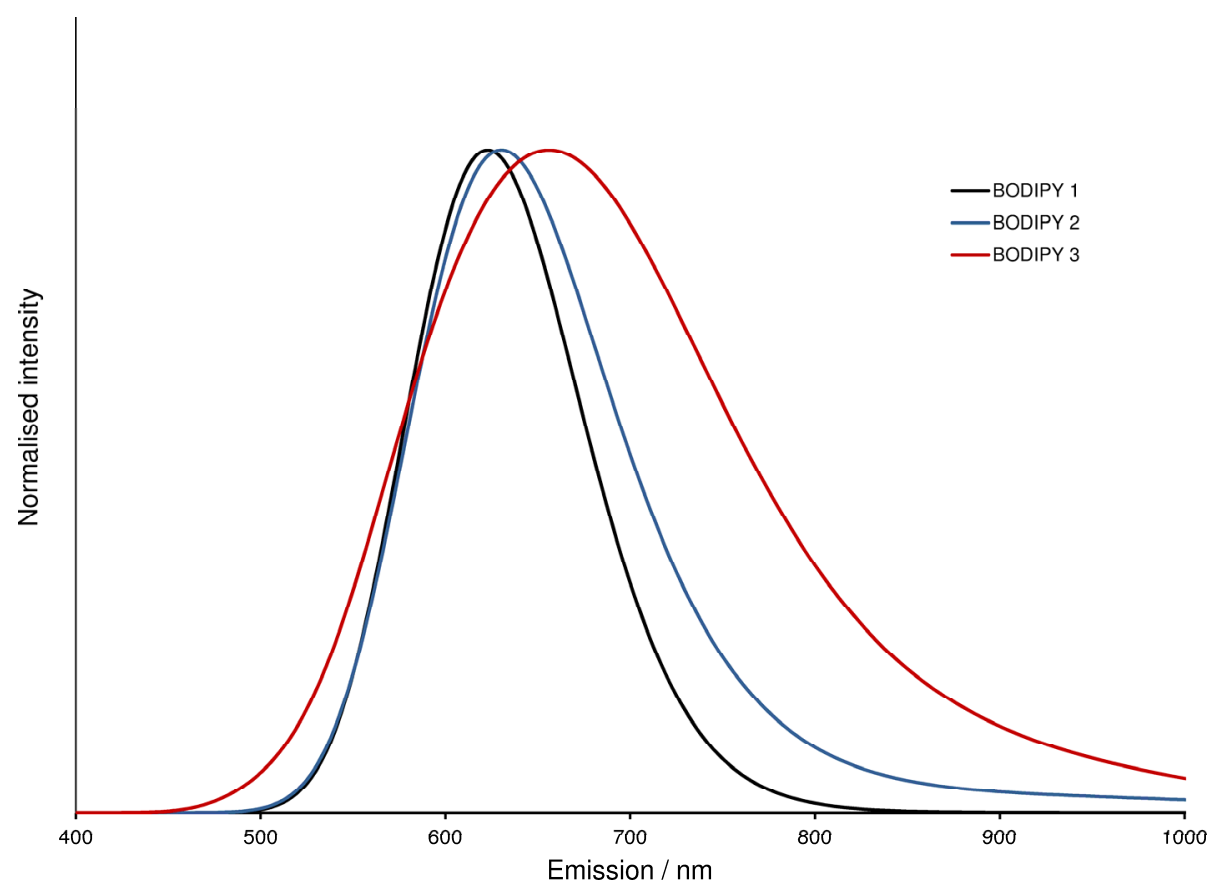

Figure S7-b. Calculated gas-phase emission spectra (in $\mathrm{nm}$ ) of 1, $\mathbf{2}$ and $\mathbf{3}$, using DFT (B3LYP/6-311G*). 


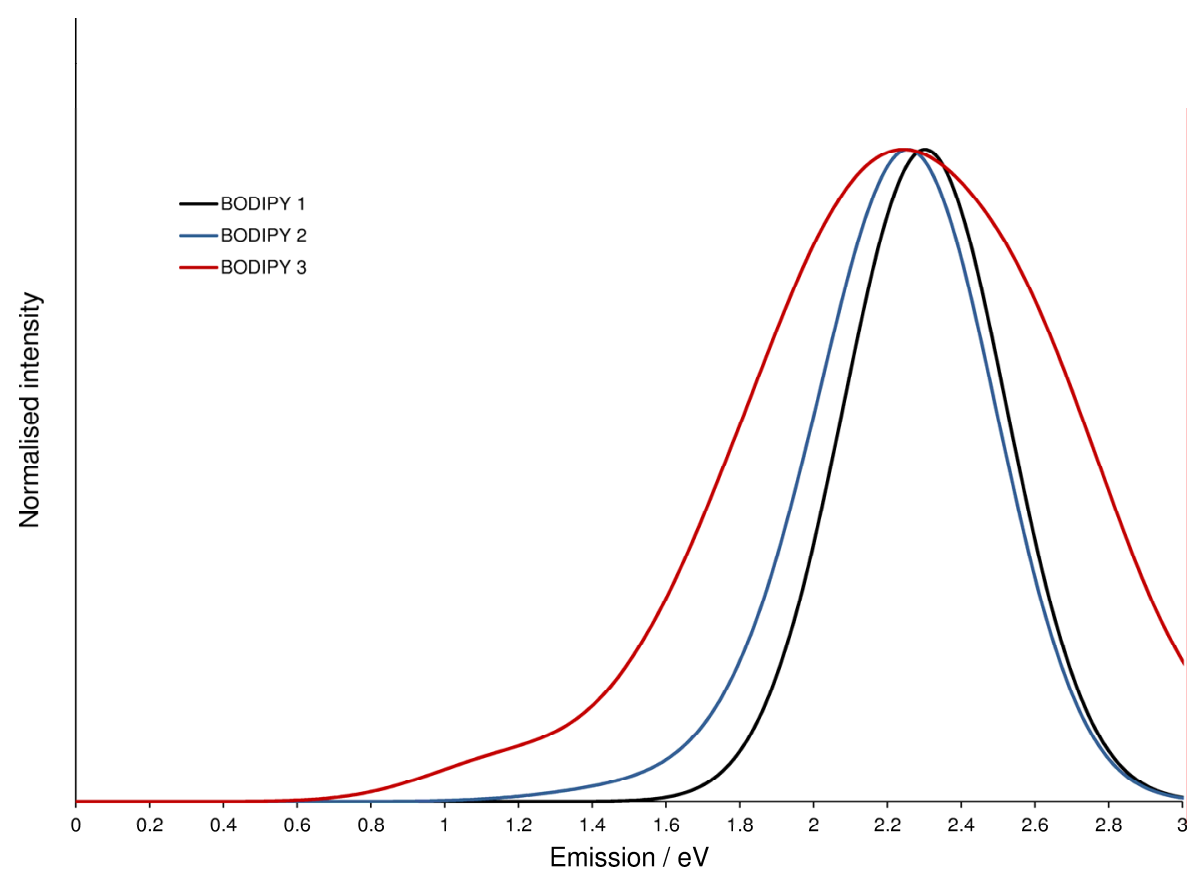

Figure S8-a. Calculated emission spectra (in eV) of $\mathbf{1 ,} 2$ and $\mathbf{3}$ in $\mathrm{CH}_{2} \mathrm{Cl}_{2}$, using DFT (B3LYP/6-311G*).

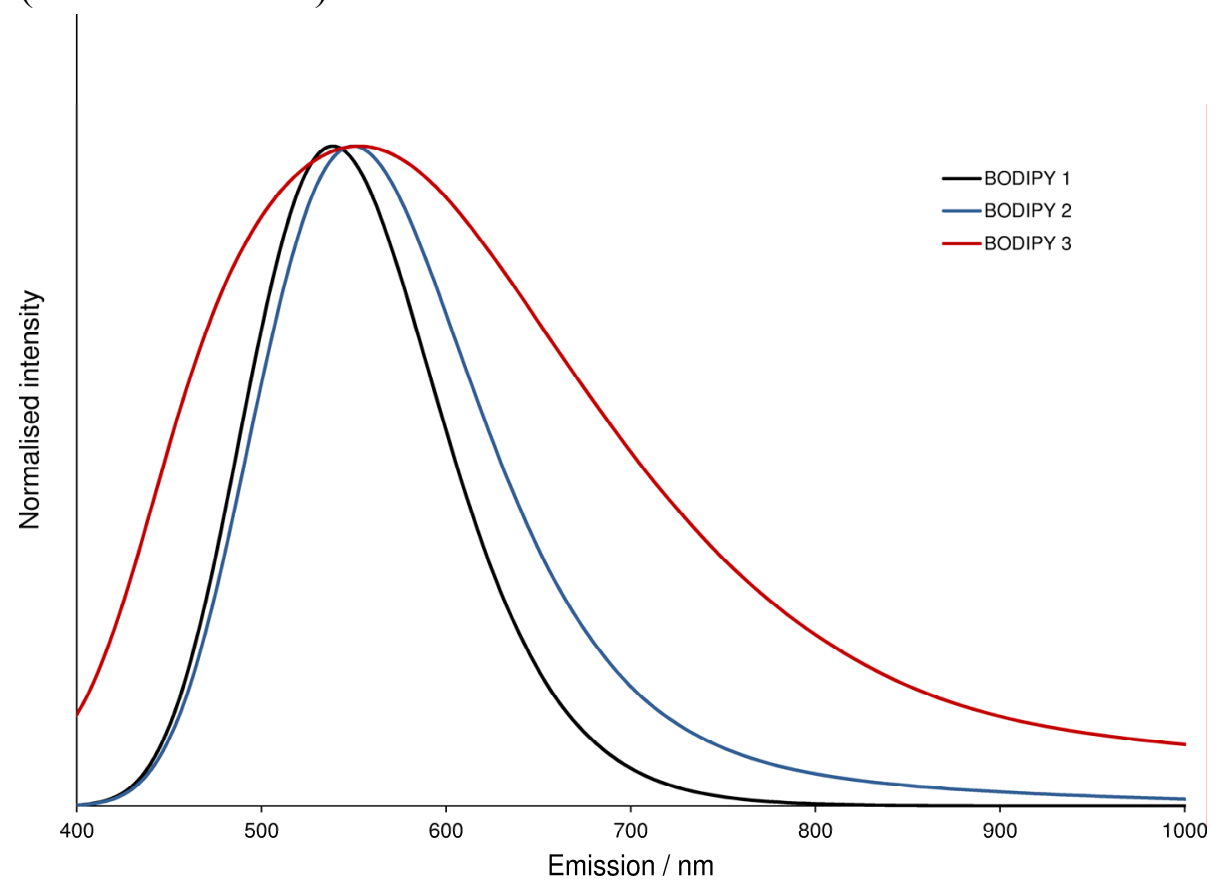

Figure S8-b. Calculated emission spectra (in nm) of $\mathbf{1 , 2}$ and 3 in $\mathrm{CH}_{2} \mathrm{Cl}_{2}$, using DFT (B3LYP/6-311G*). 
${ }^{1} \mathrm{H}$ and ${ }^{13} \mathrm{C}$ NMR Spectra of $1-5$ and 7

\section{BODIPY 1}
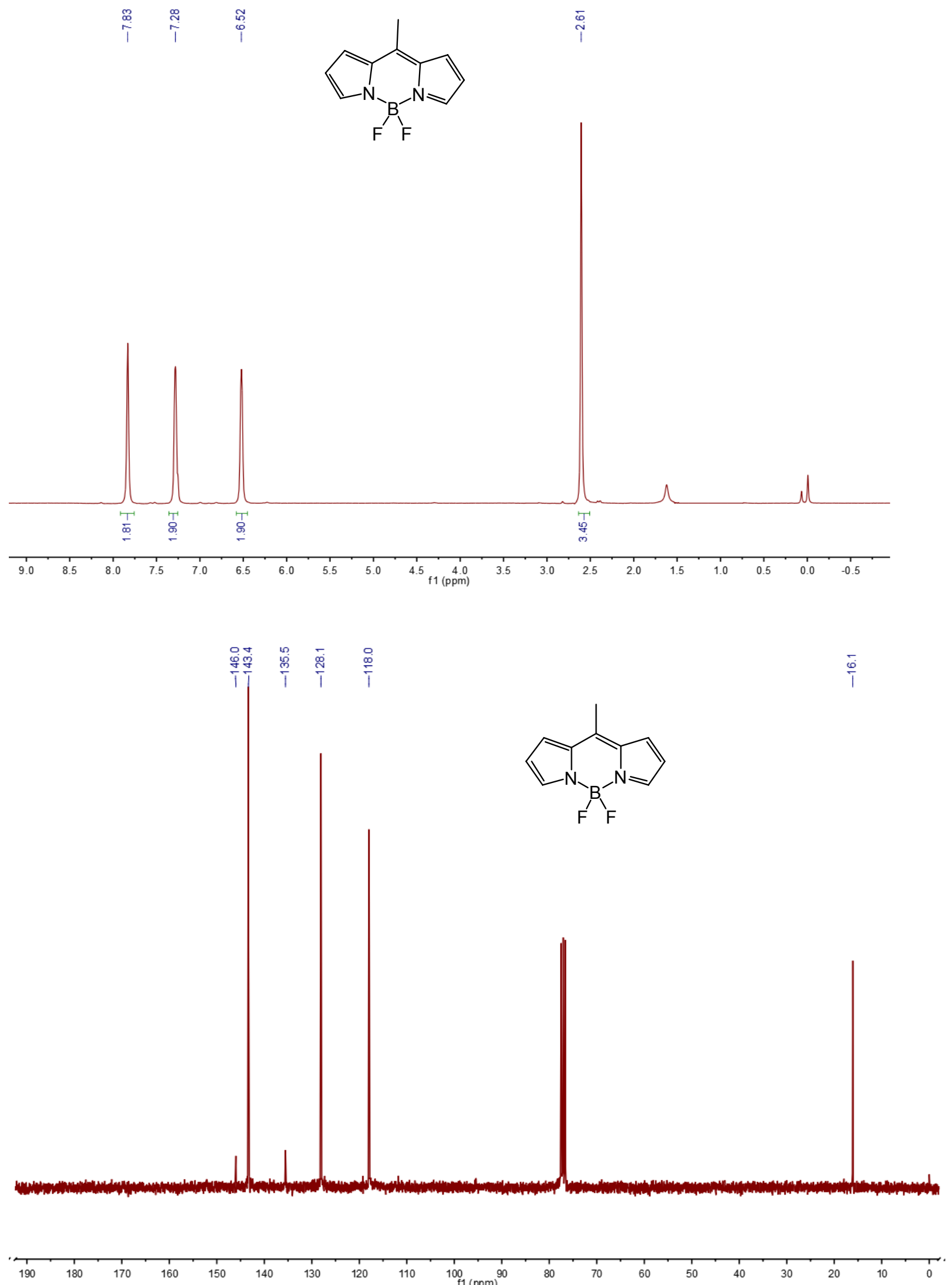
BODIPY 2

2010-2-hrh-H
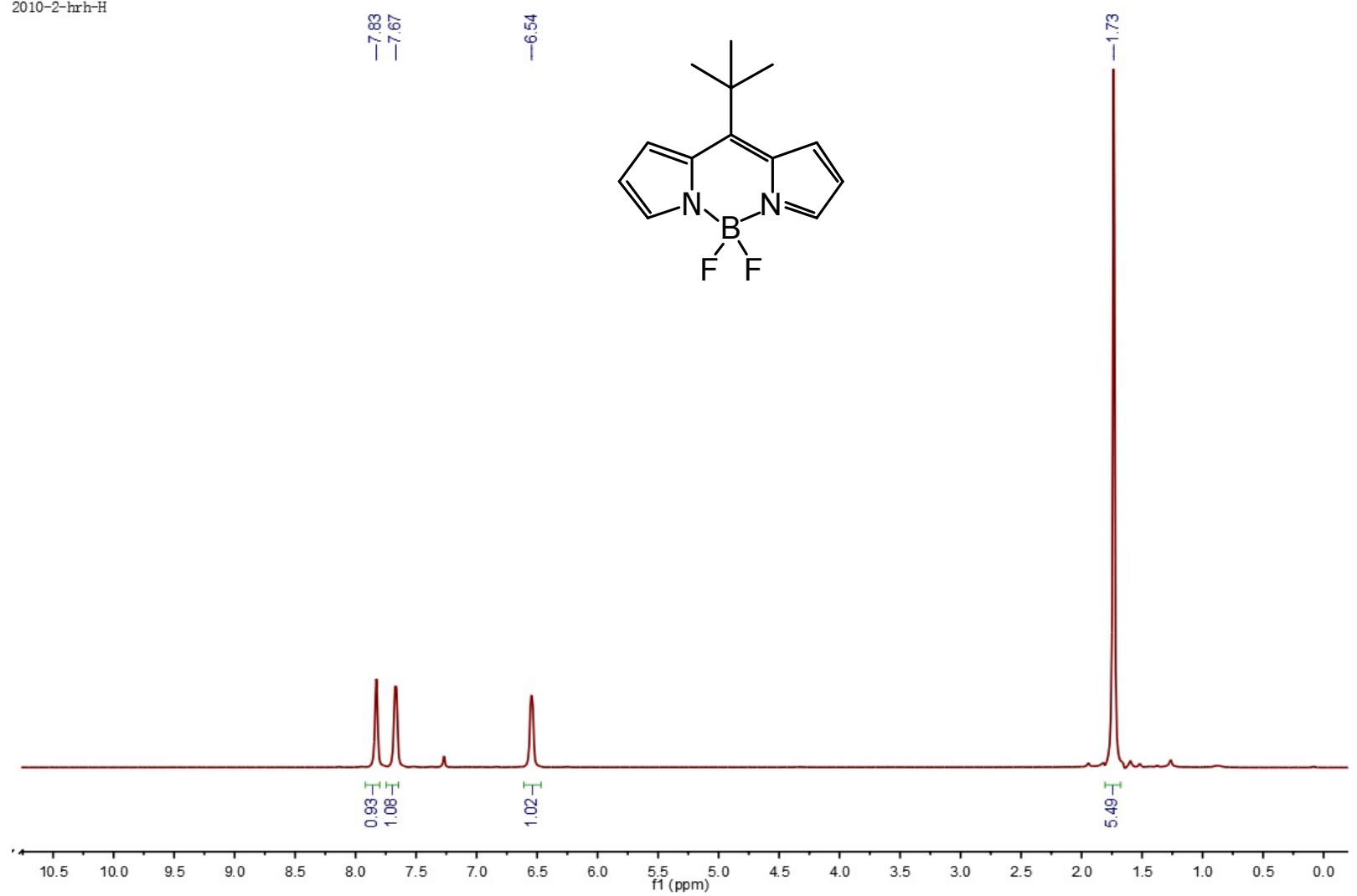

2010-2-hrh-C

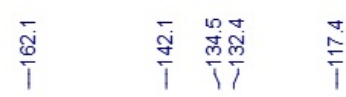
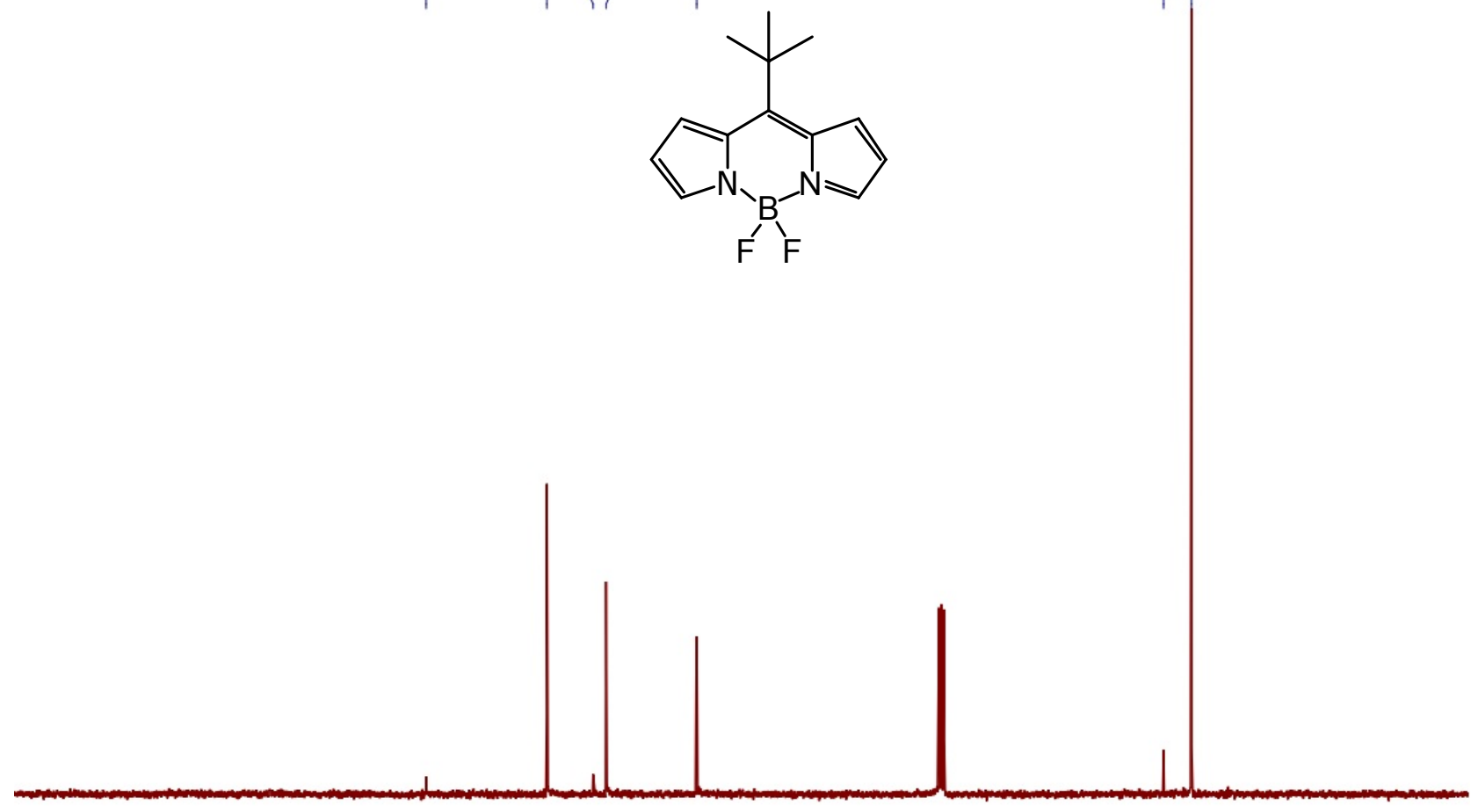

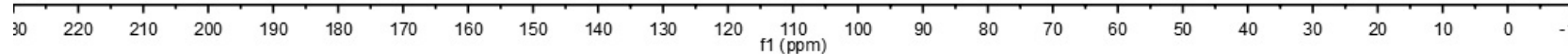


BODIPY 3

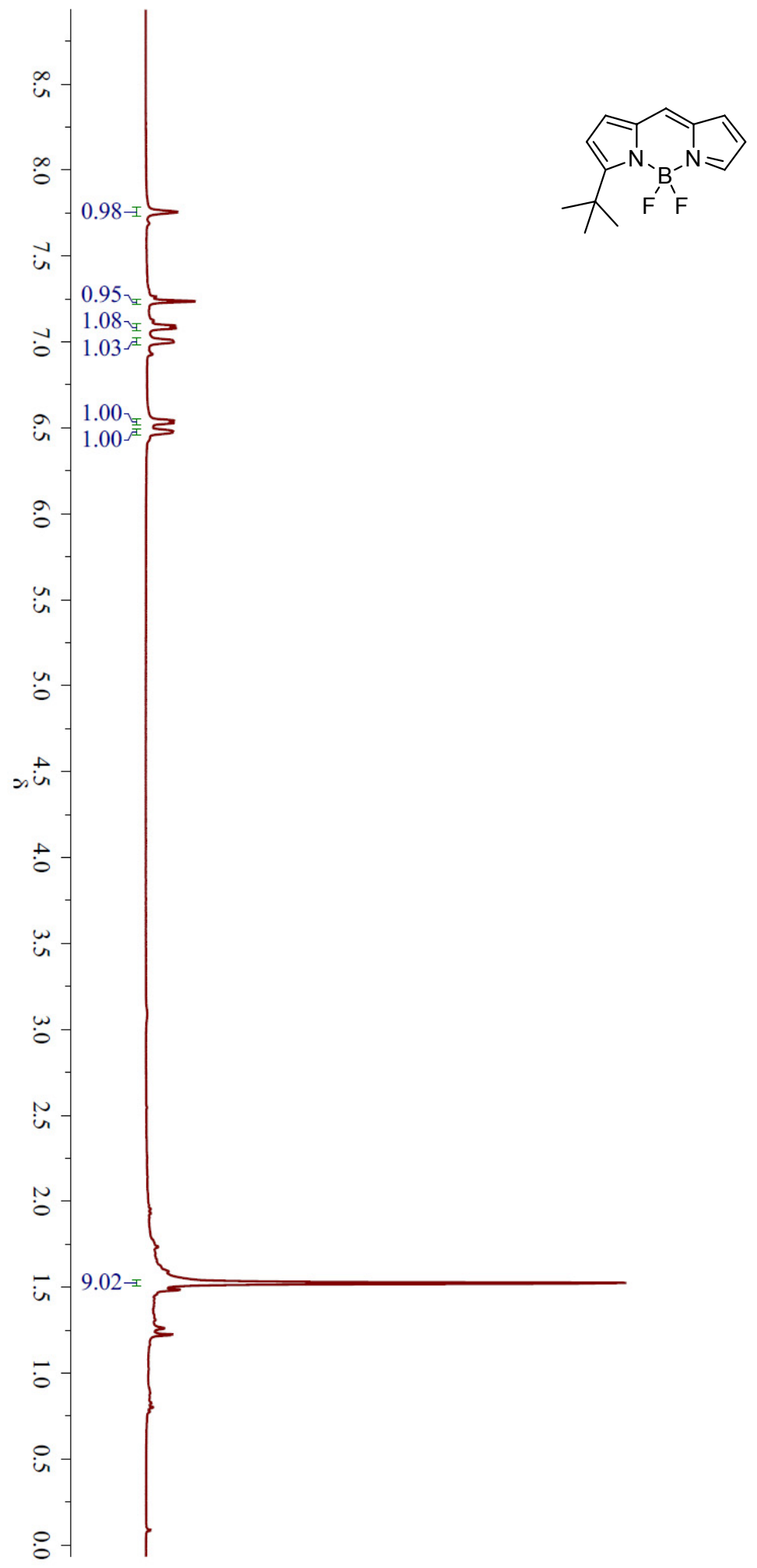




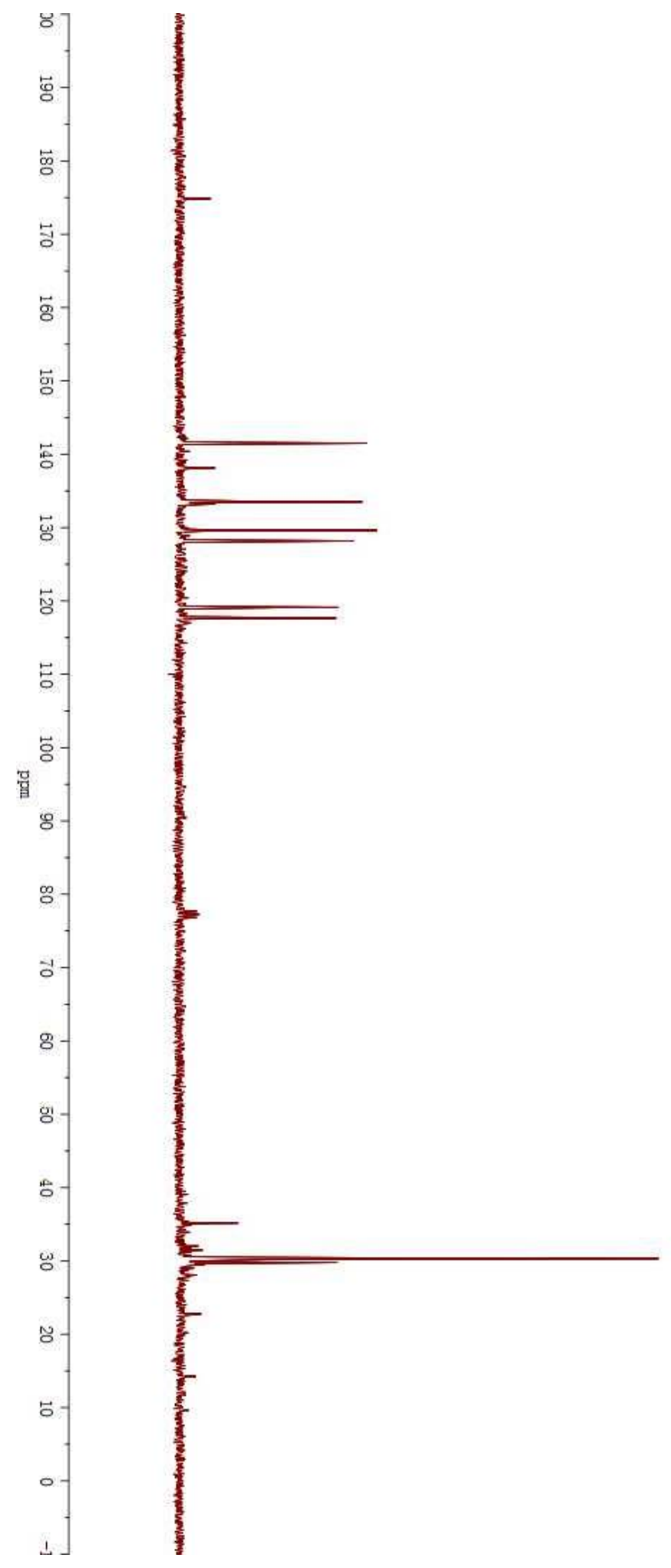

$-141.5$

$-138.1$

133.5
-133.2

-129.6
-128.2

$-119.1$

$-117.7$

-77.7
-77.3
-76.8

$-35.2$

$-30.3$ 
BODIPY 4

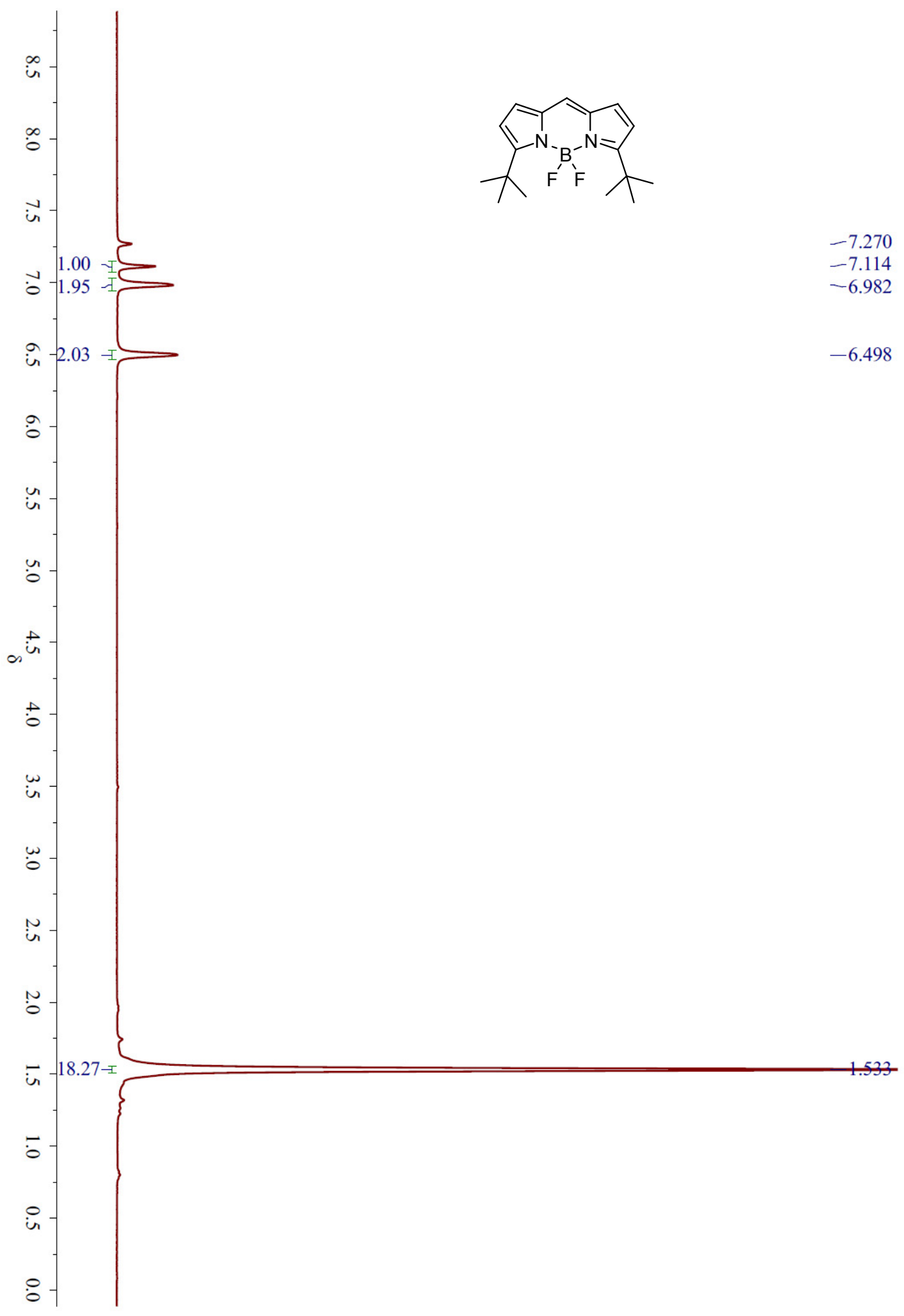




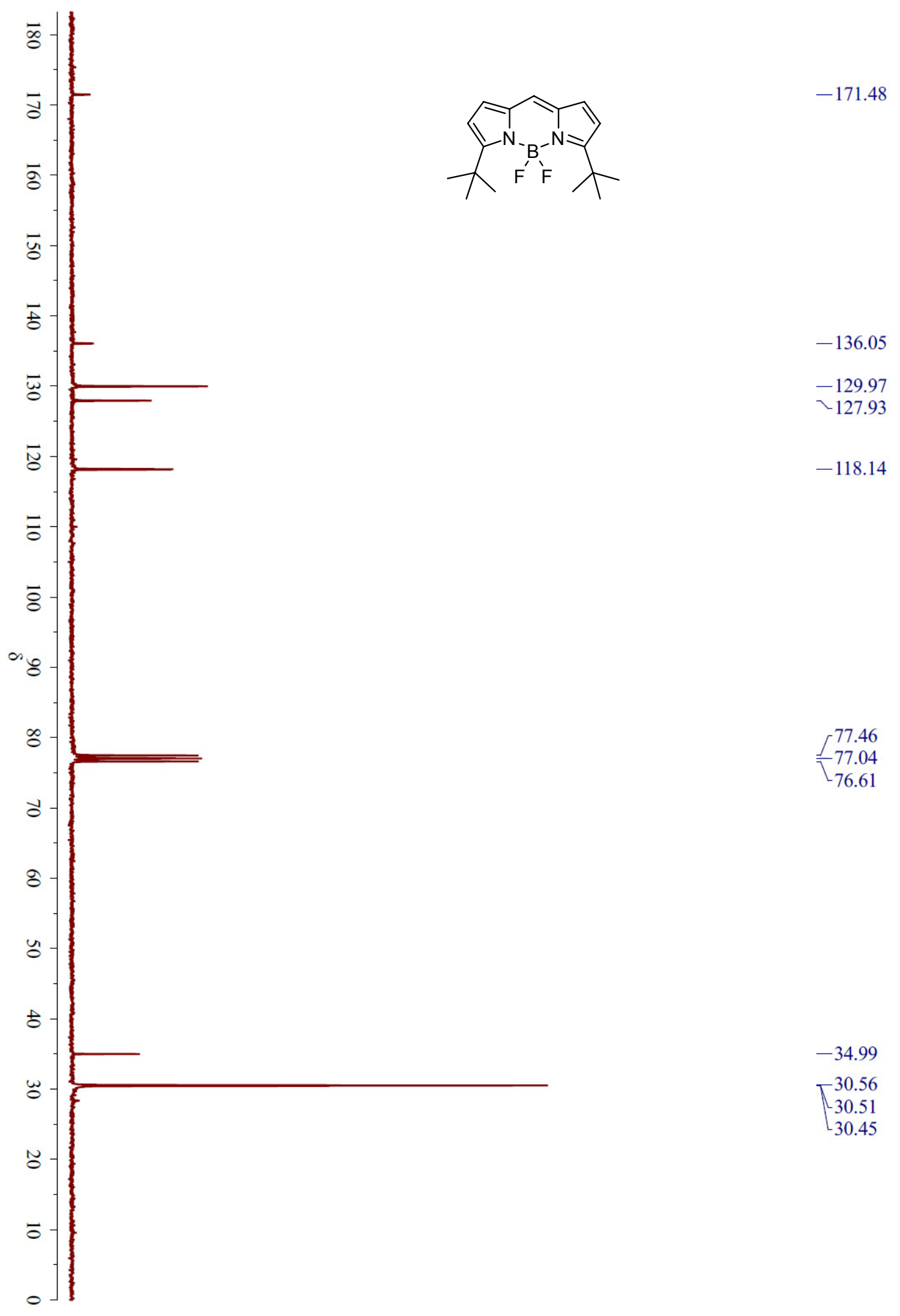


BODIPY 5

年孛

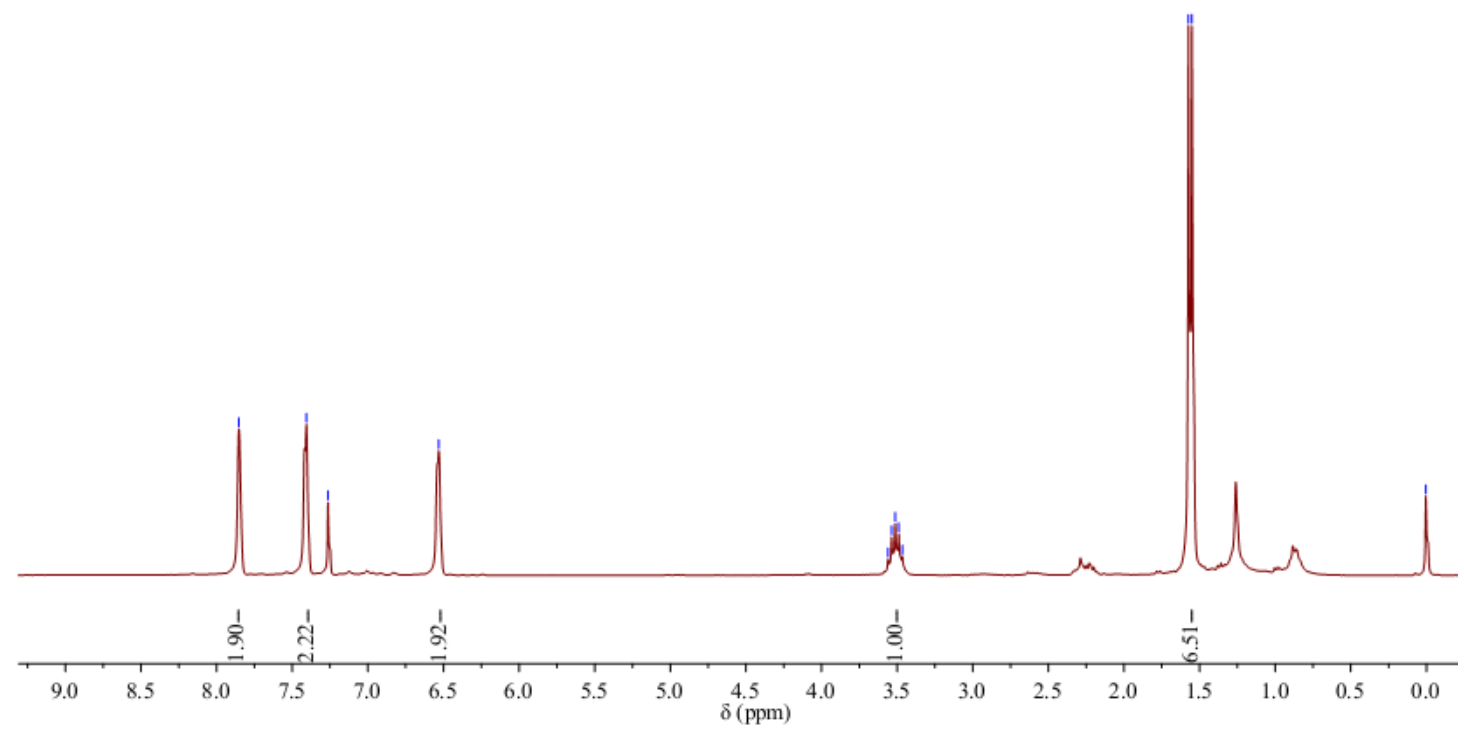<smiles></smiles>

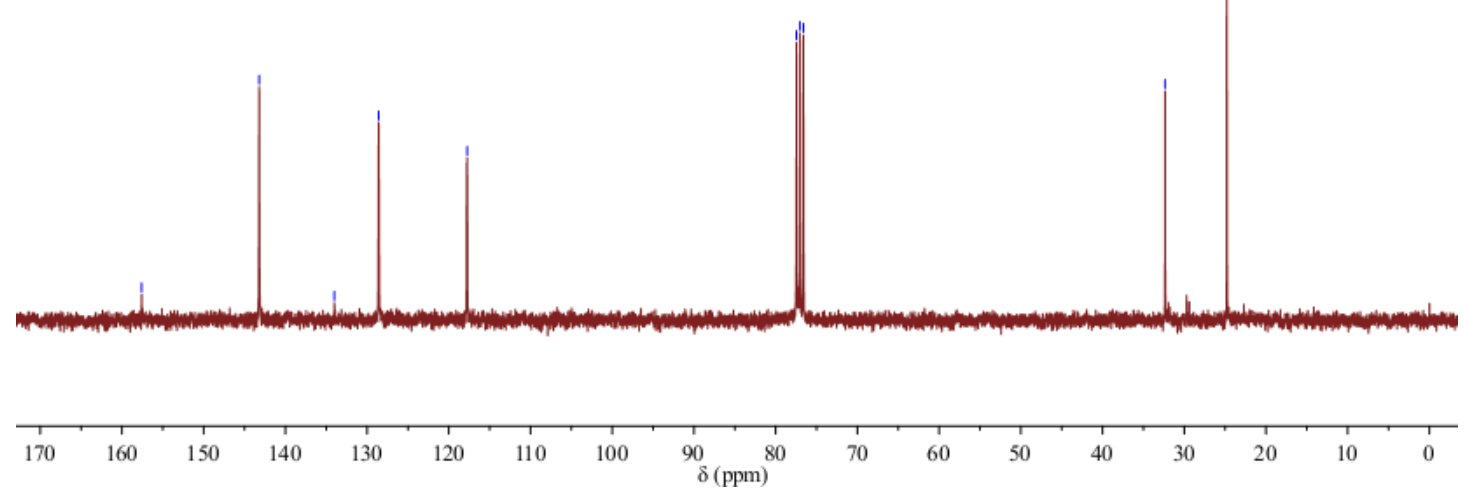


BODIPY 7

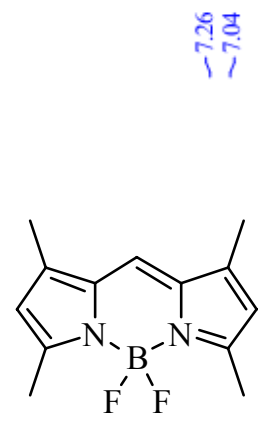

iุ

กิ่

$\stackrel{8}{i}$
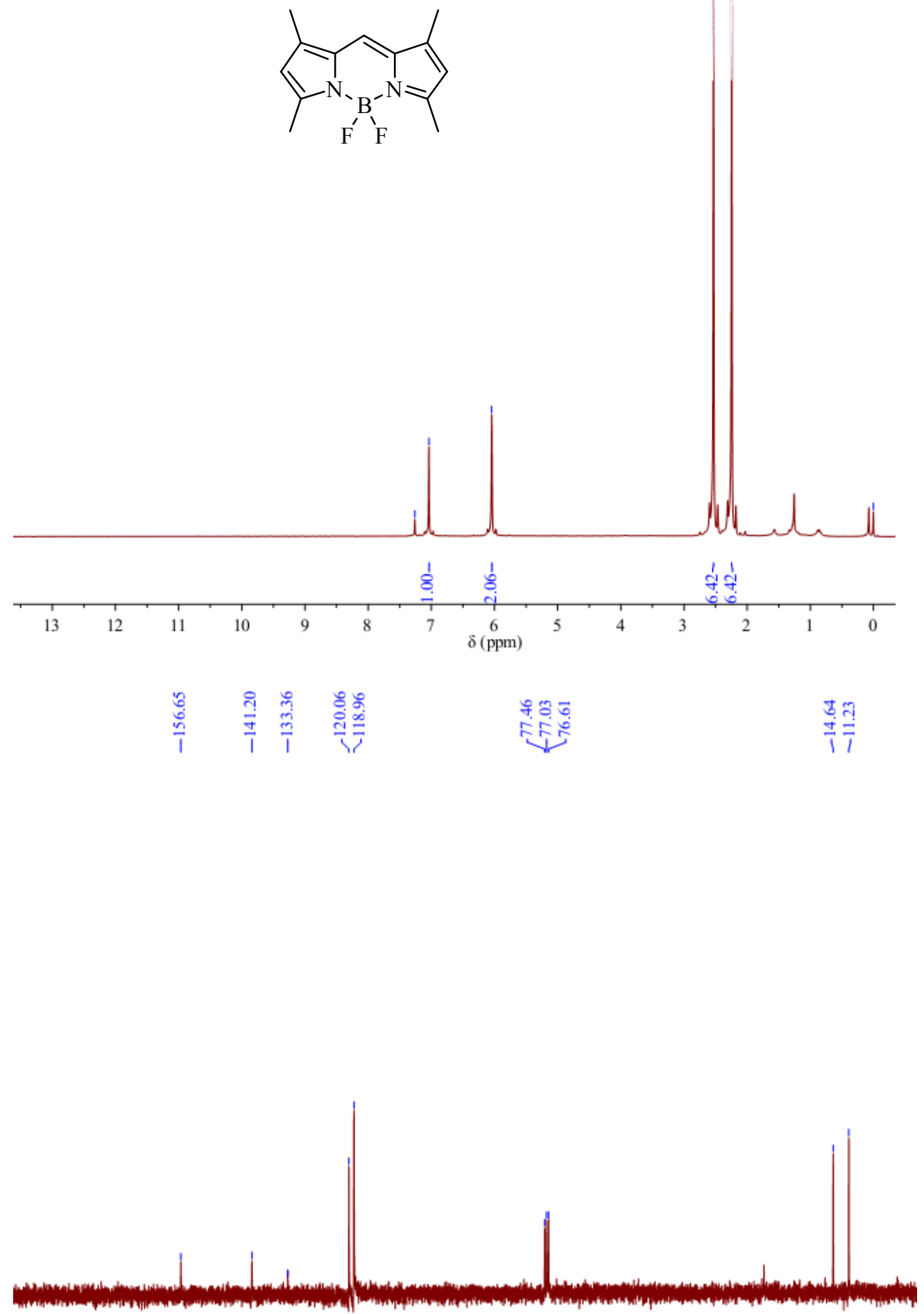

$\begin{array}{llllllllllllllllllll}190 & 180 & 170 & 160 & 150 & 140 & 130 & 120 & \begin{array}{c}110 \\ \delta(\mathrm{ppm})\end{array} & 100 & 90 & 80 & 70 & 60 & 50 & 40 & 30 & 20 & 10 & 0\end{array}$ 


\section{References}

(1) B. Valeur, B.; M. N. Berberan-Santos, M. N. Molecular Fluorescence. Principles and Applications, 2nd ed., Wiley-VCH: Weinheim (Germany), 2012.

(2) Lakowicz, J. Principles of Fluorescence Spectroscopy, 3rd ed., Springer-Verlag: New York, 2006.

(3) Olmsted, J. Calorimetric Determinations of Absolute Fluorescence Quantum Yields. J. Phys. Chem. 1979, 83, 2581-2584.

(4) Becker, W. Advanced Time-Correlated Single Photon Counting Techniques, Springer Series in Chemical Physics, Vol. 81, Springer: Berlin, 2005.

(5) vandeVen, M.; Ameloot, M.; Valeur, B.; Boens, N. Pitfalls and Their Remedies in Time-Resolved Fluorescence Spectroscopy and Microscopy. J. Fluoresc. 2005, 15, 377-413.

(6) Boens, N.; Qin, W.; Basarić, N.; Hofkens, J.; Ameloot, M.; Pouget, J.; Lefèvre, J. P.; Valeur, B.; Gratton, E.; Vandeven, M.; Silva, N. D. Jr.; Engelborghs, Y.; Willaert, K.; Sillen, A.; Rumbles, G.; Phillips, D.; Visser, A. J. W. G.; van Hoek, A.; Lakowicz, J. R.; Malak, H.; Gryczynski, I.; Szabo, A. G.; Krajcarski, D. T.; Tamai, N.; Miura, A. Fluorescence Lifetime Standards for Time and Frequency Domain Fluorescence Spectroscopy. Anal. Chem. 2007, 79, 2137-2149.

(7) Lemmetyinen, H.; Tkachenko, N. V.; Valeur, B.; Hotta, J.-i.; Ameloot, M.; Ernsting, N. P.; Gustavsson, T.; Boens, N. Time-Resolved Fluorescence Methods. Pure Appl. Chem. 2014, 86, 1969-1998.

(8) SMART, Version 5.0, Bruker AXS, Madison, WI, USA, 1998.

(9) SAINT Version 6.0, Bruker AXS, Madison, WI, USA, 1999.

(10) Sheldrick, G. M. SHELXL-97, Program for X-ray Crystal Structure Solution, University of Gottingen (Germany), 1997.

(11) SHELXTL Version 5.10, Program Library for Structure Solution and Molecular Graphics, Bruker AXS, Madison, WI, 1998.

(12) Vos de Wael, E.; Pardoen, J. A.; van Koeveringe, J. A.; Lugtenburg, J. Pyrromethene-BF 2 Complexes (4,4'-difluoro-4-bora-3a,4a-diaza-s-indacenes). Synthesis and Luminescence Properties. Recl. Trav. Chim. Pays-Bas 1977, 96, 306-309.

(13) Catalán, J. Toward a Generalized Treatment of the Solvent Effect Based on Four Empirical Scales: Dipolarity (SdP, a New Scale), Polarizability (SP), Acidity (SA), and Basicity (SB) of the Medium. J. Phys. Chem. B 2009, 113, 5951-5960.

(14) Dimroth, K.; Reichardt, C.; Siepmann, T.; Bohlmann, F. Über Pyridinium- $N$-phenol-betaine und ihre Verwendung zur Charakterisierung der Polarität von Lösungsmitteln (Pyridinium- $N$-phenol-betaine and its Application for the Characterization of Solvent Polarities). Liebigs Ann. Chem. 1963, 661, 1-37.

(15) Dimroth, K.; Reichardt, C. Über Pyridinium- $N$-phenol-betaine und ihre Verwendung zur Charakterisierung der Polarität von Lösungsmitteln, V Erweiterung der Lösungsmittelpolaritätsskala durch Verwendung Alkyl-substituierter Pyridinium- $N$-phenol-betaine (Pyridinium- $N$-phenol Betaines and Their Application for the Characterization of Solvent Polarities. Extension of the Solvent Polarity Scale by Application of Alkyl-substituted Pyridinium- $N$-phenol Betaines). Liebigs Ann. Chem. 1969, 727, 93-105.

(16) Reichardt, C. Solvatochromism, Thermochromism, Piezochromism, Halochromism, and Chirosolvatochromism of Pyridinium N-phenoxide Betaine Dyes. Chem. Soc. Rev. 1992, 21, 147-153.

(17) Kamlet, M. J.; Abboud, J. L.; Taft, R. W. The Solvatochromic Comparison Method. 6. The $\pi^{*}$ S31 
Scale of Solvent Polarities. J. Am. Chem. Soc. 1977, 99, 6027-6038.

(18) Dragos, R. S. Extension of the Unified Scale of Solvent Polarities to Acceptor Probes: Concerns about $\beta-\pi^{*}$ Parameters. J. Org. Chem. 1992, 57, 6547-6552.

(19) Catalán, J.; López, V.; Pérez, P.; Martin-Villamil, R.; Rodriguez, J. G. Progress Towards a Generalized Solvent Polarity Scale: The Solvatochromism of 2-(Dimethylamino)-7-nitrofluorene and its Homomorph 2-Fluoro-7-nitrofluorene. Liebigs Ann. 1995, 241-252.

(20) N. S. Bayliss, J. Chem. Phys., 1950, 18, 292-296. 